\title{
An Experimental Evaluation of Fixed and Fluidized Beds of Zeolite 13X for the Application of Compact Thermal Energy Storage
}

by

Dylan A. Bardy, B.Eng. (Carleton University, 2016)

A thesis submitted to

the Faculty of Graduate and Postdoctoral Affairs

in partial fulfillment of the requirements for the degree of

Master of Applied Science in Sustainable Energy

Department of Mechanical and Aerospace Engineering Carleton University

Ottawa, Ontario

August, 2018

(C)Copyright

Dylan A. Bardy, 2018 


\section{Abstract}

For thermal energy storage technologies based on physical adsorption to become a commercially viable option in the future, particular advancements in the research and development of the system's components are required to complement existing research in advanced materials. To investigate the application of fluidization as a solid-gas contacting method for low-temperature thermochemical energy storage, a bench-scale adsorption-based TES system was designed, constructed, instrumented, and commissioned. In demonstrating this technology, the objective of this research was to obtain thermodynamic data for the adsorption of water vapour onto zeolite $13 \mathrm{X}$ under fluidization to evaluate fluidized beds as potential reactor or adsorber designs. Multiple adsorption experiments were performed on samples of an 8x12 and 60x65 mesh zeolite 13X molecular sieve, comparing the effects of air flow rate and concentration of water vapour on the breakthrough and temperature lift on the energy density of fixed and fluidized adsorbent beds. Variation of the air flow rate from 10 to $30 \mathrm{~L} / \mathrm{min}$ had little effect on the amount of thermal energy released by the adsorption of water onto each sample due to equilibrium; however, the added volume of the bubbles in the fluid bed reduced its energy density significantly at higher flow rates. The concentraion of water vapour at the inlet or relative humidity of the air was shown to be one of the most significant parameters for controlling the delivery temperature of each bed. It was found that, the discharge rate of the fluid bed increased by $4 \mathrm{~W}$ per $20 \%$ increase in $\mathrm{RH}$, compared to a $6 \mathrm{~W}$ per $20 \% \mathrm{RH}$ increase for fixed beds. Tests were performed to determine the effects of fluidization and the use of a vacuum pump on the regeneration of zeolite 13X. The results of the experimental data are were then considered in scaling the adsorbent beds to meet a range of heating loads. 


\section{Acknowledgements}

I would like to thank my supervisor, Dr. Cynthia Cruickshank, for her mentorship and support over the last three years; this experience has been a highlight of my career and I hope that our paths cross again. I would also like to thank Dr. Handan Tezel for her co-supervision and expertise in guiding my research.

To Bill Wong for his interest in my project and for facilitating our industrial partnership on behalf of Leidos Canada. I must also thank Leidos Canada and the Natural Sciences and Engineering Research Council of Canada (NSERC) for their financial support through the Engage, and Collaborative Research and Development Grants (No. 492298 and 500831).

Big thank you to the guys in the machine shop, Alex Proctor, Ian Lloy and Kevin Sangster for the help and training they provided me in the machining of the parts for the adsorption column.

To my colleagues in the lab, Chris, Brock, Nina, Jordan and Tyler, it was a pleasure to work alongside you all. I would like to specifically thank Alex Hayes for his friendship, contributions to my experimental setup, and all of the belays.

To my family, Mom and Dad; Grandma and Grandpa; and Kelsey and Sarah for their love and unwavering support.

Finally, to Cam for everything over the last year. I look forward to what's next. 
"If the fool would persist in his folly he would become wise." - William Blake (Proverbs of Hell, 1790)

In loving memory of Zachary Burgoyne (1992 - 2017). 


\section{Table of Contents}

Abstract $i$

\begin{tabular}{ll}
\hline Acknowledgements & ii
\end{tabular}

Table of Contents

List of Tables vi vi

List of Figures vii

Nomenclature $\quad x$

$\begin{array}{lll}1 & \text { Introduction } & 1\end{array}$

1.1 Motivation . . . . . . . . . . . . . . . . . . . . 1

1.2 Background . . . . . . . . . . . . . . . . . . 2

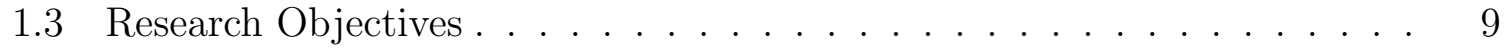

1.4 Contribution of Research . . . . . . . . . . . . . . . . . . . . . . . 9

1.5 Organization of Research . . . . . . . . . . . . . . . . . . . 10

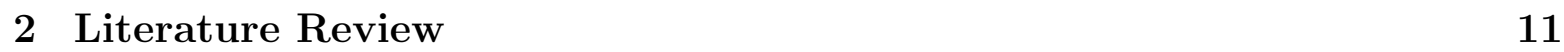

2.1 Global Status of the Technology . . . . . . . . . . . . . . . . . . . . 11

2.2 Systems for Thermochemical Storage . . . . . . . . . . . . . . . . . . 17

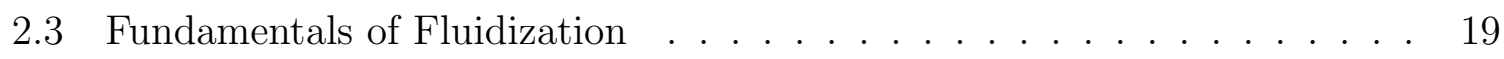

2.4 Performance Metrics $\ldots \ldots \ldots \ldots$

2.5 Comparative Studies . . . . . . . . . . . . . . . . . . . . 25

2.6 Research Direction . . . . . . . . . . . . . . . . . . . 36 


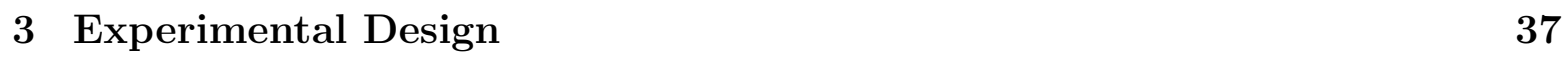

3.1 The Experimental Setup . . . . . . . . . . . . . . . . . . . . . . . . . . 37

3.2 Material Preparation . . . . . . . . . . . . . . . . . . . 46

3.3 Procedure . . . . . . . . . . . . . . . . . . . . . . . . . . . . . 47

3.4 Calculation of Various Adsorption Parameters . . . . . . . . . . . . . . . 50

4 Results \& Discussion $\quad 52$

4.1 Variation of Air Flow Rate . . . . . . . . . . . . . . . . . . . . . . 52

4.2 Variation of Relative Humidity . . . . . . . . . . . . . . . . . . . . . . . 59

4.3 Adsorption-Regeneration Cycling . . . . . . . . . . . . . . . . . 64

4.4 In-Situ Regeneration Under Partial Vacuum . . . . . . . . . . . . . . . . 66

4.5 Scaling Considerations . . . . . . . . . . . . . . . . . . . . . . . . . . . 69

$\begin{array}{lll}5 & \text { Conclusions and Future Work } & 73\end{array}$

5.1 Conclusions . . . . . . . . . . . . . . . . . . 73

5.2 Future Work . . . . . . . . . . . . . . . . . . . . . . . . . . . . . 74

\begin{tabular}{ll}
\hline References Cited & 76
\end{tabular}

\begin{tabular}{|l|l}
\hline Appendices & 82
\end{tabular}

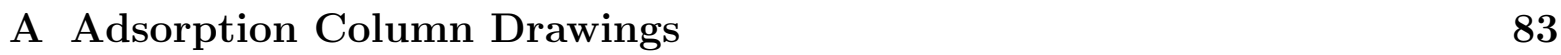

B Manufacturer Specifications \& MSDS for Zeolite 13X 96

\begin{tabular}{|ll}
\hline C Fluidization Velocity Calculations & 102
\end{tabular}

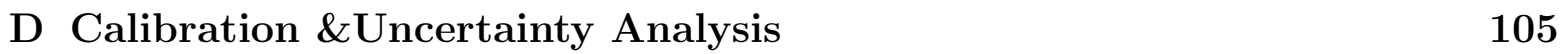

D.1 Component Calibration and Uncertainty . . . . . . . . . . . . . . . . . . 105

D.2 Overall System Uncertainty Analysis . . . . . . . . . . . . . . . . . . 107 


\section{List of Tables}

$1.1 \quad$ Reversible solid-gas reactions considered for thermal energy storage $[6 \mid . .5$

$2.1 \quad$ Key achievements by Task 42/Annex 29 Working Group A1. . . . . . . . 14

2.2 Key achievements by Task 42/Annex 29 Working Group A2. . . . . . . . 15

2.3 Key achievements by Task 42/Annex 29 Working Group A3. . . . . . . . 15

2.4 Key achievements by Task 42/Annex 29 Working Group B. . . . . . . . . 16

2.5 Key achievements by Task 42/Annex 29 Working Group C. . . . . . . . . 17

2.6 Characterization of adsorbents for thermochemical storage. . . . . . . . 27

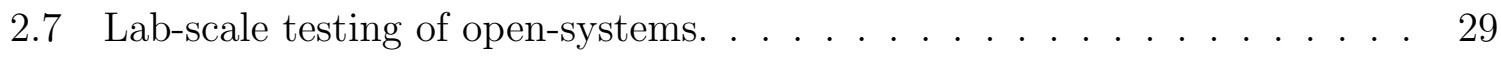

2.8 Lab-scale closed-system thermochemical projects. . . . . . . . . . . 31

2.9 Open pilot-scale thermochemical projects. . . . . . . . . . . . 33

2.10 Closed pilot-scale thermochemical projects. . . . . . . . . . . . . 35

3.1 Volume of fluid bed in column at each flow rate. . . . . . . . . 43

$3.2 \quad$ Configuration of I/O modules for the NI cRIO 9204. . . . . . . . . . 45

3.3 Labels of samples for tests varying flow rate. . . . . . . . . . . . . . 48

3.4 Labels of samples for tests varying inlet relative humidity. . . . . . . . . 48

C.1 Estimated terminal velocities and flow rates for a $210 \mu \mathrm{m}$ particle. . . . 104 


\section{List of Figures}

1.1 Classification of modes for thermal energy storage . . . . . . . . . . . . . 3

1.2 The desiccant cycle . . . . . . . . . . . . . . . . . . . . . . 7

1.3 Thermal energy density of systems compared to mode, adapted by $[18] . \quad 8$

$2.1 \quad$ Organization of IEA-SHC Task 42/ECES Annex 29 . . . . . . . . . . . . 13

2.2 Open-system concept for thermochemical energy storage. . . . . . . . . 17

2.3 Integrated vs. external adsorption systems . . . . . . . . . . . . . . . . . 18

2.4 Liquid-like behaviour of gas fluidized beds . . . . . . . . . . . . . . . . . 19

2.5 Balance of forces acting on fluidized solid particle. . . . . . . . . . . . . 20

$2.6 \quad$ Fluidization regimes of gas fluidized beds . . . . . . . . . . . . . . . . 21

3.1 The experimental setup . . . . . . . . . . . . . . . . . . . . . 37

3.2 The setup configured for adsorption experiments. . . . . . . . . . . . . . 38

3.3 The setup configured for in-situ regeneration. . . . . . . . . . . . . . . . 39

3.4 The setup configured for in-situ vacuum regeneration. . . . . . . . . . . . 40

3.5 Cross section of the adsorption column. . . . . . . . . . . . . . . . . 41

3.6 Dimensions of fixed bed for calculating volume (units in $\mathrm{mm}$ ). . . . . . . 42

$3.7 \quad$ Dimensions of fluid bed for calculating volume (units in $\mathrm{mm}$ ). . . . . . . 43

3.8 A 25 g sample of 8x12 zeolite in a fixed bed and 60x65 zeolite fluidized at $25 \mathrm{~L} / \mathrm{min}$. . . . . . . . . . . . . . . . . . . . 44

3.9 Response of MFCs to change in inlet relative humidity signal. . . . . . . 46

3.10 Subtraction of areas for calculating mass of water adsorbed. . . . . . . . 50

4.1 Concentration breakthrough of the outlet for the fixed and fluidized bed

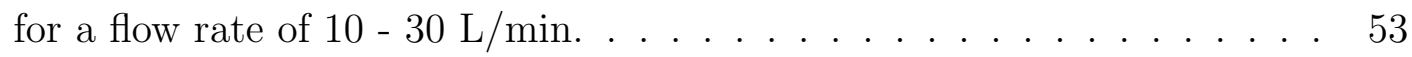


$4.2 \quad$ Illustration of MTZ Concept in a fixed adsorbent bed. . . . . . . . . . . 54

4.3 Mass transfer zone of fixed and fluidized bed with flow rate. . . . . . . . 55

4.4 Mass of water adsorbed by the fixed and fluidized beds . . . . . . . . . . 56

4.5 Heat released by $25 \mathrm{~g}$ of zeolite $13 \mathrm{X}$ in the fixed and fluidized beds. . . . 57

4.6 The storage capacity and energy density of the fixed and fluidized beds. . 58

4.7 Concentration breakthrough of the outlet for the fixed and fluidized bed for $30-70 \% \mathrm{RH}$ at inlet. . . . . . . . . . . . . . . . . . . . . . . 59

4.8 Outlet temperature lift of the fixed and fluidized bed. . . . . . . . . . . . 60

4.9 Rate of heat and specific power discharged by the fixed and fluidized beds. 62

4.10 Cumulative energy released by the fixed and fluidized beds. . . . . . . . . 63

4.11 The system temperatures and outlet relative humidity for a typical re-

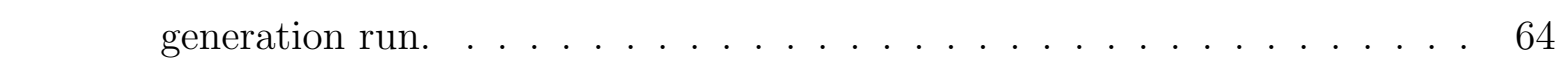

4.12 The average temperature lift and discharge rate of cycled fixed and fluidized beds during adsorption. . . . . . . . . . . . . . . . . . . . . . 65

4.13 The average energy released per cycle and cycle energy densities. . . . . . 66

4.14 Average absolute pressure of the column for regeneration under partial vacuum and atmospheric conditions. . . . . . . . . . . . . . . 67

4.15 Outlet temperatures and relative humidity of adsorption column for regeneration under partial vacuum and atmospheric conditions. . . . . . . . 68

4.16 Temperature lift and energy released for regeneration under partial vacuum and atmospheric conditions. . . . . . . . . . . . . . . . . . . . . . . 69

4.17 The total storage mass and volume of zeolite required based on annual heating load and a floor area of $100 \mathrm{~m}^{2} . \ldots \ldots \ldots$

4.18 Adsorbent bed volume of the fixed and fluidized bed, based on a floor area of $100 \mathrm{~m}^{2}$. . . . . . . . . . . . . . . . . . . 71

A1 Adsorption Column Assembly . . . . . . . . . . . . . . . . . . . . 84

A2 Inlet Sub-Assembly . . . . . . . . . . . . . . . . . . . . . . . 85

A2.1 Collar for Acrylic Tube . . . . . . . . . . . . . . . . . . 86

A2.2 Wing Nut Clamp . . . . . . . . . . . . . . . . . 87

A2.3 1-1/8" Straight Quick-Clamp Adapter . . . . . . . . . . . . . . . 88

A2.4 1-3/4" Straight Quick-Clamp Adapter . . . . . . . . . . . . . . 89 
A2.5 Quick-Clamp Gasket . . . . . . . . . . . . . . . . . 90

A2.6 200x200 Mesh Disc . . . . . . . . . . . . . . . . . . . . . . . . . . 91

A2.7 $\quad$ Inlet \& Outlet Quick-Clamp Press Fit . . . . . . . . . . . . . . . 92

A2.8 Sloped Insert . . . . . . . . . . . . . . . . . . . . . . . . . . . . . 93

A3 Acrylic Column . . . . . . . . . . . . . . . . . . . . . 94

A3 Outlet Sub-Assembly . . . . . . . . . . . . . . . . . . . . . . . . 95 


\section{Nomenclature}

\section{Abbreviations}

ACH Air Changes per Hour

BTES Borehole Thermal Energy Storage

CJC Cold Junction Compensation

DHW Domestic Hot Water

DLSC Drake Landing Solar Community

FSO Full Scale Output

IEA International Energy Agency

MFC Mass Flow Controller

MSDS Material Safety Data Sheets

P\&ID Piping and Instrumentation Diagram

PID Proportional - Integral - Derivative

RH Relative Humidity

RTD Resistance Temperature Detector

SLM Standard Liters per Minute

SOC State of Charge

TCM Thermochemical Material 


\section{TES Thermal Energy Storage}

\section{Virtual Instrument}

\section{Greek}

$\Delta \quad$ total change in variable

$\delta \quad$ change in variable per unit of time

$\omega \quad$ absolute humidity $\left(\mathrm{g}_{\text {air }} / \mathrm{kg}_{\mathrm{H}_{2} \mathrm{O}}\right)$

$\phi \quad$ relative humidity $(\%)$

$\rho \quad \operatorname{density}\left(\mathrm{kg} \cdot \mathrm{m}^{-3}\right)$

d diameter

\section{General}

$\dot{Q} \quad$ rate of heat discharge $(\mathrm{kW})$

$\dot{V} \quad$ volumetric flow rate $\left(\mathrm{m}^{3} \cdot \mathrm{s}^{-1}\right)$

$c_{p} \quad$ specific heat capacity $\left(\mathrm{kJ} \cdot \mathrm{kg}^{-1} \cdot \mathrm{K}^{-1}\right)$

$M \quad$ molar mass $\left(\mathrm{kg} \cdot \mathrm{mol}^{-1}\right)$

$P \quad$ pressure $(\mathrm{kPa})$

$Q \quad$ thermal energy $(\mathrm{kJ})$

$T$ temperature $\left({ }^{\circ} \mathrm{C}\right)$

$t \quad$ time $(\mathrm{s})$

\section{Subscripts}

a air

ads adsorption

b breakthrough 


$\begin{array}{ll}\text { d } & \text { discharge } \\ \text { e } & \text { exhaustion } \\ \text { g } & \text { gas } \\ \text { r } & \text { reaction } \\ \text { s } & \text { solid } \\ \text { tot } & \text { total } \\ \text { w } & \text { water }\end{array}$

ws saturated water vapour 


\section{Chapter 1}

\section{Introduction}

\subsection{Motivation}

It is well recognized within the sphere of clean-tech that economically viable energy storage technologies are required to realize the full potential of renewable energy by correcting the mismatch between variable demand and intermittent supply. Compared to more established methods of energy storage (namely mechanical and electrochemical), thermal energy storage (TES) technology has received less attention because of the lower financial value associated with heat. High-grade forms of energy capable of performing mechanical work (i.e., electricity and fossil fuels) are the most costly to produce, whereas low-grade thermal energy $\left(<250^{\circ} \mathrm{C}\right)$ has virtually no commercial value [1]. Economics from the perspective of exergy (considering second law thermodynamic analysis) should therefore discourage the use of high-grade energy from combustion or electricity for low-grade end-use applications such as space heating and domestic hot water (DHW); however, more than 8.5 million homes that make up Canada's single-detached residential building stock are heated by baseboard electric heaters and the combustion of natural gas [2]. While these two conventional methods of heating can boast high energy efficiencies, they produce greenhouse gases, are subject to increasingly volatile energy prices, and rely on a distribution infrastructure that is both strained and aging. New and energy efficient space and water heating technologies are integral to reducing energy usage in Canadian residential buildings, where conventional heating technologies account for over 80 percent of energy use in this sector [2]. 
As a renewable source of heat (i.e., naturally replenished within a human timescale), solar thermal energy can be collected in the range of $300-900 \mathrm{kWh} / \mathrm{m}^{2} /$ year, which could meet the 110 GJ heating load of a typical Canadian home with $30-100 \mathrm{~m}^{2}$ of solar thermal collector area [3, 4]. While most Canadian cities experience sufficient insolation for solar thermal technology between the spring and fall equinoxes, sizable seasonal storage capacity is required for the winter months.

North America's first seasonal solar thermal storage system for the Drake Landing Solar Community (DLSC) of Okotoks, Alberta, stores solar thermal energy as sensible heat in a borehole thermal energy storage (BTES) system. In addition to requiring extensive drilling, this BTES system amounts to just over 34,000 $\mathrm{m}^{3}$ of underground storage volume for 52 homes, which limits the feasibility of implementing similar systems exclusively to the new construction market [5]. Therefore, to increase the penetration of solar thermal heating in Canada and include the potential for retrofit applications, more compact technologies for TES with higher energy densities need to be developed.

Thermal energy storage through solid-gas thermochemical processes has been demonstrated as a more compact mode of thermal energy storage than sensible or latent TES. International research has identified promising material candidates for this technology through investigations of multiple lab and pilot-scale systems of a packed-bed type. Fluidization is another method of solid-gas contacting that is used extensively in industry for its noted advantages of higher heat and mass transfer; however, fluidized beds for low-temperature thermochemical storage have only been considered conceptually in the literature. This work was therefore motivated to evaluate the use of fluidized beds as a component of thermochemical TES systems through experiments at the bench-scale.

\subsection{Background}

As classified in Figure 1.1, three modes are considered for the storage of thermal energy: sensible, latent, and thermochemical heat. An understanding of the principles of each mode is required to appreciate the challenges that TES technologies must overcome to be a viable option in the future. 


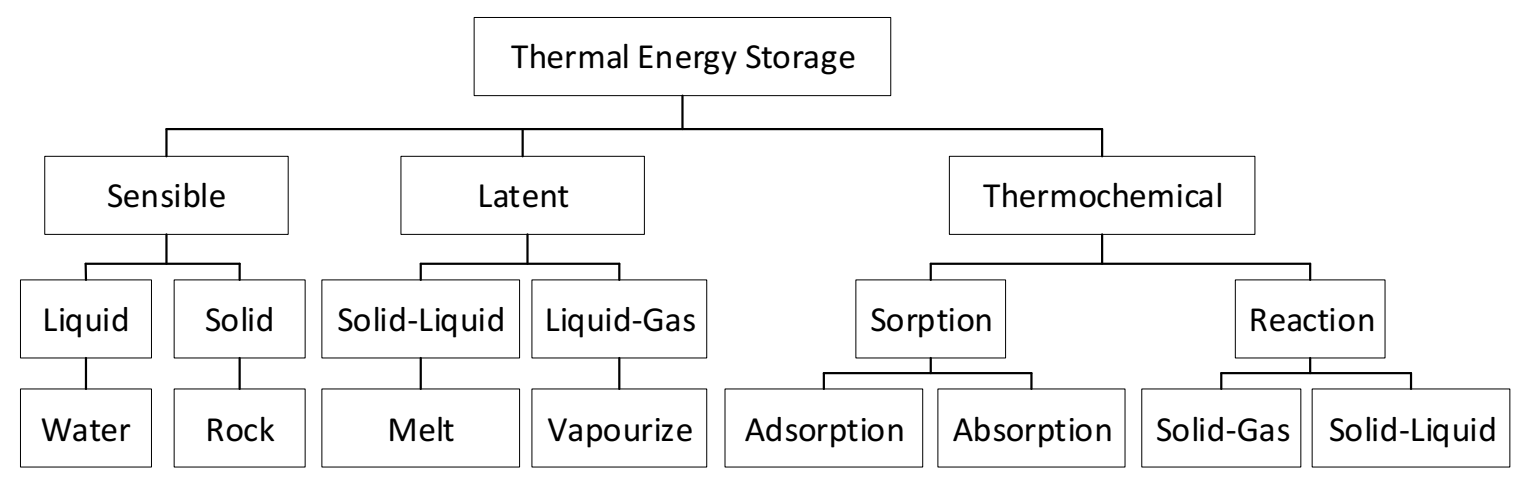

Figure 1.1: Classification of modes for thermal energy storage, adapted from [6].

\subsubsection{Sensible Heat}

Sensible heat refers to thermal energy stored in the change in temperature of a material (generally in the liquid or solid phase) [7]. The amount of energy that can be stored in a sensible TES system is limited by the specific heat capacity and the density of the material:

$$
Q=m c_{p} \Delta T
$$

Thermal energy, $Q$, is therefore stored in a material of mass $m$ with a specific heat capacity $c_{p}$ as it experiences a change in temperature, $\Delta T$. Liquid water for example can absorb $58.1 \times 10^{-3} \mathrm{kWh}$ of heat per liter, providing an energy density of $58.1 \mathrm{kWh} / \mathrm{m}^{3}$ for a $\Delta T$ of $50^{\circ} \mathrm{C}$. Realistic energy densities must also factor in the added volume of insulation to minimize heat losses. The energy density of a 1,000 L $\left(1 \mathrm{~m}^{3}\right)$ cylindrical buffer tank for example, is reduced to $36 \mathrm{kWh} / \mathrm{m}^{3}$ if its effective volume is increased to $1.6 \mathrm{~m}^{3}$ with the addition of just $10 \mathrm{~cm}$ of insulation [8].

Sensible TES consisting of tanks of water are however widely used, especially for diurnal TES systems, where they are cycled daily. Liquid water systems can also be modular and extended beyond the volume of a single tank as demonstrated by Cruickshank and Harrison [9] in their evaluation of a multi-tank TES. Smaller water tanks such as these have been used commercially as buffers for meeting peak hot water demand from boilers and renewable heating technologies in domestic systems. 


\subsubsection{Latent Heat}

Thermal energy stored in the change in phase of a material at constant temperature is referred to as latent heat [7]. The phase change materials (PCM) considered are generally those that can transition from solid to liquid, or from liquid to vapour, and therefore the specific heat of solidification/fusion or vapourization and the temperature at which the phase change occurs are of design importance. The energy stored in a PCM undergoing a change in phase between a liquid $\left(c_{p, l}\right)$ and a solid $\left(c_{p, s}\right)$ is given by:

$$
Q=m\left[c_{p, s}\left(T_{m}-T_{i}\right)+\Delta h_{m}+c_{p, l}\left(T_{f}-T_{m}\right)\right]
$$

where $\Delta h_{m}$ is the latent heat of fusion, and $T_{m}, T_{i}$, and $T_{f}$ are the melting, initial and final temperature of the PCM, respectively. PCMs can be contained in conventional building elements or ecapsulated as self-contained elements. Wert et al. [10 have combined the two methods by incorporating plates of an encapsulated organic PCM with an energy density of $50-55 \mathrm{kWh} / \mathrm{m}^{3}$ into the duct work of an experimental setup representing a commercial HVAC system. Other demonstration projects have been deployed and $\mathrm{R} \& \mathrm{D}$ efforts are focused on improving thermal stability to enable commercialization.

\subsubsection{Thermochemical Heat}

Thermochemical heat is the product of reversible chemical reactions and physical adsorption. Most of these processes take place between a solid thermochemical material (TCM) and a gas in a component that is typically referred to as a reactor.

\section{Reversible Chemical Reactions}

Thermochemical storage gets its namesake from the reversible chemical reactions that make up this mode of thermal energy storage. In theory, waste heat from an industrial process, or solar thermal energy can be stored and released in a loss-free manner by means of a bimolecular reaction:

$$
\mathrm{A}_{(\mathrm{s})}+\mathrm{B}_{(\mathrm{g})} \underset{\text { storage }}{\stackrel{\text { discharge }}{\rightleftharpoons}} \mathrm{C}_{(\mathrm{s})}+\Delta H_{r}
$$


The forward reaction of Equation 1.3 is exothermic, and heat is a product of the association of species $\mathrm{A}$ and $\mathrm{B}$ to form species $\mathrm{C}$ and the heat of reaction, $\Delta H_{r}$. Heat is therefore stored in the reverse endothermic reaction of dissociating species $\mathrm{C}$ into species $\mathrm{A}$ and $\mathrm{B}$. The reversible chemical reactions that are considered most in the literature for thermochemical storage have been summarized by Letcher [6] in Table 1.1.

Table 1.1: Reversible solid-gas reactions considered for thermal energy storage $[6]$.

\begin{tabular}{|c|c|c|}
\hline Type of Reaction & Reaction & Temperature $\left[{ }^{\circ} \mathrm{C}\right]$ \\
\hline \multirow{5}{*}{$\begin{array}{l}\text { Dehydration } \\
\text { of salt hydrates }\end{array}$} & $\mathrm{MgSO}_{4} \cdot 7 \mathrm{H}_{2} \mathrm{O} \rightleftharpoons \mathrm{MgSO}_{4} \cdot \mathrm{H}_{2} \mathrm{O}+6 \mathrm{H}_{2} \mathrm{O}$ & $100-150$ \\
\hline & $\mathrm{MgCl}_{2} \cdot 6 \mathrm{H}_{2} \mathrm{O} \rightleftharpoons \mathrm{MgCl}_{2} \cdot \mathrm{H}_{2} \mathrm{O}+5 \mathrm{H}_{2} \mathrm{O}$ & $100-130$ \\
\hline & $\mathrm{CaCl}_{2} \cdot 6 \mathrm{H}_{2} \mathrm{O} \rightleftharpoons \mathrm{CaCl}_{2} \cdot \mathrm{H}_{2} \mathrm{O}+5 \mathrm{H}_{2} \mathrm{O}$ & $150-200$ \\
\hline & $\mathrm{CuSO}_{4} \cdot 5 \mathrm{H}_{2} \mathrm{O} \rightleftharpoons \mathrm{CaCl}_{2} \cdot \mathrm{H}_{2} \mathrm{O}+4 \mathrm{H}_{2} \mathrm{O}$ & $120-160$ \\
\hline & $\mathrm{CuSO}_{4} \cdot \mathrm{H}_{2} \mathrm{O} \rightleftharpoons \mathrm{CuSO}_{4}+\mathrm{H}_{2} \mathrm{O}$ & $210-260$ \\
\hline \multirow{3}{*}{$\begin{array}{l}\text { Deammoniation } \\
\text { of ammonium chlorides }\end{array}$} & $\mathrm{CaCl}_{2} \cdot 8 \mathrm{NH}_{3} \rightleftharpoons \mathrm{CaCl}_{2} \cdot 4 \mathrm{NH}_{3}+4 \mathrm{NH}_{3}$ & $25-100$ \\
\hline & $\mathrm{CaCl}_{2} \cdot 8 \mathrm{NH}_{3} \rightleftharpoons \mathrm{CaCl}_{2} \cdot 2 \mathrm{NH}_{3}+2 \mathrm{NH}_{3}$ & $40-120$ \\
\hline & $\mathrm{MnCl}_{2} \cdot 6 \mathrm{NH}_{3} \rightleftharpoons \mathrm{MnCl}_{2} \cdot 2 \mathrm{NH}_{3}+4 \mathrm{NH}_{3}$ & $40-160$ \\
\hline \multirow{2}{*}{$\begin{array}{l}\text { Dehydration } \\
\text { of metal hydrides }\end{array}$} & $\mathrm{MgH}_{2} \rightleftharpoons \mathrm{Mg}+\mathrm{H}_{2}$ & $200-400$ \\
\hline & $\mathrm{Mg}_{2} \mathrm{NiH}_{4} \rightleftharpoons \mathrm{Mg}_{2} \mathrm{Ni}+\mathrm{H}_{2}$ & $150-300$ \\
\hline \multirow{3}{*}{$\begin{array}{l}\text { Dehydration } \\
\text { of metal hydroxides }\end{array}$} & $\mathrm{Mg}(\mathrm{OH})_{2} \rightleftharpoons \mathrm{MgO}+\mathrm{H}_{2} \mathrm{O}$ & $250-350$ \\
\hline & $\mathrm{Ca}(\mathrm{OH})_{2} \rightleftharpoons \mathrm{CaO}+\mathrm{H}_{2} \mathrm{O}$ & $450-550$ \\
\hline & $\mathrm{Ba}(\mathrm{OH})_{2} \rightleftharpoons \mathrm{BaO}+\mathrm{H}_{2} \mathrm{O}$ & $700-800$ \\
\hline \multirow{3}{*}{$\begin{array}{l}\text { Decarboxylation } \\
\text { of metal carbonates }\end{array}$} & $\mathrm{ZnCO}_{3} \rightleftharpoons \mathrm{ZnO}+\mathrm{CO}_{2}$ & $100-150$ \\
\hline & $\mathrm{MgCO}_{3} \rightleftharpoons \mathrm{MgO}+\mathrm{CO}_{2}$ & $350-450$ \\
\hline & $\mathrm{CaCO}_{3} \rightleftharpoons \mathrm{CaO}+\mathrm{CO}_{2}$ & $850-950$ \\
\hline
\end{tabular}

Of the reactions listed in Table 1.1, those that involve the dehydration of salt hydrates and metal hydroxides are the most appropriate for thermal energy storage systems for buildings with water vapour and heat being the only products. The deammoniation of ammonium chlorides and dehydration of metal hydrides would require additional components for separating and collecting ammonia and hydrogen gas which pose a hazard to human health. 


\section{Physical Adsorption}

Thermal energy can also be stored in the adsorption of gas molecules onto the surface of solid adsorbent materials, where the component that facilitates this process is referred to as the adsorber. Adsorption as a result of only van der Waals interactions and weak electrostatic forces is referred to as "physical adsorption" or "physisorption", and involves the formation of multiple molecular layers of adsorbate on the solid adsorbent. Most the of literature on adsorption for the application of thermal energy storage refers to the adsorption of water vapour onto fixed beds of adsorbent according to Equation 1.4.

$$
\mathrm{A}_{(\mathrm{s})}+\mathrm{nH}_{2} \mathrm{O}_{(\mathrm{g})} \underset{\text { storage }}{\stackrel{\text { discharge }}{\rightleftharpoons}} \mathrm{A}_{(\mathrm{s})} \cdot \mathrm{nH}_{2} \mathrm{O}_{(\mathrm{s})}+\Delta H_{a d s}
$$

In the forward step of Equation 1.4, multiple layers of the adsorbate (gaseous water) are formed on the surface of a solid adsorbent, A. This step is exothermic because the molecules of adsorbate are more stable on the surface of the adsorbent than in the free phase [11. It is this heat of adsorption, $\Delta H_{a d s}$, that can be used for heating space or DHW. During desorption, or the reverse step of Equation 1.4 the addition of an amount of heat sufficient to destabilize the adsorbed vapour will cause water to be driven off the adsorbent, regenerating the material to its maximum potential for adsorption.

\subsubsection{Thermochemical Materials}

\section{Salt Hydrates}

Thermochemical heat is released in the hydration of anhydrous salts, and stored by dehydrating them with low grade heat $\left(100^{\circ} \mathrm{C}<\mathrm{T}<260^{\circ} \mathrm{C}\right)$. These salts can be hydrated until they are essentially saturated during discharge, and can then be dehydrated feasibly to their monohydrate. In general, salt hydrates have relatively high thermochemical energy densities $\left(300-400 \mathrm{kWh} / \mathrm{m}^{3}\right)$, but lower discharge power as shown by van Essen et al [12]. During hydration, salt hydrates can also form a gel-like structure which can become a non-porous layer that limits mass transfer if dried as researched by Zondag et al. [13]. For some salt hydrates, corrosive gases are the product of regeneration reactions and material degradation may occur above a threshold temperature. 


\section{Adsorbents}

Solid adsorbent materials behave like desiccants and have an affinity for water vapour in the atmosphere, and adsorb and desorb gases according to the three step desiccant cycle of Figure 1.2.
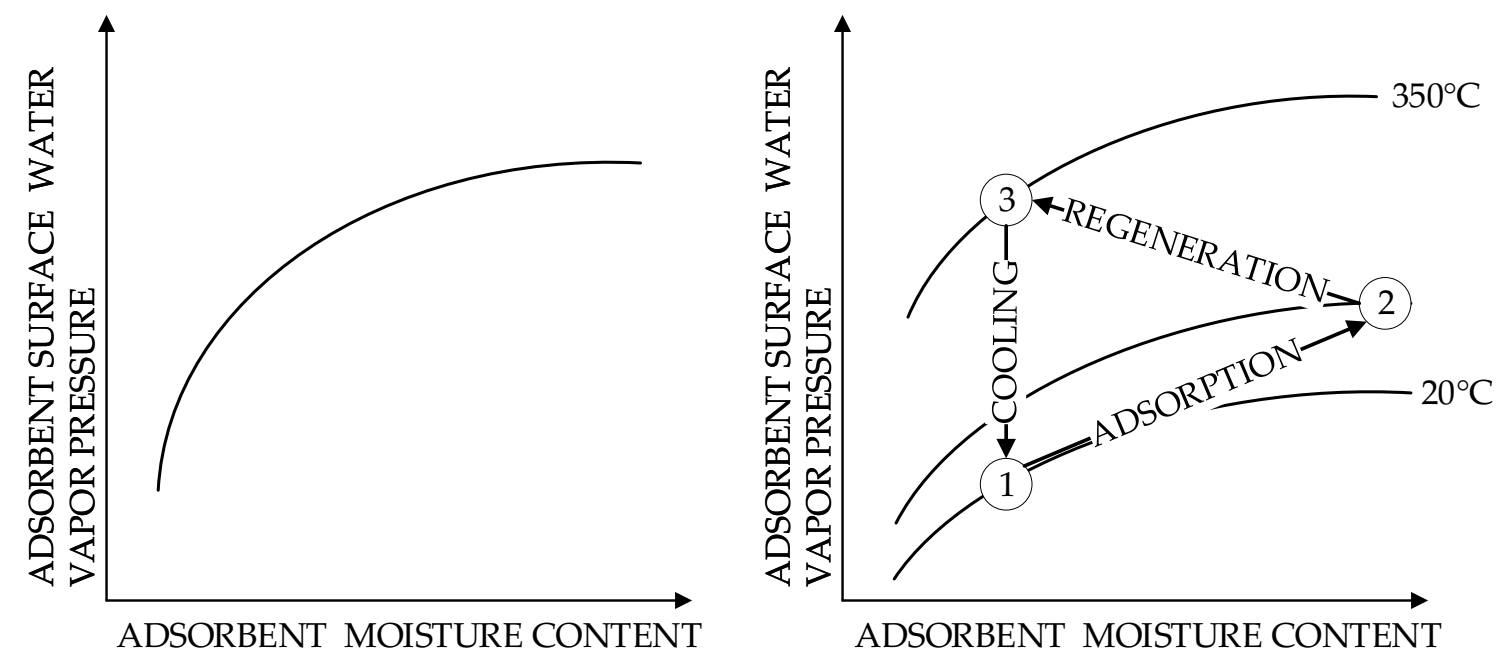

Figure 1.2: Adsorbent water vapour pressure as a function of moisture content (left) and the adsorption-regeneration cycle (right), adapted from [14].

Similar to the saturation of salt hydrates, adsorbents have a maximum capacity for adsorption based on the vapour pressure of the adsorbate gas (y-axis of Figure 1.2) and the pressure at the surface of the adsorbent (abscissa of Figure 1.2) as a function of the moisture accumulated. The adsorption step from 1 - 2 results in an adsorbent that is at a higher temperature and a higher vapour pressure at its surface that comes to equilibrium with the surrounding air. Increasing the temperature of the adsorbent from steps 2 - 3 makes the vapour pressure of the water on it surface to become greater than that of the surrounding air, causing energized molecules of water vapour to return to the free phase (regeneration). Before the adsorbent can adsorb again, it must cool from steps 3 - 1 to decrease the vapour pressure at its surface. Adsorbents such as zeolites exhibit lower energy storage potential than salt hydrates, with energy densities of 100 $200 \mathrm{kWh} / \mathrm{m}^{3}$; however, they offer a high thermal stability and rate of discharge 15 . 


\section{Zeolites}

Zeolites are crystalline aluminosilicates of alkali or alkali earth elements such as sodium, potassium, and calcium, and are synthesized and used in industry for applications of water treatment and removing $\mathrm{CO}_{2}$ from flue gases [16]. Conventionally these materials are shaped by manufacturers as beads or pellets, containing up to $20 \mathrm{wt} \%$ binder that is inert for adsorption [17.

Overall, Figure 1.3 shows how the energy densities of each mode as a process alone compare to the effective energy storage densities of their systems which include the added volume of other components that are specific to each technology.

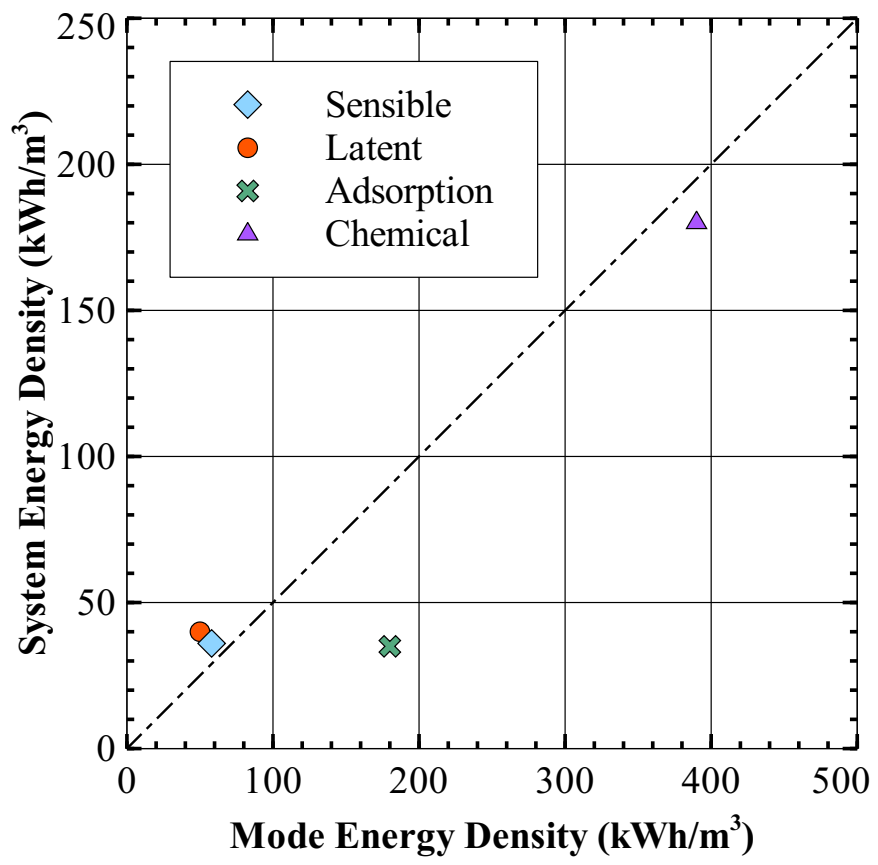

Figure 1.3: Thermal energy density of systems compared to mode, adapted by $[18]$.

Despite offering a higher energy density as a mode of thermal energy storage, it can be seen that adsorption-based TES sytems are comparable to sensible and latent thermal energy stores as packaged systems. Because adsorption TES systems are so much earlier in development with most of the cited values for energy density based on research conducted using fixed adsorbent beds, this present work was compelled to investigate other potential contacting methods for this application in pursuit of reducing the size of the adsorber component. 


\section{$1.3 \quad$ Research Objectives}

The main objective of this research was to obtain experimental data on the thermodynamic adsorption behaviour of a 60x65 mesh zeolite 13X molecular sieve under fluidization and provide analysis regarding a scale up study based on the results. The following objectives were set to obtain this analysis, including:

- conducting a comprehensive literature review of the state of the art in compact thermal energy storage;

- the design, construction, and commissioning of the experimental setup, including the plumbing, instrumentation, and the machining of an adsorption column; and

- developing a procedure to evaluate fixed and fluidized beds as components in TES systems under various conditions of the adsorbate (flow rate, concentration, pressure, and temperature)

\subsection{Contribution of Research}

This work included the:

1. Development of an apparatus for comparing the adsorption behaviour of fixed and fluidized beds of zeolite 13X;

2. Experimental evaluation of the performance of the adsorbent beds under various charge and discharge conditions; and

3. Proposal of a methodology for scaling adsorption-based thermal energy storages. 


\subsection{Organization of Research}

This thesis is divided into the following chapters:

Chapter 2 presents a review of the current literature on thermochemical energy storage, including a comparison of the laboratory and pilot-scale studies that influenced this work;

Chapter 3 presents the physical design of the apparatus and an outline of the test procedure followed for this work;

Chapter 4 presents the results of the experimental study based on temperature and humidity profiles; and

Chapter 5 presents conclusions drawn from this study, and discusses recommendations for future work.

Appendices A to D present additional information that support this research. 


\section{Chapter 2}

\section{Literature Review}

This chapter contains a review of the literature on past and current research activities focused on the potential of thermochemical materials to provide thermal energy storage for residential heating applications. The status of thermochemical energy storage within the landscape of international energy policy is summarized, including the major achievements of researching members of a task force on the subject; a review of thermochemical energy storage system types is given, with emphasis on fluidization and fluidized bed technology; and, an outline of the different performance metrics used to evaluate the performance of thermochemical energy storage systems is then presented, providing context for a series of comparative studies and the experimental evaluation of the system developed for this work.

\subsection{Global Status of the Technology}

\subsubsection{The International Energy Agency}

The International Energy Agency (IEA) is an autonomous body within the Organization for Economic Co-operation and Development (OECD) that has led the global dialogue on energy since 1974. The IEA advocates policies that will enhance the accessibility, reliability, and sustainability of energy in its 29 member countries and beyond. It achieves this work through Technology Collaboration Programs (TCP) that provide data and authoritative analysis on the full spectrum of energy issues. 


\subsubsection{IEA - Solar Heating and Cooling Program}

Established in 1977, the Solar Heating and Cooling Program (SHC) is a TCP of the IEA that promotes all aspects of solar thermal energy through the collaborative efforts of international expertise. Objectives of this program include the research, development, and demonstration of new solar thermal technologies. This work is carried out through a series of Tasks or research projects that study various aspects of solar heating and cooling. Each Task is managed by an operating agent from one of the member countries or sponsoring organizations, and overall control of the program lies with an executive committee.

\subsubsection{IEA - SHC Task 42}

Recognizing energy storage as an integral component of energy-efficient systems, the Energy Conservation and Energy Storage (ECES) Program of the IEA is comprised of a strategic plan for the research, development, dissemination, and market deployment of energy storage technologies. Task 42 is a joint Task with Annex 29 of the ECES titled Compact Thermal Energy Storage: Material Development for System Integration, which has an overall objective of developing advanced materials and systems for the compact storage of thermal energy. The objectives of Task 42/Annex 29 as outlined by its position paper [19] were to:

- identify material requirements via numerical simulation of known storage technologies;

- identify, design, and develop new and composite materials;

- develop reliable and reproducible measuring and testing procedures to characterize new storage materials;

- enhance the performance, stability, and cost-effectiveness of new storage materials;

- develop multi-scale numerical models that describe and predict the performance of new materials;

- develop and demonstrate novel compact thermal energy storage systems employing the advanced materials; and 
- develop a method for the economic evaluation of compact thermal energy storage systems

Activities for the Task were divided between five working groups (WG) organized in a matrix according to Figure 2.1

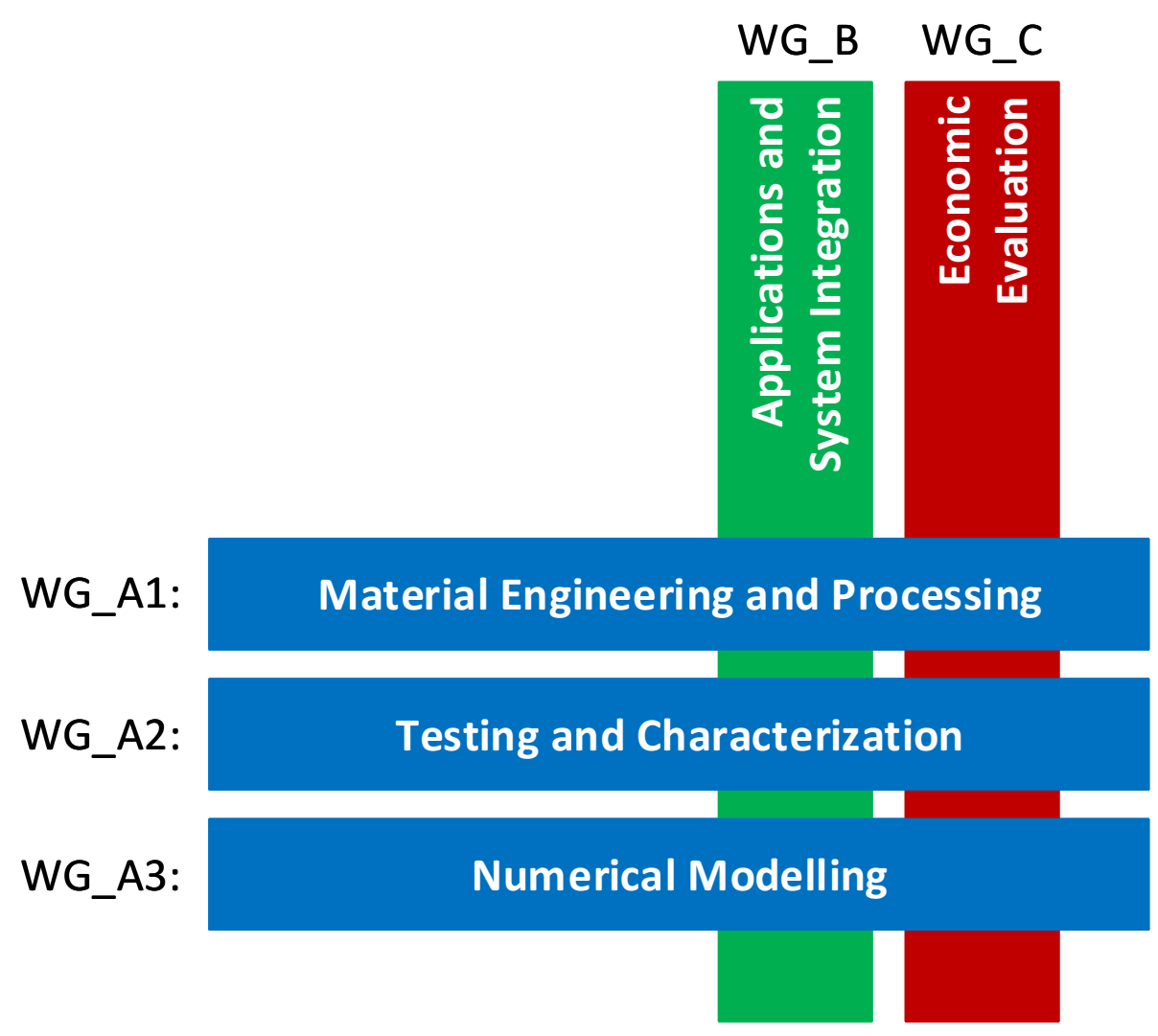

Figure 2.1: Organization of IEA-SHC Task 42/ECES Annex 29, adapted from $[19]$.

The WG forming the blue rows of Figure 2.1 represented three categories related to materials (A1, A2, and A3). The activities of these WG intersected with Working Groups B and C, which focused on system development and the economic evaluation of compact thermal energy storage systems, respectively. The Task officially started January 1, 2009 and ended December 31, 2015.

The key achievements of each WG for Task 42/Annex 29 pertaining to thermochemical storage are summarized in Tables $2.1-2.5$. 
Table 2.1: Key achievements by Task 42/Annex 29 Working Group A1.

\begin{tabular}{|c|c|}
\hline Member of WG_A1 & Activities \\
\hline $\begin{array}{l}\text { Leuphana University } \\
\text { (Germany) }\end{array}$ & $\begin{array}{l}\text { - using a reactor simulation, found } \mathrm{SrBr}_{2} \cdot 6 \mathrm{H}_{2} \mathrm{O} \\
\left(392 \mathrm{kWh} / \mathrm{m}^{3}\right), \mathrm{LaCl}_{3} \cdot 7 \mathrm{H}_{2} \mathrm{O}\left(359 \mathrm{kWh} / \mathrm{m}^{3}\right) \text {, } \\
\text { and } \mathrm{MgSO}_{4} \cdot 6 \mathrm{H}_{2} \mathrm{O}\left(340 \mathrm{kWh} / \mathrm{m}^{3}\right) \text { as potential } \\
\text { candidates out of a study of } 125 \text { salt hydrates } \\
\text { based on thermodynamics and non-toxicity } 20 \\
\text { - experiments limiting water vapour flow } \\
\text { demonstrated the possibility to avoid the } \\
\text { formation of solutions (improving cycle stability) } \\
\text { with hydration; however, this was found to be } \\
\text { infeasible at the macro-scale } 21 \\
\text { - the impregnation of salt hydrates into vermiculite } \\
\text { improved cycle stability and thermal conductivity } \\
\text { but decreased energy density } 22\end{array}$ \\
\hline $\begin{array}{l}\text { Universities of Lleida } \\
\text { \& Barcelona (Spain) }\end{array}$ & $\begin{array}{l}\text { - from corrosion tests between inorganic TCM } \\
\text { and metal reactor vessels, recommend that only } \\
316 \text { stainless steel should be used for reactors } \\
\text { containing } \mathrm{CaCl}_{2}, \mathrm{Na}_{2} \mathrm{~S}, \mathrm{CaO}, \mathrm{MgSO}_{4} \text {, } \\
\text { and } \mathrm{MgCl}_{2} \\
\text { - the thermo-physical characterization of } \mathrm{CaCl}_{2} \\
\left(408 \mathrm{kWh} / \mathrm{m}^{3}\right) \text { and zeolite }\left(55 \mathrm{kWh} / \mathrm{m}^{3}\right) \\
\text { was examined } 24\end{array}$ \\
\hline TH-Wildau (Germany) & $\begin{array}{l}\text { - modified the hydrophilic character of } \mathrm{NaY} \\
\text { zeolites via dealumination through a steaming } \\
\text { process, shifting their adsorption isotherm } \\
\text { to permit regeneration at temperatures less } \\
\text { than } 100^{\circ} \mathrm{C} 25\end{array}$ \\
\hline
\end{tabular}


Table 2.2: Key achievements by Task 42/Annex 29 Working Group A2.

\begin{tabular}{|c|c|}
\hline Member of WG_A2 & Activities \\
\hline TH-Wildau (Germany) & $\begin{array}{l}\text { - characterized two binder-free zeolites: } \\
13 \mathrm{XBF} \text { and NaYBF (Chemiewerke Bad Köstritz) } \\
\text { which showed water adsorption capacities slightly } \\
\text { greater than } 30 \text { wt. } \% \text {, with no degradation under } \\
\text { temperatures of } 180 \text { to } 200^{\circ} \mathrm{C} \mid 26\end{array}$ \\
\hline $\begin{array}{l}\text { Eindhoven University of } \\
\text { Technology (The Netherlands) }\end{array}$ & $\begin{array}{l}\text { - characterized the dehydration of two reference } \\
\text { materials }\left(\mathrm{Li}_{2} \mathrm{SO}_{4} \cdot \mathrm{H}_{2} \mathrm{O} \text { and } \mathrm{CuSO}_{4} \cdot 5 \mathrm{H}_{2} \mathrm{O}\right) \text { by } \\
\text { TG-DSC thermal analyses, and in-situ XRD } \\
\text { measurements and microscopic observations on } \\
\text { monocrystals } 27] \\
\text { - compared to sulfates such as } \mathrm{MgSO}_{4} \cdot 7 \mathrm{H}_{2} \mathrm{O} \\
\left(589 \mathrm{kWh} / \mathrm{m}^{3}\right) \text {, chlorides such as } \mathrm{MgCl}_{2} \cdot 6 \mathrm{H}_{2} \mathrm{O} \\
\left(508 \mathrm{kWh} / \mathrm{m}^{3}\right) \text { were found to offer a lower } \\
\text { energy density, but a higher temperature lift } \\
\text { and better stability if restricted to a } 40-130^{\circ} \mathrm{C} \\
\text { operating range [27] }\end{array}$ \\
\hline
\end{tabular}

Table 2.3: Key achievements by Task 42/Annex 29 Working Group A3.

\begin{tabular}{|c|c|}
\hline Member of WG_A3 & Activities \\
\hline Gaastra-Nedea et al. $[28]$ & $\begin{array}{l}\text { - simulations of molecular dynamics (MD) of a } \mathrm{MgCl}_{2} \\
\text { system showed a similar trend to that found from } \\
\text { thermodynamic equilibrium: a higher water vapour } \\
\text { pressure counteracts both the dehydration and } \\
\text { hydrolysis reaction whereas a higher temperature } \\
\text { increases the amount of dehydration and hydrolysis } \\
\text { - hydrolysis occurring from the di-hydrate was predicted } \\
\text { to be unlikely under the conditions of the heat storage } \\
\text { system, while MD simulations showed that up until a } \\
\text { water vapour pressure of } 20 \text { - } 40 \text { mbar, HCl is formed } \\
\text { - MD results for three different water vapour pressures } \\
\text { showed that a higher vapour pressure ensures a more } \\
\text { crystalline stucture with a lower diffusivity of water }\end{array}$ \\
\hline
\end{tabular}


Table 2.4: Key achievements by Task 42/Annex 29 Working Group B.

\begin{tabular}{|c|c|}
\hline Member of WG_B & Activities \\
\hline $\begin{array}{c}\text { ITW University of } \\
\text { Stuttgart (Germany) } 29\end{array}$ & $\begin{array}{l}\text { FlowTCS Project: } \\
\text { - developed an open sorption process with zeolite and } \\
\text { salt impregnated zeolite in an external, quasi-continuous, } \\
\text { cross-flow reactor concept of } 30 \mathrm{~L} \text { volume coupled with } \\
200 \mathrm{~L} \text { of material storage }\end{array}$ \\
\hline CETHIL |30| & $\begin{array}{l}\text { STAID Project: } \\
\text { - developed an } 80 \mathrm{~kg} \text { zeolite system consisting of two } \\
40 \mathrm{~kg} \text { sub-reactors that could be configured in series } \\
\text { and in parallel; the serial configuration developed a } \\
\text { maximum power of } 2.25 \mathrm{~kW}\end{array}$ \\
\hline ZAE Bayern |31| & $\begin{array}{l}\text { Mobile Sorption Heat Storage: } \\
\text { - developed a zeolite sorption storage mounted on a } \\
\text { semi-trailer that was charged using waste heat from } \\
\text { an incineration plant }\left(130^{\circ} \mathrm{C}\right) \text {, and then driven to a } \\
\text { industrial drying process where heat from the discharge } \\
\text { of the storage }\left(160^{\circ} \mathrm{C}\right) \text { was used to reduce the use } \\
\text { natural gas } \\
\text { - the storage contained } 14 \text { tons of zeolite in a } 22 \mathrm{~m}^{3} \\
\text { volume and could realize a capacity of } 2.3 \mathrm{MWh} \text { with } \\
\text { adsorption inlet conditions of } 60^{\circ} \mathrm{C} \text { and } 0.009 \mathrm{~kg}_{\mathrm{H}_{2} \mathrm{O}} / \mathrm{kg}_{d a}\end{array}$ \\
\hline
\end{tabular}


Table 2.5: Key achievements by Task 42/Annex 29 Working Group C.

\begin{tabular}{|l|l|}
\hline Member of WG_C & \multicolumn{1}{|c|}{ Activities } \\
\hline Rathgeber et al. $[32$ & $\begin{array}{l}\text { - developed and tested a tool for the economic evaluation } \\
\text { of } 26 \text { existing thermal energy storage projects for specific } \\
\text { users and applications } \\
\text { - determined that the annual number of storage cycles } \\
\text { had the largest influence on the cost effectiveness of the } \\
\text { storages, and that a major fraction of the investment } \\
\text { costs for the investigated projects were not of the } \\
\text { storage material itself but costs of the storage } \\
\text { container or reactor including the charging } \\
\text { and discharging unit }\end{array}$ \\
\hline
\end{tabular}

\subsection{Systems for Thermochemical Storage}

\subsubsection{Open vs. Closed Systems}

A thermochemical process employing a solid/water pair can operate according to two different modes: the solid can react with pure water vapour at low pressure in a closed system, or with a moist air flow at atmospheric pressure in an open system (see Figure 2.2p.

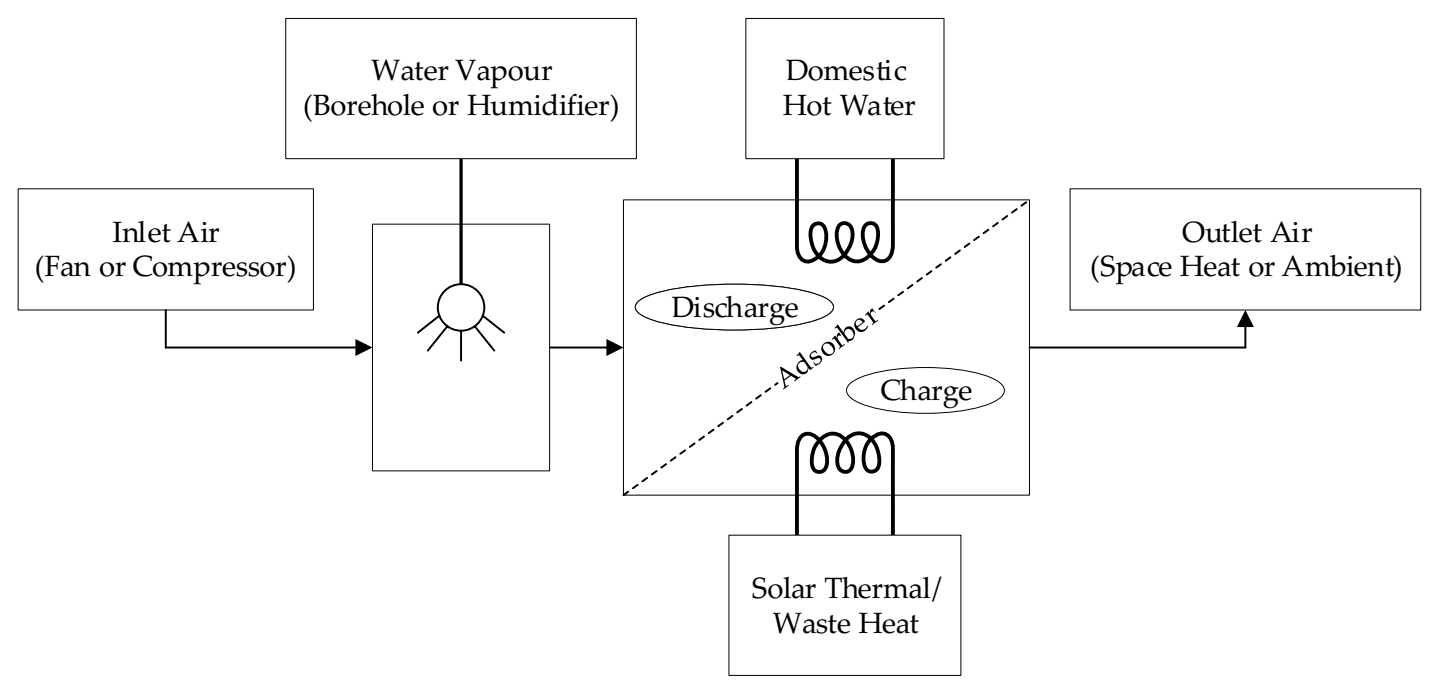

Figure 2.2: Open-system concept for thermochemical energy storage. 
In Figure 2.2, the adsorber refers to the component of the open-system in which the adsorption and regeneration processes take place. During adsorption (discharge), air driven by a fan or a compressor is mixed with water vapour from a humidifier or a borehole heat exchanger to produce the water vapour adsorbate. The heat released in the adsorber can be transferred to an air-to-water heat exchanger for heating DHW, or can be supplied directly to heating a space. During regeneration (charge), dry air entering the adsorber could be heated by a loop circulating an appropriate heat transfer fluid for solar thermal energy or low-grade waste heat from an industrial process. The moist air leaving the adsorber would be released to the ambient environment, instead of being condensed and re-used in the case of a closed system.

\section{Integrated vs. External Systems}

Two main concepts for adsorbers are described in the literature: the integrated type in which adsorption occurs within the entire storage of the material itself, or the external type where the active adsorbent material is kept separate from the adsorber (see Figure 2.3).
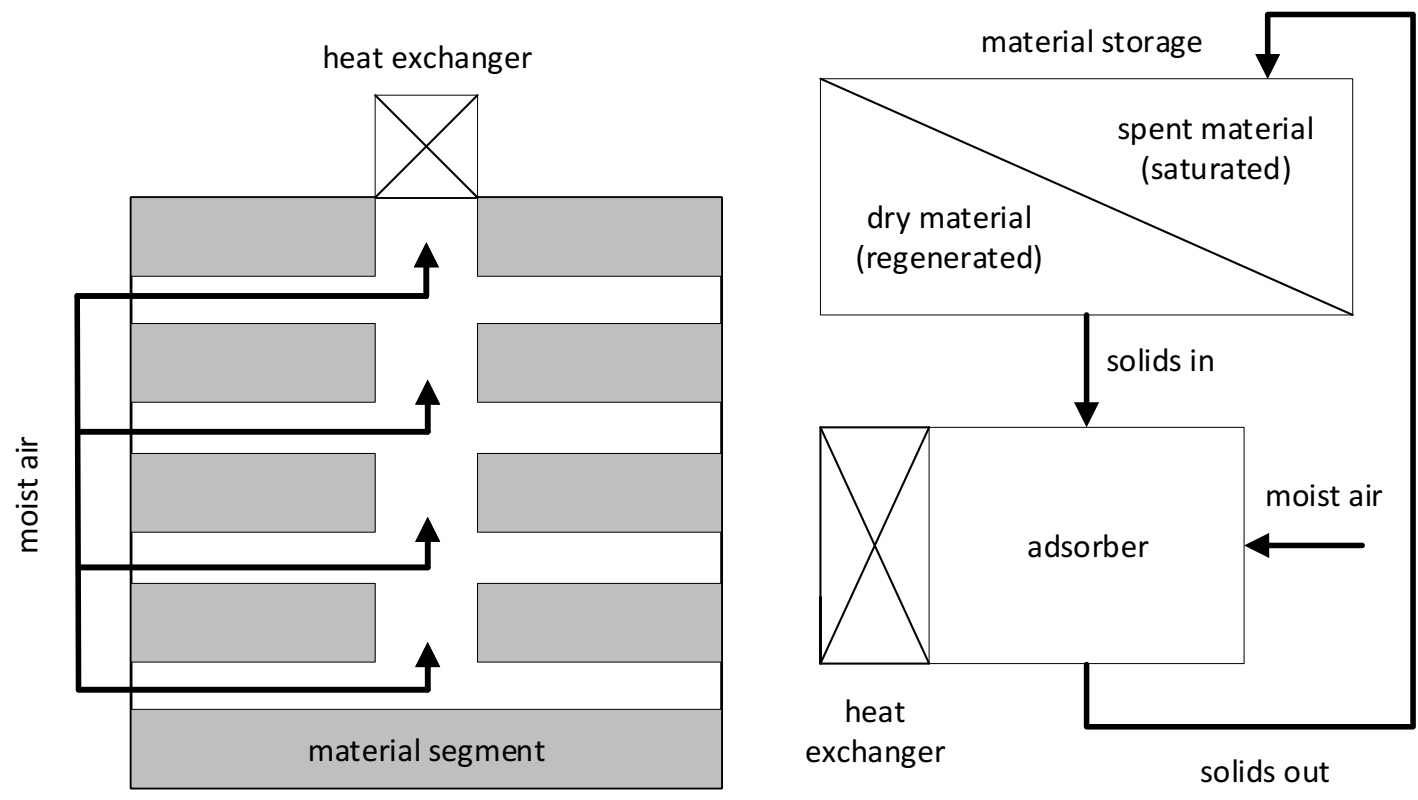

Figure 2.3: Integrated (left) vs. external (right) adsorption systems, adapted from $[33]$. 
The integrated concept is technologically easier to realize as it requires no additional mechanisms and input energy for material transport as the adsorbent is stationary within the storage. During charge of the system however, studies have shown that higher regeneration temperatures are required, implying that temperature resistant materials are required throughout the entire storage system [33]. Because the material storage and adsorber are the same component, this concept is better suited for diurnal applications where the system is charged and discharged as single cycles.

The external concept is technologically more complex as it requires material transport between the material storage and the adsorber. The adsorbent material used must also be abrasion resistant to be transportable. Adsorption and regeneration are however reduced to only a fraction of the total material at a time. This gives the external concept the advantage of reduced heat losses during regeneration, and gives the system more flexibility in terms of the rate at which material is charged and discharged

\subsection{Fundamentals of Fluidization}

As shown by Figure 2.4, fluidization is a phenomenon in which a bed of fine solids exhibits fluid-like behaviour through contact with an upward moving gas or liquid, i.e., a fluidized bed of solids will not resist an applied shear or tangential stress by a static deflection, but move and deform continuously as long as the stress is applied 34.

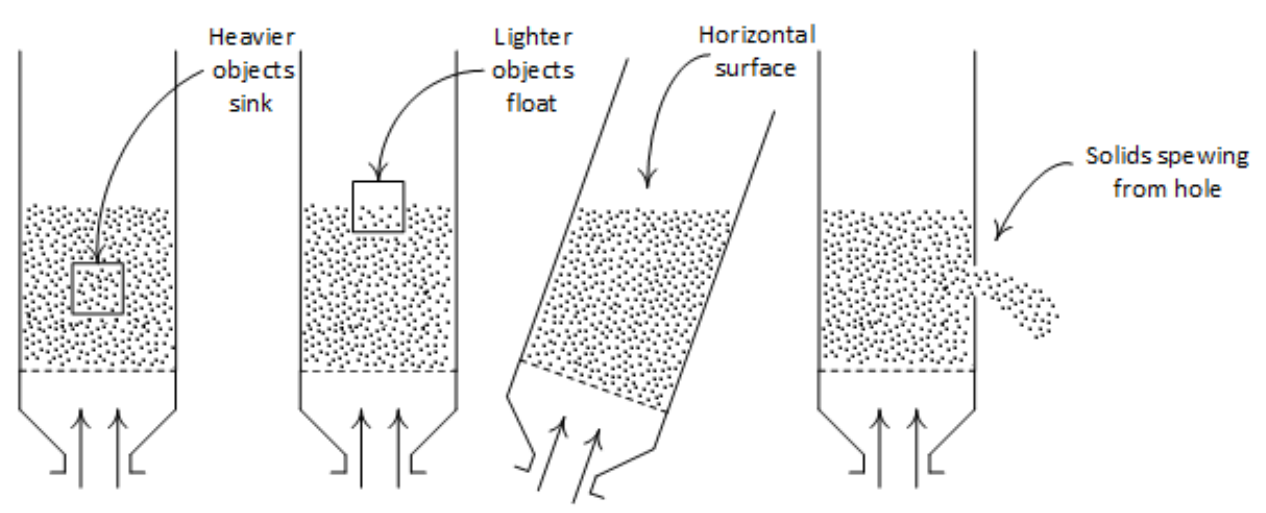

Figure 2.4: Liquid-like behaviour of gas fluidized beds, adapted from [35]. 
The fluidized solids in the bed of Figure 2.4 respond to the applied stress of an immersed object by moving around it completely in the case of the sinking heavier object; lighter objects pushed into the bed will pop up and remain floating at the surface 35]. This contrasts the expected behaviour from a stagnant non-fluidized bed of solids which would respond to the weight of the object with an equal and opposite force prohibiting it from sinking into the bed. Should the fluidized bed be tipped, the solids will respond by maintaining a horizontal surface, and if a hole were to be made in the side of the bed, the solids would spew from the hole in the form of a jet.

The degree of contact observed between a batch of solids and a fluid depends on the balance of the force of gravity (weight) and force of drag acting on individual particles. These forces depend on physical properties including the diameter of the particle $\left(d_{p}\right)$ and the difference in the density between the fluid and the particle (see Figure 2.5).

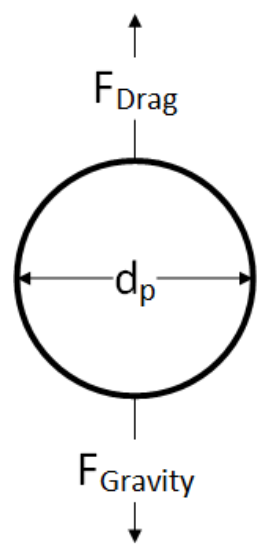

Figure 2.5: Balance of forces acting on fluidized solid particle.

Referring to the fluidization regimes of Figure 2.6, at a low flow rate, the fluid will simply pass through the void spaces of stationary particles in what is referred to as a fixed bed. All regimes of fluidization therefore begin with a fixed bed in which the force of gravity is greater than that of the force of drag on individual particles of the bed. At higher gas velocities, the force of drag will increase proportionally with the flow rate of the fluid to counterbalance the force of gravity, suspending the particles in a state of minimum fluidization. 

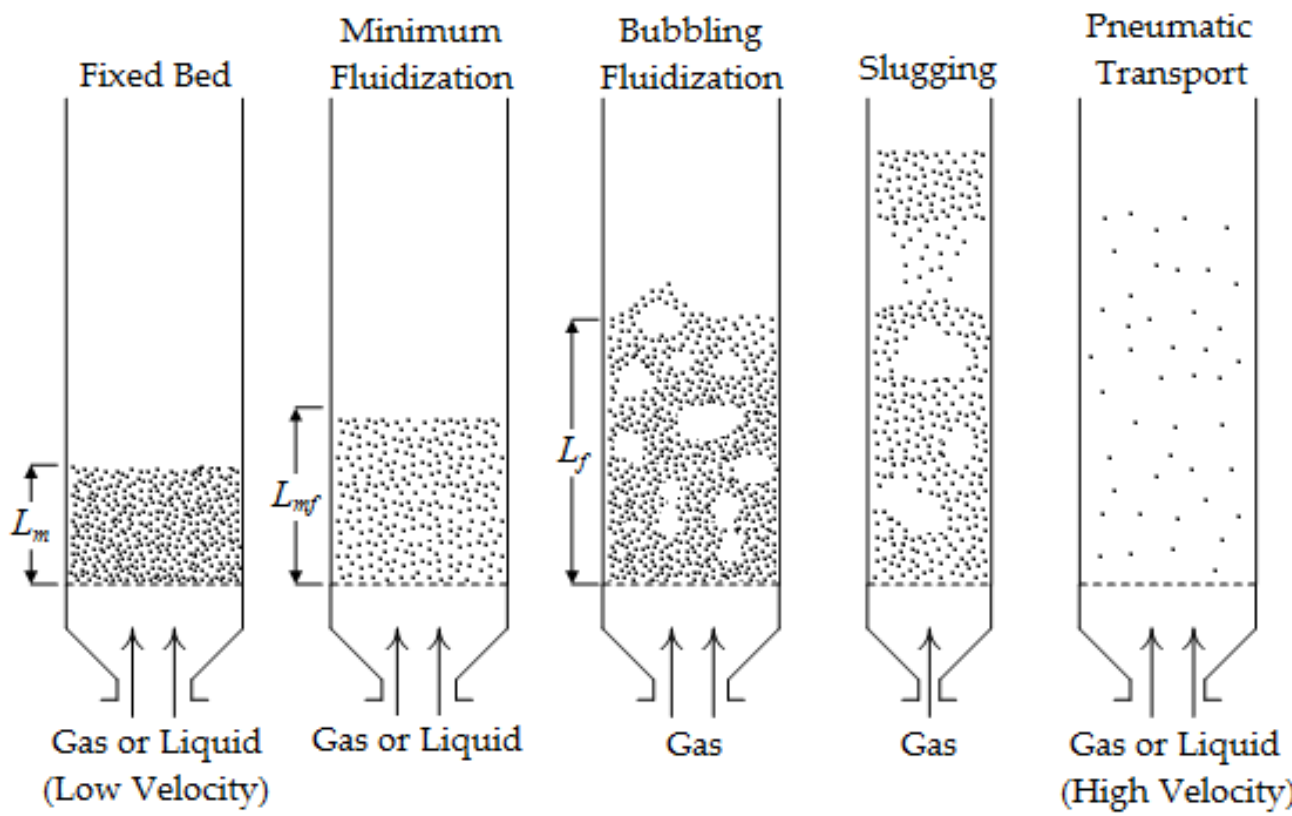

(High Velocity)

Figure 2.6: Fluidization regimes of gas fluidized beds, adapted from [35].

Increasing the flow rate beyond minimum fluidization for gas-solid systems, however, will result in large instabilities producing the bubbling and channeling of gas as shown for the bubbling fluidization regime of Figure 2.6. The vigorous agitation of the solids at higher velocities becomes more violent, providing a high level of mixing in a bed that does not expand significantly beyond its volume observed at minimum fluidization 35.

While the quality of fluidization in a gas-solid bed will be largely determined by the properties of the solid and fluid alone (see Section 1.5.1), factors such as gas flow rate, bed geometry, and internal components of the bed will influence the rate of solid mixing in the bed. Referring to Figure 2.6, slugging is a phenomenon that is occurs in long, narrow beds that allow bubbles to grow to the point that they become large enough to push a slug of cohesive solids upwards. The slug eventually disintegrates as another slug forms and this behaviour continues in oscillation. Such behaviour is undesirable for industrial applications due to the lack of solid-gas contacting present in this regime. Lastly, lean phase fluidization or pneumatic transport will occur at the highest velocities at which solids are carried out of the bed, providing little opportunity for contact between the solid and fluid. 


\section{Particle Size and Fluidization Velocity}

The quality of fluidization relating to the size and coalescence of bubbles in a bubbling bed largely depends on the diameter of the particles $\left(d_{\mathrm{p}}\right)$ and the difference between the density of the solid and gas phases $\left(\rho_{\mathrm{s}}-\rho_{\mathrm{g}}\right)$. While fluidization quality also depends on the geometry of the bed, non-ideal behavior such as slugging occurs when cohesive forces between the solids are greater than forces of drag.

Geldart 36] classified particles according to these properties into four groups: A, B, $\mathrm{C}$, and D, which display different fluidization characteristics based on the cohesion forces between particles for each group. Compared to group B particles that begin bubbling immediately at the minimum fluidization velocity $\left(u_{\mathrm{mf}}\right)$, a bed of group A particles will exhibit unique fluidization behavior, by expanding in height over the minimum fluidization velocity before bubbling at a higher velocity. Enhanced gas-solid contact efficiency has been observed with this behavior, making group A particles ideal for industrial applications 37]. Additionally, Shaul et al. 38 have observed that the pressure drop in fluidized beds of group A particles is not affected by the height to diameter (H/D) ratio

of the bed, placing less technological constraints on design and scale-up. The pressure drop within a bed of group B solids however will increase with the H/D ratio of material. Group C particles are so fine and cohesive that they do not exhibit bubbling fluidization but channel and slug according to Figure 2.6. Group D particles exhibit a less efficient spouting fluidization at significantly higher gas velocities than other groups due to the higher force of drag required to act over a larger particle diameter.

This present work is concerned with smaller particles from group A which will provide the fluidized case and larger particles from group D which will provide the fixed bed case. Geldart [36] defined group A of solids as having a small mean size and/or a density of less than $1.4 \mathrm{~g} / \mathrm{cm}^{3}$. With a bulk density of $0.64 \mathrm{~g} / \mathrm{cm}^{3}$, zeolite $13 X$ particles in the range of 50 to $300 \mu \mathrm{m}$ should exhibit group A fluidization characteristics according to Geldart's empirical powder classification diagram. A 60x65 Tyler mesh, or sieved zeolite of 210 - $250 \mu \mathrm{m}$ in particle diameter was prepared for this research based on the assumption that it would behave as a group A solid. 
Per Kunii and Levenspiel [35], the minimum fluidization velocity of smaller particles belonging to this group can be calculated according to:

$$
u_{\mathrm{mf}}=\frac{d_{\mathrm{p}}^{2}\left(\rho_{\mathrm{s}}-\rho_{\mathrm{g}}\right) g}{1650 \mu} \quad R e_{\mathrm{p}}<20
$$

For comparison, the minimum fluidization velocity of large particles can be calculated according to:

$$
u_{\mathrm{mf}}=\left[\frac{d_{\mathrm{p}}\left(\rho_{\mathrm{s}}-\rho_{\mathrm{g}}\right) g}{24.5 \rho_{\mathrm{g}}}\right]^{\frac{1}{2}} \quad R e_{\mathrm{p}}>1000
$$

For $0.001<R e_{\mathrm{p}}<4000$, Equation 2.1 and have been found to give predictions of $u_{\mathrm{mf}}$ with a standard deviation of $\pm 34 \%$ [39]. To avoid carry-over of solids from a bed, the gas velocity should be kept somewhere between the $u_{\mathrm{mf}}$ of the mean particle diameter and the terminal velocity $\left(u_{\mathrm{t}}\right)$ of the smallest diameter present for the size distribution in appreciable quantity. The terminal velocity can be obtained from experimental correlations of the dimensionless groups $C_{\mathrm{d}} R e_{\mathrm{p}}{ }^{2}$ versus $R e_{\mathrm{p}}$, where:

$$
R e_{\mathrm{p}}=\frac{d_{\mathrm{p}} \rho_{\mathrm{g}} u_{\mathrm{t}}}{\mu}
$$

and the velocity independent group is defined as:

$$
C_{\mathrm{d}} R e_{\mathrm{p}}^{2}=\frac{4 g d_{\mathrm{p}}^{3} \rho_{\mathrm{g}}\left(\rho_{\mathrm{s}}-\rho_{\mathrm{g}}\right)}{3 \mu^{2}}
$$

\subsection{Performance Metrics}

Thermochemical energy storage systems can be compared using a number of different parameters to evaluate the performance of thermochemical materials and systems as a whole. Some of the key performance parameters used within the literature and this work are discussed in the following paragraphs. 


\section{Energy Released}

The energy released (discharged) is a measurement of the amount of heat discharged over the length of hydration or adsorption, and is calculated by measuring the change in the thermodynamic properties of the air into and out of the TES system according to:

$$
Q_{\mathrm{d}}=\rho \dot{V} c_{\mathrm{p}} \Delta T\left(t_{n}-t_{n-1}\right)
$$

For Equation 2.5, the mass term of Equation 1.1 is replaced by the mass flow rate of the water vapour taken up by the TCM over the length of hydration or adsorption per time step $\left(t_{n}-t_{n-1}\right)$, or 10 seconds for the data acquisition (DAQ) system used in this work. The density and specific heat capacity of Equation 2.5 are of moist air, and $\Delta T$ is the temperature lift, or the difference in temperature at the inlet and outlet of the system.

\section{Energy Density}

The energy density is an indication of the compactness of a TES system and is most commonly expressed in terms of $\mathrm{kWh} / \mathrm{m}^{3}$. Studies in the literature typically define energy density in terms of the material and the prototype as a whole considering their respective volumes:

$$
\text { Energy Density }=\frac{\text { Energy Released }}{\text { Column or Material Volume }}
$$

\section{Specific Power and Storage Capacity}

The specific power of a TES is the average rate at which heat was released per mass of TCM during hydration or adsorption $[\mathrm{W} / \mathrm{kg}]$. The storage capacity considers the specific power of the system released over the length of the hydration or adsorption process $[\mathrm{Wh} / \mathrm{kg}]$.

$$
\text { Storage Capacity or Specific Power }=\frac{\text { Energy or Rate of Heat Released }}{\text { Mass of Material }}
$$




\subsection{Comparative Studies}

\subsubsection{Material Characterization and Selection}

A high hydration or adsorption capacity (water uptake) is essential for a high energy density, and high kinetics are required for a high thermal power output during the discharge of a thermochemical system. TCM candidates must also offer high cyclability (i.e., not degrade over time), and for the built environment, they must be non-toxic.

\section{Salt Hydrates}

Considering these requirements, N'Tsoukpoe et al. (2014) conducted a three-step screening process for identifying suitable material candidates for low temperature thermochemical energy storage [20]. Out of 125 material candidates:

- 45 salts passed an initial discrimination based on toxicity and flammability;

- 17 salts showed reversibility from TGA measurements; and

- 3 salts $\left(\mathrm{SrBr}_{2} \cdot 6 \mathrm{H}_{2} \mathrm{O}, \mathrm{LaCl}_{3} \cdot 7 \mathrm{H}_{2} \mathrm{O}\right.$, and $\left.\mathrm{MgSO}_{4} \cdot 6 \mathrm{H}_{2} \mathrm{O}\right)$ were selected for further study

The three most promising candidates, however, tended to form partial solutions during hydration, which led to the formation of non-porous layers, limiting vapour diffusion during dehydration processes. In addition to these limitations, it was determined that these materials don't offer the energy density or heat recovery efficiency to compete with simpler technologies such as sensible heat storage.

van Essen et al. [12] from the Energy Research Centre of The Netherlands (ECN) studied the hydration and dehydration behaviour of $\mathrm{MgSO}_{4}$ through thermogravimetric analysis (TGA) and differential scanning calorimetry (DSC). From these experiments, it was observed that $88 \%$ of stored energy was released from samples exposed to air at $25^{\circ} \mathrm{C}$ with a water vapour pressure of $2.3 \mathrm{kPa}$. While $\mathrm{MgSO}_{4}$ was shown to store almost nine times more energy than can be stored in water as sensible heat, only a maximum temperature lift of $4^{\circ} \mathrm{C}$ was observed.

Researchers at ECN also investigated the application of $\mathrm{MgCl}_{2} \cdot 6 \mathrm{H}_{2} \mathrm{O}$ for seasonal heat storage [13]. Investigations by TGA and an evacuated reactor setup showed that 
$\mathrm{MgCl}_{2} \cdot 6 \mathrm{H}_{2} \mathrm{O}$ started to form a mono-hydrate at $120^{\circ} \mathrm{C}$, and began forming corrosive $\mathrm{HCl}$ at temperatures above $135^{\circ} \mathrm{C}$. During hydration, material was found to form a gel-like structure that increased the pressure drop across the bed in a larger reactor.

Lele et al. (2015) measured the thermal conductivity of material candidates for thermochemical storage using DSC [40]. Thermal conductivities of $0.3-1.3 \mathrm{~W} / \mathrm{m} \cdot \mathrm{K}$ were observed obtained from the four salts studied. The use of a carrier matrix was discussed as a potential method of improving conductivity and mitigating the formation of gels during hydration.

\section{Adsorbents}

Through numerical modeling validated by experimental work, Mette et al. (2014) have shown that zeolite $13 \mathrm{X}$ is characterized by a high water uptake and fast kinetics 41. The experimental results show the influence of the wall of a fixed bed reactor on the temperature lift profile, with a higher bed porosity in near wall regions having led to faster completion of adsorption.

Cortés et al. (2010) used TGA and mass spectrometry to study the equilibrium adsorption of water vapour on zeolite 13X [42]. Similar to the calorimetric measurements of Mette et al. (2014), it was observed that as the uptake of water increased from 0.06 - $0.22 \mathrm{~g}_{\mathrm{H}_{2} \mathrm{O}} / \mathrm{g}_{13 X}$, the energy released decreased from 3,430 to 3,010 $\mathrm{J} / \mathrm{g}_{\mathrm{H}_{2} \mathrm{O}}$. From this result, it was inferred that when the zeolite is close to its maximum uptake at equilibrium, the thermodynamic properties of adsorption are similar to those of pure water.

For the application of separating $\mathrm{CO}_{2}$ from flue gases, Hauchhum and Mahanta investigated the adsorption behaviour of a variety of zeolites including $13 \mathrm{X}$ in a fixed bed [43]. These investigations were extended to a fluidized bed, in which the adsorption capacity of zeolite increased by $1.9 \mathrm{~mol}_{\mathrm{CO}_{2}} \mathrm{~kg}_{13 \mathrm{X}}^{-1}[44]$.

Details of the experimental setup and results for the foregoing characterization of adsorbents are summarized in Table 2.6. 
Table 2.6: Characterization of adsorbents for thermochemical storage.

\begin{tabular}{|c|c|c|}
\hline Author(s) & Experimental Setup & Performance \\
\hline Mette et al. [41] & $\begin{array}{l}\text { Material: } \\
170 \text { g of } 8 \times 10 \text { mesh, } \\
\text { binderless zeolite } 13 \mathrm{X} \\
\text { Sorbate: } \mathrm{H}_{2} \mathrm{O} \text { gas } \\
\left(\mathrm{P}_{\mathrm{H}_{2} \mathrm{O}}: 5-30 \text { mbar }\right) \\
\text { Apparatus: fixed bed, } \\
\mathrm{H}=140 \text { mm, ID }=50 \mathrm{~mm} \\
(\mathrm{H}: \mathrm{ID} \text { of } 2.8) \\
\text { Inlet Temperature(s): } \\
30 \& 50^{\circ} \mathrm{C} \text { (adsorption) } \\
180^{\circ} \mathrm{C} \text { (desorption) }\end{array}$ & $\begin{array}{l}\text { Temperature Lift: } \\
10^{\circ} \mathrm{C} @ 5 \text { mbar }\left(\mathrm{T}_{\mathrm{in}}=30^{\circ} \mathrm{C}\right) \\
37.5^{\circ} \mathrm{C} @ 15 \operatorname{mbar}\left(\mathrm{T}_{\mathrm{in}}=30^{\circ} \mathrm{C}\right) \\
35^{\circ} \mathrm{C} @ 15 \operatorname{mbar}\left(\mathrm{T}_{\mathrm{in}}=50^{\circ} \mathrm{C}\right) \\
75^{\circ} \mathrm{C} @ 30 \mathrm{mbar}\left(\mathrm{T}_{\mathrm{in}}=30^{\circ} \mathrm{C}\right)\end{array}$ \\
\hline $\begin{array}{l}\text { Hauchhum } \\
\text { and Mahanta }[43]\end{array}$ & $\begin{array}{l}\text { Material: } \\
\text { zeolite } 13 \mathrm{X}(20 \mathrm{~g}) \text {, } \\
8 \mathrm{x} 12 \text { mesh } \\
\text { Sorbate: } \mathrm{CO}_{2} \text { gas } \\
\left(\mathrm{P}_{\mathrm{CO}_{2}}: 0-1 \text { bar }\right) \\
\text { Apparatus: } \\
\text { packed-fixed bed } \\
200 \text { mm long, } 27 \text { mm ID } \\
(\mathrm{H}: \mathrm{ID} \text { of } 7.4) \\
\text { Flow Rate: } \\
15 \mathrm{~L} / \text { min (adsorption) } \\
\text { Inlet Temperature(s): } \\
25 \text { - } 60^{\circ} \mathrm{C} \text { (adsorption) }\end{array}$ & $\begin{array}{l}\mathrm{CO}_{2} \text { Adsorbed: } \\
4.215 \mathrm{~mol}_{\mathrm{CO}_{2}} \mathrm{~kg}_{13 X}^{-1}\end{array}$ \\
\hline
\end{tabular}


Table 2.6 - continued

\begin{tabular}{|c|c|c|}
\hline Author(s) & Experimental Setup & Performance \\
\hline $\begin{array}{l}\text { Hauchhum } \\
\text { and Mahanta } \mid 44]\end{array}$ & $\begin{array}{l}\text { Material: } \\
\text { zeolite } 13 \mathrm{X}(200-300 \mathrm{~g}) \text {, } \\
8 \times 12 \text { mesh } \\
\text { Sorbate: } \mathrm{CO}_{2} \text { gas } \\
\left(\mathrm{P}_{\mathrm{CO}_{2}}: 0-4 \text { bar }\right) \\
\text { Apparatus: fluidized bed } \\
1300 \mathrm{~mm} \text { long, } 50 \mathrm{~mm} \mathrm{ID} \text {, } \\
(\mathrm{H}: \mathrm{ID} \text { of } 3.2-4.7), \\
310 \text { - } 462 \mathrm{~mL} \\
\text { Flow Rate: } 15 \mathrm{~L} / \mathrm{min} \\
\text { Inlet Temperature(s): } \\
25 \text { - } 60^{\circ} \mathrm{C} \text { (adsorption) }\end{array}$ & $\begin{array}{l}\mathrm{CO}_{2} \text { Adsorbed: } \\
6.13 \mathrm{~mol}_{\mathrm{CO}_{2}} \mathrm{~kg}_{13 X}^{-1}\end{array}$ \\
\hline
\end{tabular}

\subsubsection{Lab-Scale Prototypes}

\section{Open Lab-Scale Systems}

Dicaire and Tezel from the University of Ottawa investigated the effects of adsorption flow rate, regeneration temperature, feed air humidity, and cycling on a hybrid adsorbent comprised of activated alumina and zeolite 13X [45]. Adsorption flow rate and cycling were shown to have no effect on the energy density of the AA13X sample; however, increasing the regeneration temperature by $170^{\circ} \mathrm{C}$ was found to increase energy density by $50 \mathrm{kWh} / \mathrm{m}^{3}$. Using the same experimental setup, Lefebvre et al. 46 conducted a parametric study which examined the effect of column dimension, particle diameter, adsorption activation energy, flow rate, column void fraction, and adsorbent heat of adsorption on the performance of an adsorption-based system.

Nonnen et al. (2016) demonstrated long-term heat storage based on the sorption of water on a $\mathrm{CaCl}_{2}$ and $\mathrm{Na}-\mathrm{X}$ composite material in both a lab-scale apparatus and hardware-in-the-loop (HIL) test bench [47]. The work concerning the HIL test-bench is unique in the literature for considering the concepts of a pre-reactor and gravity driven material transport. 
Zondag et al. (2013) at ECN developed a prototype capable of providing $50 \mathrm{~W}$ of thermal power to a load for 40 hours through the hydration of $\mathrm{MgCl}_{2} \cdot 2 \mathrm{H}_{2} \mathrm{O}$, indicating an effective energy density of approximately $139 \mathrm{kWh} / \mathrm{m}^{3}$ [48]. From the pressure drop measured across the reactor bed, the prototype was determined to have a COP of 12 .

Details of the experimental setup and performance of each open lab-scale prototype are summarized in Table 2.7.

Table 2.7: Lab-scale testing of open-systems.

\begin{tabular}{|c|c|c|}
\hline Author(s) & Experimental Setup & Performance \\
\hline $\begin{array}{l}\text { Dicaire } \\
\text { and Tezel } 445\end{array}$ & $\begin{array}{l}\text { Material: } \\
55 \text { g of } 8 x 12 \text { mesh activated } \\
\text { alumina and zeolite } 13 \mathrm{X} \\
\text { (AA13X) } \\
\text { Sorbate: } \mathrm{H}_{2} \mathrm{O} \text { gas } \\
\text { (RH: } 100 \% \text { for adsorption, } \\
0 \text { \& } 50 \% \text { for desorption) } \\
\text { Apparatus: packed-fixed bed } \\
70 \text { mm long, } 38.1 \text { mm OD } \\
(62.76 \text { mL, H/D Ratio of } 1.8) \\
\text { Flow Rate: } \\
24 \mathrm{~L} / \text { min (adsorption), } \\
8-24 \mathrm{~L} / \mathrm{min} \text { (desorption) } \\
\text { Inlet Temperature(s): } \\
20{ }^{\circ} \mathrm{C} \text { (adsorption), } \\
80-250^{\circ} \mathrm{C} \text { (desorption) }\end{array}$ & $\begin{array}{l}\text { Temperature Lift: } 55^{\circ} \mathrm{C} \\
\text { Energy Density: } \\
197 \mathrm{kWh} / \mathrm{m}^{3} \pm 7 \mathrm{kWh} / \mathrm{m}^{3} \\
\text { Regeneration: } \\
2 \text { - } 3 \text { hours } \\
\text { Cycling: } \\
50 \text { runs with no effect on } \\
\text { energy density } \\
\text { Storage Efficiency: } \\
30 \text { - } 60 \% \text { for } 80-250^{\circ} \mathrm{C}\end{array}$ \\
\hline
\end{tabular}


Table 2.7 - continued

\begin{tabular}{|c|c|c|}
\hline Author(s) & Experimental Setup & Performance \\
\hline Nonnen et al. 47 & $\begin{array}{l}\text { Material: } 15 \mathrm{CaCl}_{2} / \mathrm{Na}-\mathrm{X} \\
\text { Sorbate: } \mathrm{H}_{2} \mathrm{O} \text { gas } \\
\left(\mathrm{P}_{\mathrm{H}_{2} \mathrm{O}}: 15 \text { mbar }\right) \\
\text { Apparatus: } \\
\text { lab-scale apparatus: } \\
\text { packed-fixed bed, } \\
7 \mathrm{~cm}^{3} \text { bed volume } \\
\text { hardware-in-the-loop (HIL) } \\
\text { test bench: gravity driven, } \\
24 \mathrm{~L} \text { material volume } \\
\text { Flow Rate: } \\
0.3 \mathrm{~kg} / \mathrm{h} \text { (lab-scale), } \\
150 \mathrm{~kg} / \mathrm{h} \text { (HIL) } \\
\text { Inlet Temperature(s): } \\
\text { Discharge: } \\
30^{\circ} \mathrm{C} \text { lab-scale, } 28^{\circ} \mathrm{C} \mathrm{HIL} \\
\text { Charge: } \\
110^{\circ} \mathrm{C} \text { lab-scale, } 180^{\circ} \mathrm{C} \mathrm{HIL}\end{array}$ & $\begin{array}{l} \\
\text { Temperature Lift: } \\
35^{\circ} \mathrm{C} \text { in HIL } \\
\text { Discharge Power: } \\
1.2 \mathrm{~kW} \text { (HIL test bench) } \\
\text { Energy Density: } \\
260 \mathrm{kWh} / \mathrm{m}^{3} \text { (lab-scale) }\end{array}$ \\
\hline Zondag et al. 48 & $\begin{array}{l}\text { Material: } \mathrm{MgCl}_{2} \cdot 6 \mathrm{H}_{2} \mathrm{O}(17 \mathrm{~L}) \\
\text { Sorbate: } \mathrm{H}_{2} \mathrm{O} \text { gas } \\
\left(\mathrm{P}_{\mathrm{H}_{2} \mathrm{O}}: 12 \mathrm{mbar}\right) \\
\text { Apparatus: packed bed } \\
\text { Flow Rate: } 510 \mathrm{~L} / \mathrm{min} \\
\text { Inlet Temperature }(\mathrm{s}): \\
\text { Hydration: } \\
25^{\circ} \mathrm{C}\left(T_{\text {evap }}=10^{\circ} \mathrm{C}\right) \\
50^{\circ} \mathrm{C}\left(T_{\text {evap }}=25^{\circ} \mathrm{C}\right) \\
\text { Dehydration: } 130^{\circ} \mathrm{C}\end{array}$ & $\begin{array}{l}\text { Temperature Lift: } \\
62^{\circ} \mathrm{C} @ \mathrm{~T}_{\text {in }}=25^{\circ} \mathrm{C} \\
18^{\circ} \mathrm{C} @ \mathrm{~T}_{\text {in }}=50^{\circ} \mathrm{C} \\
\text { Discharge Power: } \\
50 \text { - } 150 \mathrm{~W} \\
\text { Energy Density: } \\
139 \mathrm{kWh} / \mathrm{m}^{3} \\
\text { Pressure Drop: } \\
100 \mathrm{~Pa} \text { (packed bed), } \\
220 \mathrm{~Pa} \text { (system) }\end{array}$ \\
\hline
\end{tabular}




\section{Closed Lab-Scale Systems}

With the goal of developing a large-scale thermochemical energy storage to be integrated with industrial processes and HVAC systems, Lass-Seyoum et al. (2012) conducted adsorption experiments for various zeolites at the lab-scale in $1.5 \mathrm{~L}$ and $15 \mathrm{~L}$ closed-system apparatus. Suitable storage materials and process conditions were characterized in the $1.5 \mathrm{~L}$ system, while heat exchanger concepts were optimized in the development of the $15 \mathrm{~L}$ system 49$]$.

Details of the experimental setup and performance of each closed lab-scale prototype are summarized in Table 2.8 .

Table 2.8: Lab-scale closed-system thermochemical projects.

\begin{tabular}{|c|c|c|}
\hline Author(s) & Experimental Setup & Performance \\
\hline Lass-Seyoum et al. 49 & $\begin{array}{l}\text { Material: various zeolites } \\
(800-900 \mathrm{~g}), 8 \times 12 \text { mesh } \\
\text { Sorbate: } \mathrm{H}_{2} \mathrm{O} \text { gas } \\
\left(\mathrm{P}_{\mathrm{H}_{2} \mathrm{O}}: 42 \mathrm{mbar}\right) \\
\text { Apparatus: packed bed }(1.5 \mathrm{~L}) \\
\text { Inlet Temperature }(\mathrm{s}) \text { : } \\
30^{\circ} \mathrm{C} \text { (adsorption), } \\
90-200^{\circ} \mathrm{C} \text { (desorption) }\end{array}$ & $\begin{array}{l}\text { Storage Capacity: } \\
160-220 \mathrm{Wh} / \mathrm{kg} \\
\text { Specific Power: } \\
60-240 \mathrm{~W} / \mathrm{kg}\end{array}$ \\
\hline Lass-Seyoum et al. 49 & $\begin{array}{l}\text { Material: } \sim 15 \mathrm{~L} \text { of various } \\
\text { zeolites, } 8 \times 12 \text { mesh } \\
\text { Sorbate: } \mathrm{H}_{2} \mathrm{O} \text { gas } \\
\text { Apparatus: packed bed }(15 \mathrm{~L}) \\
\text { Inlet Temperature(s): } \\
20^{\circ} \mathrm{C} \text { (adsorption), } \\
90-200^{\circ} \mathrm{C} \text { (desorption) }\end{array}$ & $\begin{array}{l}\text { Storage Capacity: } \\
180-240 \mathrm{Wh} / \mathrm{kg} \\
\text { Specific Power: } \\
45-66 \mathrm{~W} / \mathrm{kg}\end{array}$ \\
\hline
\end{tabular}




\subsubsection{Pilot-Scale Prototypes}

\section{Open Pilot-Scale Systems}

From a 2D analysis of the second-law applied to a model of an open and closed system [50], Michel et al. developed a large-scale prototype involving the hydration of $400 \mathrm{~kg}$ of $\mathrm{SrBr}_{2}$ in an open system [51]. The mass flow rate of the moist air was determined to have a strong influence on the reaction kinetics and thermal power of the reactor; increasing the flow rate of the moist air from 150 to $313 \mathrm{~m}^{3} / \mathrm{h}$ resulted in a $500 \mathrm{~W}$ increase in thermal power released during hydration. Based on specifications requiring a supply of $2 \mathrm{~kW}$ of heat over a 2 hour period, Johannes et al. (2015) developed a high-powered open storage system comprised of two $40 \mathrm{~kg}$ beds of zeolite 13X that were configured in series and parallel [30]. From investigations of two regeneration temperatures $\left(120 \& 180^{\circ} \mathrm{C}\right)$, two flow rates $\left(120 \& 180 \mathrm{~m}^{3} / \mathrm{h}\right)$, and two levels of relative humidity (50 \& 70\%), it was found that:

1. A lower regeneration temperature results in a lower amount of energy released, but at the same maximum power.

2. A higher humidity during adsorption results in a higher maximum released power.

3. A reduction in the air flow rate leads to a reduction of the maximum released power with the same amount of stored energy released.

Gaeini et al. developed a $250 \mathrm{~L}$ open storage system capable of discharging $3.6 \mathrm{~kW}$ of heat with its four reactor segments running in parallel; each segment could provide up to $0.9 \mathrm{~kW}$ for 10 hours [52]. Over an 18 hour adsorption period, each segment released an average of $12 \mathrm{kWh}$ of heat which equates to almost $70 \%$ of the heat supplied to each segment during the 7 hour regeneration process. By reducing non-reactive zones within the system, Gaeini et al. expect to increase the energy density of the setup to almost $145 \mathrm{kWh} / \mathrm{m}^{3}$.

Details of the experimental setup and performance of each open pilot-scale prototype are summarized in Table 2.9 . 
Table 2.9: Open pilot-scale thermochemical projects.

\begin{tabular}{|c|c|c|}
\hline Author(s) & Experimental Setup & Performance \\
\hline Michel et al. [51] & $\begin{array}{l}\text { Material: } \\
400 \mathrm{~kg} \text { of } \mathrm{SrBr}_{2} \cdot 6 \mathrm{H}_{2} \mathrm{O} \\
\text { Sorbate: } \mathrm{H}_{2} \mathrm{O} \text { gas } \\
\left(4.3-6.2 \mathrm{~g}_{\mathrm{H}_{2} \mathrm{O}} / \mathrm{kg}_{d a} @ 25{ }^{\circ} \mathrm{C}\right) \\
\text { Apparatus: } \\
\text { modular porous fixed bed, } \\
8 \text { rectangular modules } \\
(8 \times 50 \mathrm{~kg} \text { of hydrated salt), } \\
\mathrm{L}=74.9 \mathrm{~cm} \\
\mathrm{~W}=72 \mathrm{~cm} \\
\mathrm{H}=96.6 \mathrm{~cm}, \\
\left(0.52 \mathrm{~m}^{3} \text { or } 520 \mathrm{~L}\right) \\
\text { Flow Rate: } \\
290^{3} / \mathrm{h} \text { (hydration), } \\
313 \mathrm{~m}^{3} / \mathrm{h} \text { (dehydration) } \\
\text { Inlet Temperature: } \\
25^{\circ} \mathrm{C} \text { (hydration), } \\
80{ }^{\circ} \mathrm{C} \text { (dehydration) }\end{array}$ & $\begin{array}{l}\text { Discharge Power: } \\
300-800 \mathrm{~W} \\
\text { Specific Power: } \\
0.75-2 \mathrm{~W} / \mathrm{kg} \\
\text { Energy Density: } \\
203 \mathrm{kWh} / \mathrm{m}^{3} \text { (reactor), } \\
388 \mathrm{kWh} / \mathrm{m}^{3} \text { (salt bed) } \\
\text { Storage Capacity: } \\
105 \mathrm{kWh}(262.5 \mathrm{Wh} / \mathrm{kg} \text { ) } \\
\text { Pressure Drop: } \\
60 \text { to } 560 \mathrm{~Pa} \text { (bed) }\end{array}$ \\
\hline Johannes et al. $\mid 30$ & $\begin{array}{l}\text { Material: } \\
80 \text { kg of Zeolite } 13 \mathrm{X} \\
\text { Sorbate: } \\
\mathrm{H}_{2} \mathrm{O} \text { gas } 50 \& 70 \% \mathrm{RH} \\
\text { Apparatus: } \\
\text { two packed beds } \\
\text { (40 kg of zeolite each) } \\
\text { Flow Rate: } \\
120 \& 180 \mathrm{~m}^{3} / \mathrm{h} \\
\text { Inlet Temperature: } \\
20{ }^{\circ} \mathrm{C} \text { (adsorption), } \\
120 \& 180^{\circ} \mathrm{C} \text { (desorption) }\end{array}$ & $\begin{array}{l}\text { Temperature Lift: } \\
37^{\circ} \mathrm{C} \\
\text { Discharge Power: } \\
\text { 1,410 - } 2,249 \mathrm{~W} \\
\text { Specific Power: } \\
27.5 \mathrm{~W} / \mathrm{kg} \\
\text { COP: } 1.7 \text { - } 6.8 \\
\text { Storage Efficiency: } \\
34-54.1 \%\end{array}$ \\
\hline
\end{tabular}


Table 2.9 - continued

\begin{tabular}{|c|c|c|}
\hline Author(s) & Experimental Setup & Performance \\
\hline Gaeini et al. $\mid 52]$ & $\begin{array}{l}\text { Material: } \\
170 \mathrm{~kg} \text { of Zeolite } 13 \mathrm{XBF} \\
\text { Sorbate: } \mathrm{H}_{2} \mathrm{O} \text { gas } \\
\left(5.2 \mathrm{~g}_{\mathrm{H}_{2} \mathrm{O}} / \mathrm{kg}_{d a}\right) \\
\text { Apparatus: packed bed, } \\
\text { four cuboid } 62.5 \mathrm{~L} \text { segments } \\
(250 \mathrm{~L}), 2: 1 \text { (W:H) aspect ratio } \\
\text { Flow Rate: } \\
50 \mathrm{~g} / \mathrm{s} \text { (adsorption) } \\
33 \mathrm{~g} / \mathrm{s} \text { (desorption) } \\
\text { Inlet Temperature: } \\
10^{\circ} \mathrm{C} \text { (adsorption), } \\
190^{\circ} \mathrm{C} \text { (desorption) }\end{array}$ & $\begin{array}{l}\text { Temperature Lift: } \\
18^{\circ} \mathrm{C} \\
\text { Discharge Power: } \\
3.6 \mathrm{~kW} \text { for } 10 \text { hours } \\
\text { Storage Capacity: } \\
17 \mathrm{kWh} \text { (100 Wh/kg) } \\
\text { Energy Density: } \\
198 \mathrm{kWh} / \mathrm{m}^{3} \text { (material) } \\
108 \mathrm{kWh} / \mathrm{m}^{3} \text { (prototype) } \\
\text { Storage Efficiency: } \\
67 \% \\
\text { Pressure Drop: } \\
30 \text { Pa (bed) }\end{array}$ \\
\hline
\end{tabular}

\section{Closed Pilot-Scale Systems}

Lass-Seyoum (2016) conducted experiments on a large-scale (750 L) adsorption thermochemical store in combination with solar thermal heat pipes. Adequate thermal energy for hot water and space heating (i.e., temperatures above $60^{\circ} \mathrm{C}$ ) were obtained even after succeeding discharge processes over 4 days [53].

Finck et al. (2013) designed an adsorption heat storage module based on a desired capacity of $3 \mathrm{kWh}$ for supplying space heat with a temperature lift of $20^{\circ} \mathrm{C}$ at a rate of $800 \mathrm{~W}$ [54]. Decreasing the temperature difference between the condenser and the inlet for desorption from 100 to $80^{\circ} \mathrm{C}$ resulted in a $30 \%$ reduction in the energy released by the module [55].

Details of the experimental setup and performance of each closed pilot-scale prototype are summarized in Table 2.10. 
Table 2.10: Closed pilot-scale thermochemical projects.

\begin{tabular}{|c|c|c|}
\hline Author(s) & Experimental Setup & Performance \\
\hline Lass-Seyoum et al. 53 & $\begin{array}{l}\text { Material: } 750 \mathrm{~L} \text { of zeolite } \\
\text { (type unknown) } \\
\text { Sorbate: } \mathrm{H}_{2} \mathrm{O} \text { gas } \\
\text { Apparatus: } 0.75 \mathrm{~m}^{3} \text {, } \\
\text { stationary bed (Solarlux) } \\
\text { Flow Rate: } \\
2.5 \mathrm{~m}^{3} / \mathrm{h} \text { "heat carrier", } \\
1.8 \mathrm{~m}^{3} / \mathrm{h} \text { "cooling cycle" } \\
\text { Inlet Temperature: } \\
25-30^{\circ} \mathrm{C} \text { (adsorption) } \\
100-120^{\circ} \mathrm{C} \text { (desorption) }\end{array}$ & $\begin{array}{l}\text { Energy Density: } \\
200-220 \mathrm{kWh} / \mathrm{m}^{3} \\
\text { Temperature Lift: } \\
40{ }^{\circ} \mathrm{C} \\
\text { Storage Capacity: } \\
150-220 \mathrm{Wh} / \mathrm{kg} \\
\text { Specific Power: } \\
19-50 \mathrm{~W} / \mathrm{kg}\end{array}$ \\
\hline Finck et al. 55,55 & $\begin{array}{l}\text { Material: zeolite } 5 \mathrm{~A} \\
(40 \mathrm{~kg}), 8 \mathrm{x} 12 \text { mesh } \\
\text { Sorbate: } \mathrm{H}_{2} \mathrm{O} \text { gas } \\
\text { Apparatus: packed bed, } \\
\text { eight } 1000 \mathrm{x} 300 \mathrm{x} 33 \mathrm{~mm} \text { blocks } \\
\text { containing zeolite with a } \\
\text { cylindrical vessel } \\
\mathrm{OD}=502 \mathrm{~mm} \\
\mathrm{H}=1,454 \mathrm{~mm} \\
\text { Inlet Temperature: } \\
20^{\circ} \mathrm{C} \text { (adsorption) } \\
103^{\circ} \mathrm{C} \text { (desorption) }\end{array}$ & $\begin{array}{l}\text { Energy Density: } \\
47 \mathrm{kWh} / \mathrm{m}^{3} \text { (material), } \\
12.5 \mathrm{kWh} / \mathrm{m}^{3} \text { (overall) } \\
\text { Temperature Lift: } \\
33^{\circ} \mathrm{C} \\
\text { Storage Capacity: } \\
63 \mathrm{Wh} / \mathrm{kg} \\
\text { Specific Power: } \\
24 \mathrm{~W} / \mathrm{kg}, 740-971 \mathrm{~W} \\
\text { transferred to load }\end{array}$ \\
\hline
\end{tabular}




\subsection{Research Direction}

To date, the main focus of research projects on compact thermochemical energy storage has been on material characterization and development, the bulk of which have been conducted in Europe, with fewer research activities taking place in North America. A review of the literature on thermochemical energy storage has highlighted that research and development initiatives on the systems aspects of the technology are required to match efforts that have been made to characterize and develop new materials.

Given its capacities in advanced building mechanical systems, Canada has the potential to carry out the applied research and development to commercialize the mechanical systems of this technology. In their 2012 assessment of the technology, SAIC Canada concluded that key developments required to realize thermochemical storage are reactor \& adsorber designs, methods of transporting charged and discharged material, and methods of determining the state of charge of the system [8. Many designs and methods exist for contacting the solid TCMs with air; however, most of the bench and pilot-scale systems reviewed were of the integral type based on packed-bed designs because of their design simplicity.

Despite being used extensively in industry for their noted advantages of higher heat and mass transfer compared to fixed beds, fluidized beds have only been considered conceptually for the application of low-temperature thermochemical energy storage. Experimental studies in other fields have only focused on the pure adsorption characteristics of zeolite in fluidized beds (i.e., breakthrough and capacity). Therefore, there is a lack of thermodynamic data to support the evaluation of these systems for thermal energy storage. The proposed research direction for this work was therefore to investigate the thermodynamic behaviour (i.e., temperature lift and energy released) of zeolites in a

fluidized bed and compare their performance to a fixed bed of equal size, drawing conclusions regarding the scaling of the two bed types. 


\section{Chapter 3}

\section{Experimental Design}

This chapter provides a detailed description of the experimental apparatus developed for evaluating fixed and fluidized beds of zeolite 13X for the application of thermochemical energy storage. Following this description, methodologies regarding material preparation, experimental procedure, and calculations are described.

\subsection{The Experimental Setup}

The experimental setup that was designed, constructed, and commissioned during this study is shown as Figure 3.1.

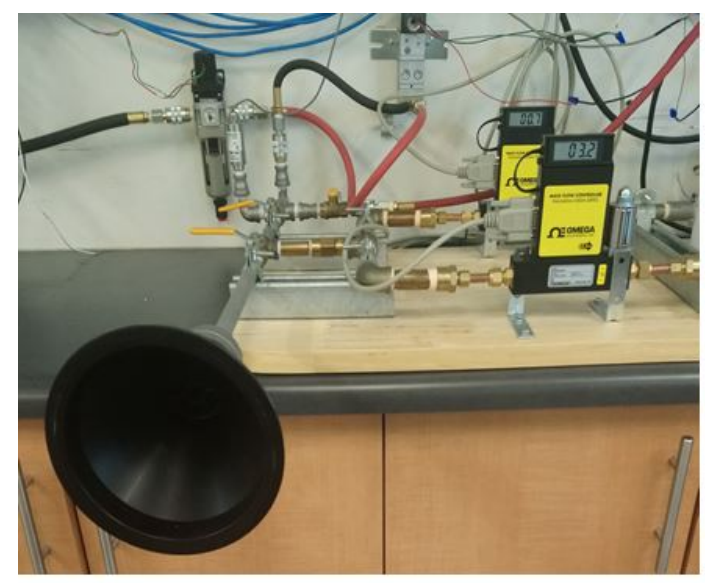

(a)

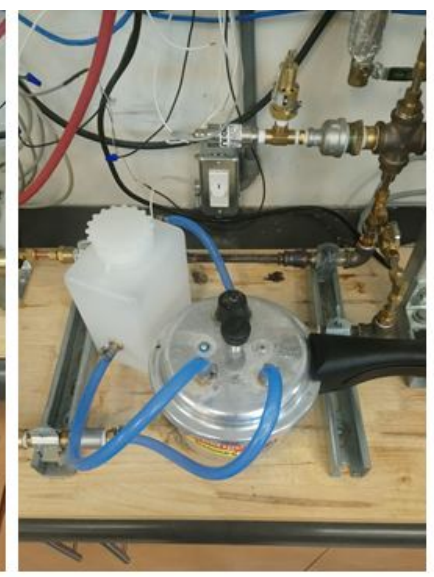

(b)

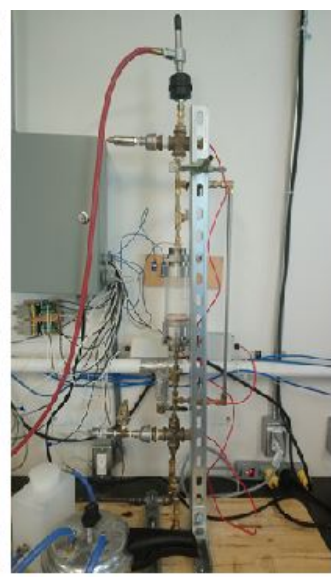

(c)

Figure 3.1: The experimental setup including (a) the pressure and flow control (b) the in-line air heater and bubbler (c) the adsorption column. 


\subsubsection{Adsorption Configuration}

Figure 3.2 is a piping and instrumentation diagram (P\&ID) of the system configured for the adsorption experiments performed in this work. Compressed air from the building's supply was made available in the laboratory by means of an industrial quickdisconnect tap on the bench. This air was first passed through a manual pressure regulator that reduced the pressure of the supply air to 60 psig and filtered out oil, water, and other particles that could be present in the line. The air was further regulated by an $\mathrm{I} / \mathrm{P}$ converter which could remotely regulate the pressure of the air between 0 and 60 psig with a $4-20 \mathrm{~mA}$ signal.

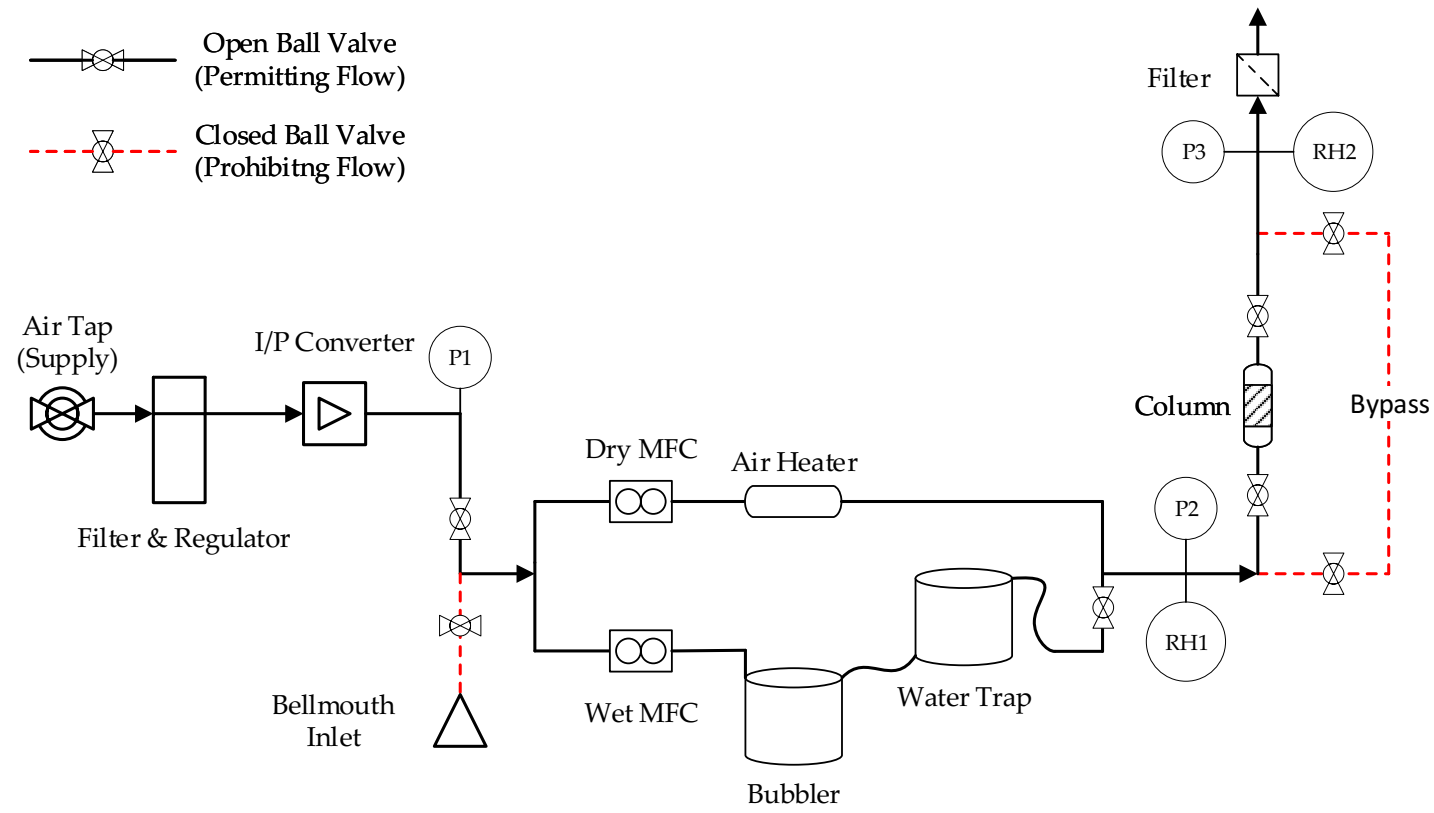

Figure 3.2: The setup configured for adsorption experiments.

Before the air was split between a dry and wet pathway, a pressure transducer (P1) measured the pressure of the air entering the apparatus, which was used to indicate the amount of pressure drop across the system with additional measurements made at P2 and P3. The humidity (mixing ratio) and therefore the vapour pressure of the water entering the adsorption column was controlled by two mass flow controllers (wet and dry MFC) with a 0 - 5 Vdc signal. The flow controlled by the dry MFC was passed through a $500 \mathrm{~W}$ in-line air heater controlled by potentiometer and a feedback loop to maintain 
a constant temperature of $25^{\circ} \mathrm{C}$ at the inlet of column. The flow controlled by the wet MFC was bubbled through a vessel containing water; a water trap following the bubbler prevented liquid water from entering the adsorption column.

The relative humidity and temperature of the air entering and exiting the adsorption column were measured by two high-temperature relative humidity transmitters (RH1 and RH2 respectively). Signals from two MFCs in conjunction with the inlet relative humidity measurement were used in a PID control loop to maintain a set mixing ratio at the inlet of the adsorption column (see subsection 3.1.6). The bypass allowed for the mixing ratio and temperature of the air to stabilize prior to introducing the air to the column at the beginning of an experiment.

\subsubsection{Regeneration Configuration}

\section{Non-Vacuum Regeneration}

Figure 3.3 is a P\&ID of the bench-scale adsorption TES system configured for insitu regeneration of the adsorbent under the near atmospheric pressure of the building's compressed air supply.
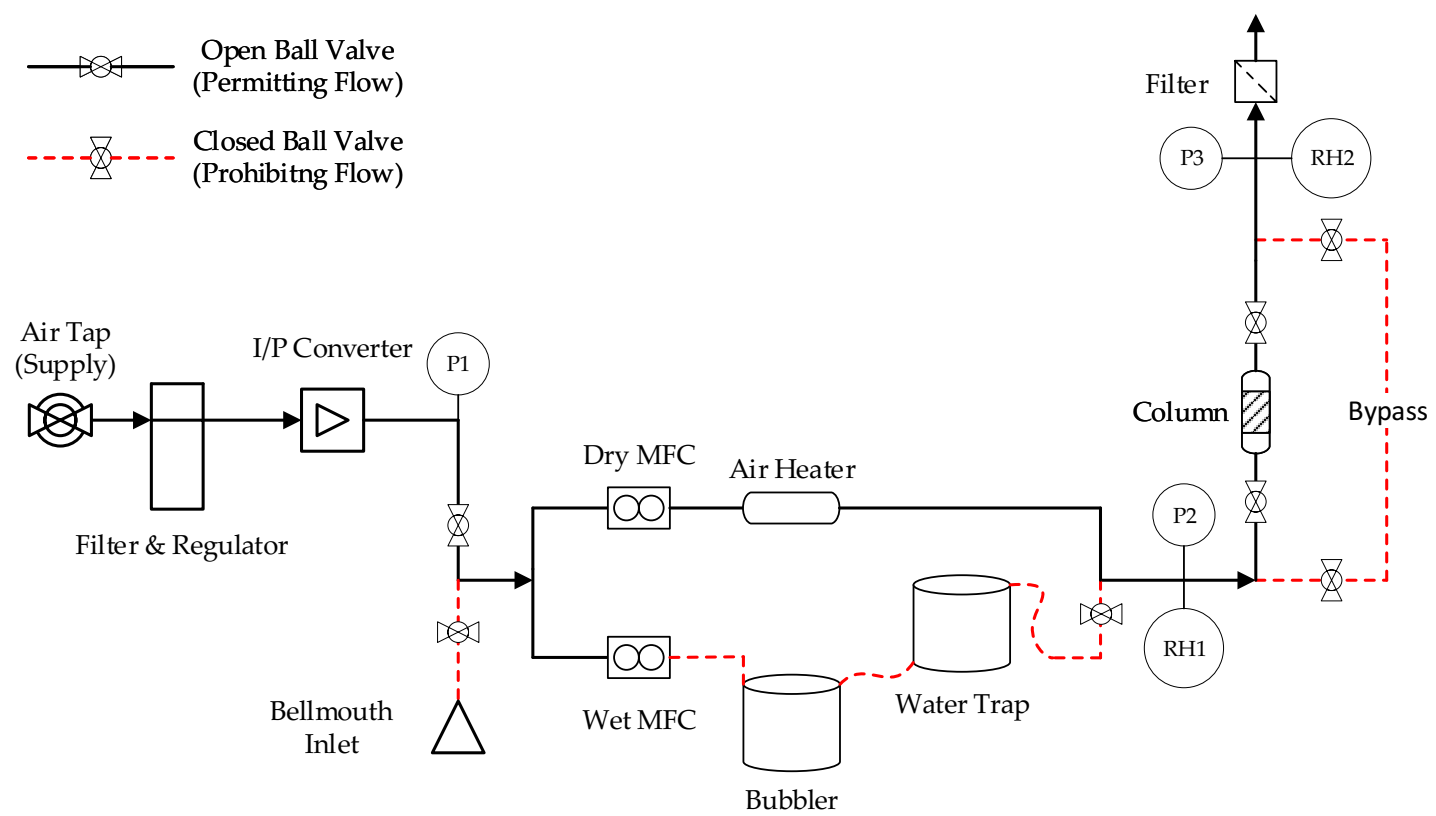

Figure 3.3: The setup configured for in-situ regeneration. 
The configuration of Figure 3.3 is similar to that shown in Figure 3.2 except that the flow rate of the wet $\mathrm{MFC}$ is set to $0 \mathrm{~L} / \mathrm{min}$ and the ball valve following the water trap is closed, directing the air exclusively through the dry MFC pathway.

\section{Partial Vacuum Regeneration}

Figure 3.4 is a diagram of the system configured for in-situ regeneration under a partial vacuum. Similar to Figure 3.3, air is only able to flow through the dry MFC pathway; however, a material conveying vacuum pump (Vaccon DF 2-3) located at the outlet of the system is used to pull air ambient air into the apparatus at the bellmouth inlet.

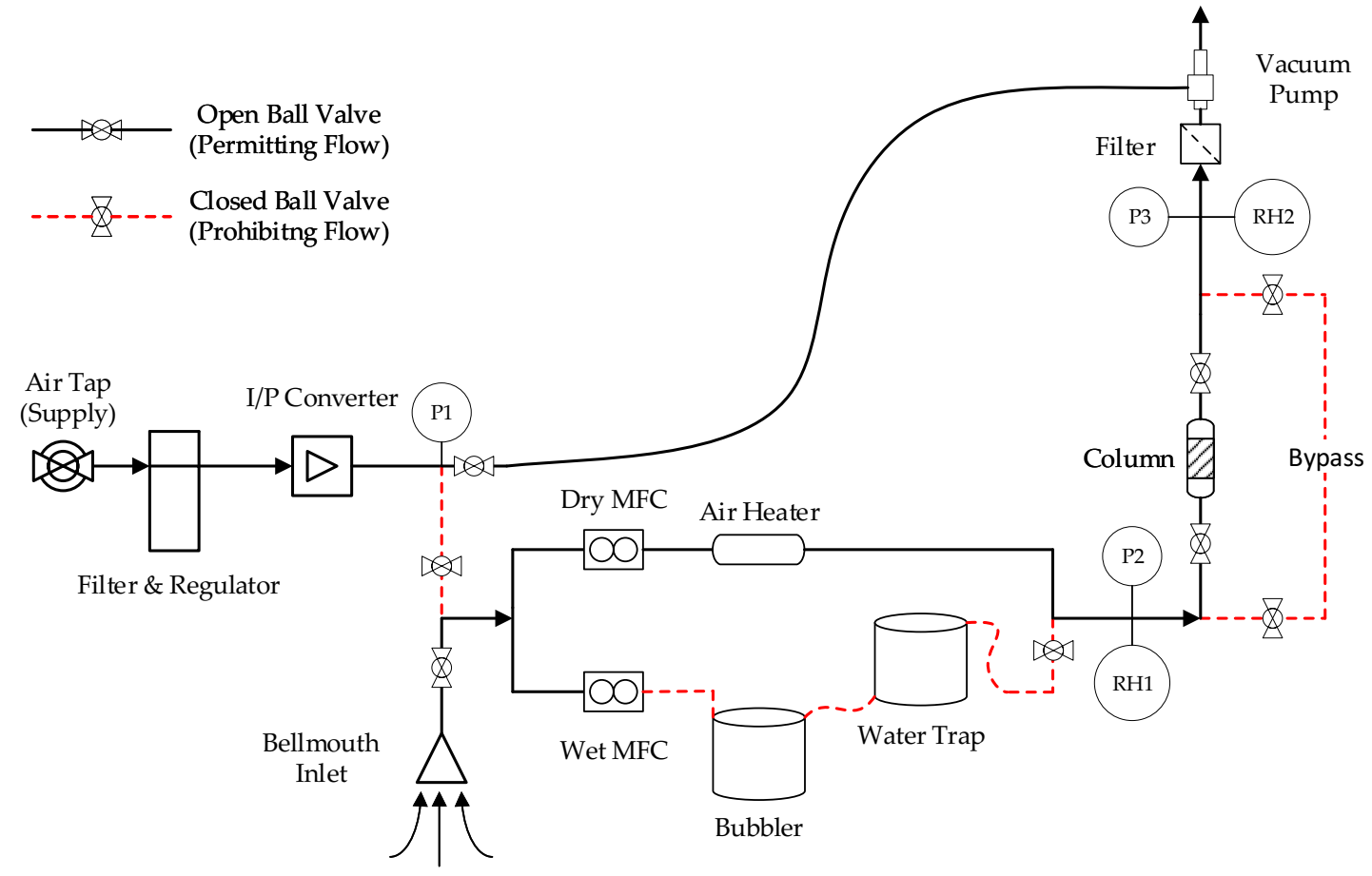

Figure 3.4: The setup configured for in-situ vacuum regeneration.

\subsubsection{The Adsorption Column}

The zeolite that underwent the adsorption and regeneration processes in this work was contained in an acrylic column (see Figure 3.5). Air entered from the bottom of the column at the inlet and moved upward through the zeolite, exiting from the outlet at the top. 


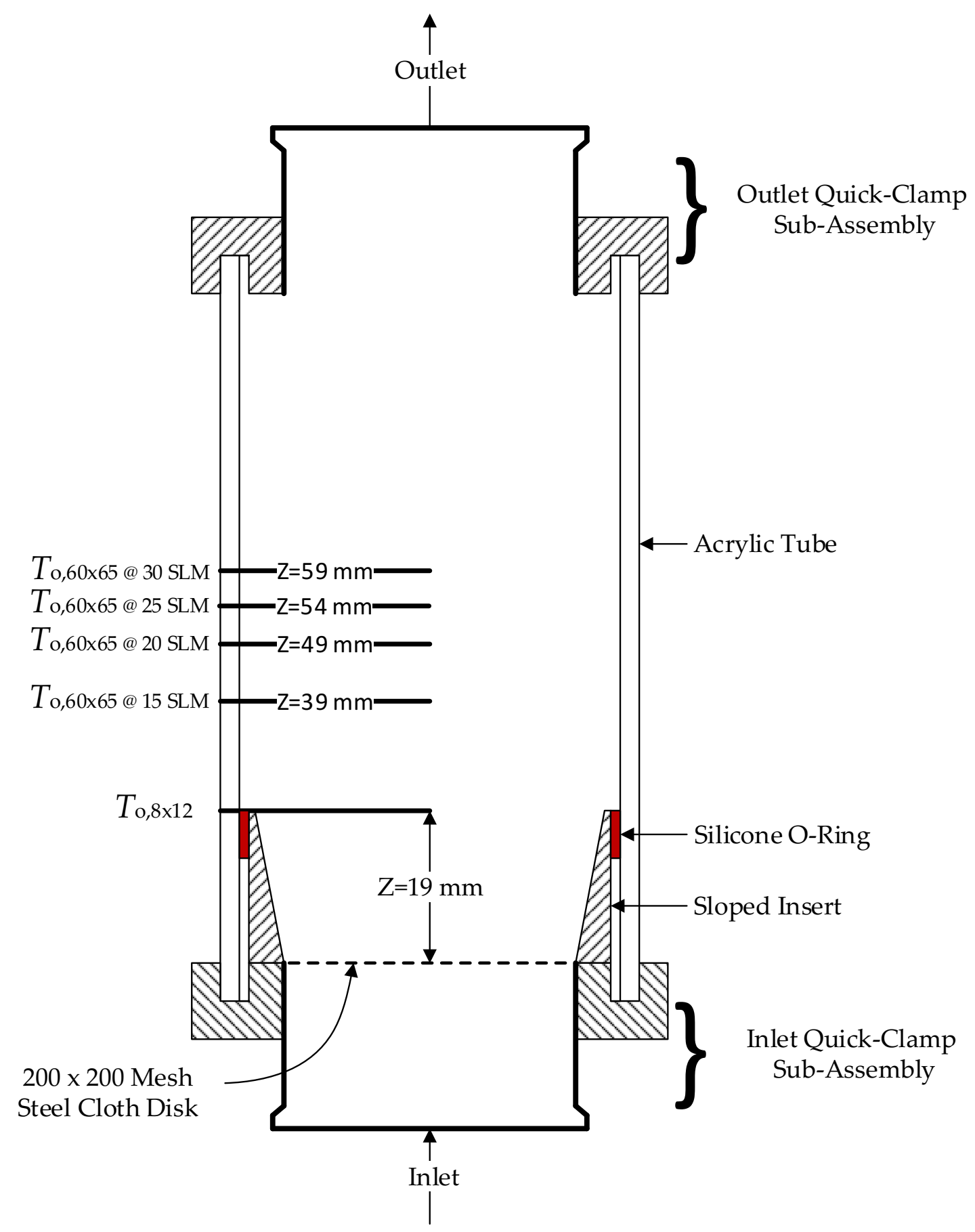

Figure 3.5: Cross section of the adsorption column.

Samples of zeolite rested on the steel cloth disc which was glued between the sloped insert and the acrylic tube collar as part of the inlet sub-assembly (see Figure A2). 
Thermocouples were located axially within the column and it was assumed that there was no radial temperature gradient. The outlet temperature for the fixed bed $\left(T_{8 \times 12}\right)$ was measured by a T-type thermocouple just above the height of a $25 \mathrm{~g}$ sample of $8 \times 12$ mesh zeolite at $Z=19 \mathrm{~mm}$. Similarly, the outlet temperatures of the fluidized bed $\left(T_{60 \times 65}\right)$ was measured by thermocouples at the peak bubble height of a $25 \mathrm{~g}$ sample of 60x65 mesh zeolite fluidized at each flow rate $\left(Z_{f}\right)$. A different acrylic column was used for each flow rate of the fluidized bed.

The top of the acrylic column was glued inside the outlet quick clamp-collar sub assembly, while the bottom portion was sealed by a silicone o-ring and could be separated from the inlet quick-clamp sub-assembly for cleaning and maintenance of the column. The inlet and outlet quick-clamp sub-assemblies interfaced with the rest of the plumbing of the apparatus by way of matching machined parts (see Appendix A for engineering drawings).

The shape of the fixed bed of 8x12 mesh zeolite was approximated as a truncated cone (Figure 3.6) and its volume was calculated using Equation 3.1, where $Z$ is the height of the static bed at $19 \mathrm{~mm}$.
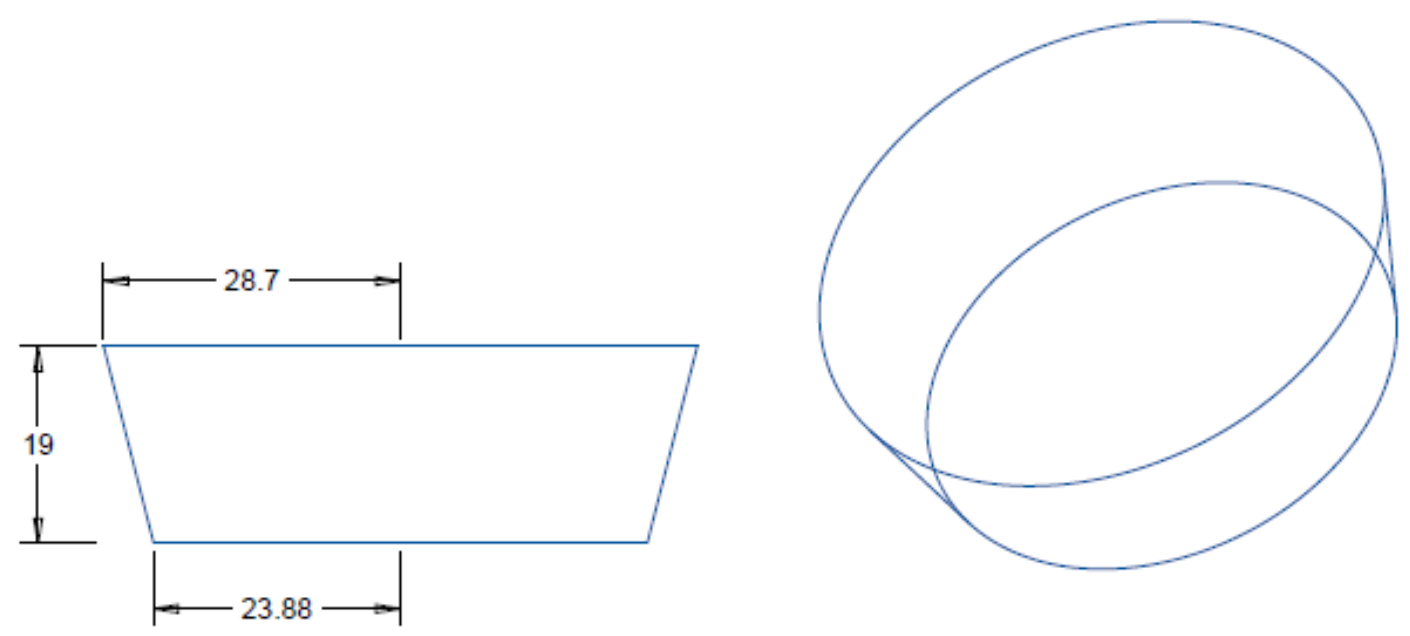

Figure 3.6: Dimensions of fixed bed for calculating volume (units in mm).

$$
\begin{aligned}
V_{\text {fixed }} & =\frac{1}{3} \pi\left(r_{1}^{2}+r_{1} r_{2}+r_{2}^{2}\right) Z_{\mathrm{o}} \\
& =\frac{1}{3} \pi\left((23.88 \mathrm{~mm})^{2}+(23.88 \mathrm{~mm})(28.7 \mathrm{~mm})+(28.7 \mathrm{~mm})^{2}\right)(19 \mathrm{~mm}) \\
& =41.4 \mathrm{~cm}^{3}
\end{aligned}
$$


This volume was used to calculate the energy density of the column for the fixed bed. The shape of the fluid bed of 60x65 mesh zeolite was considered to be that of the fixed bed plus the volume of a cylinder the height of the bubbles above the static height of the fixed bed for a particular flow rate $\left(Z_{\mathrm{f}}-Z_{\mathrm{o}}\right)$ per Figure 3.7 and Equation 3.2.
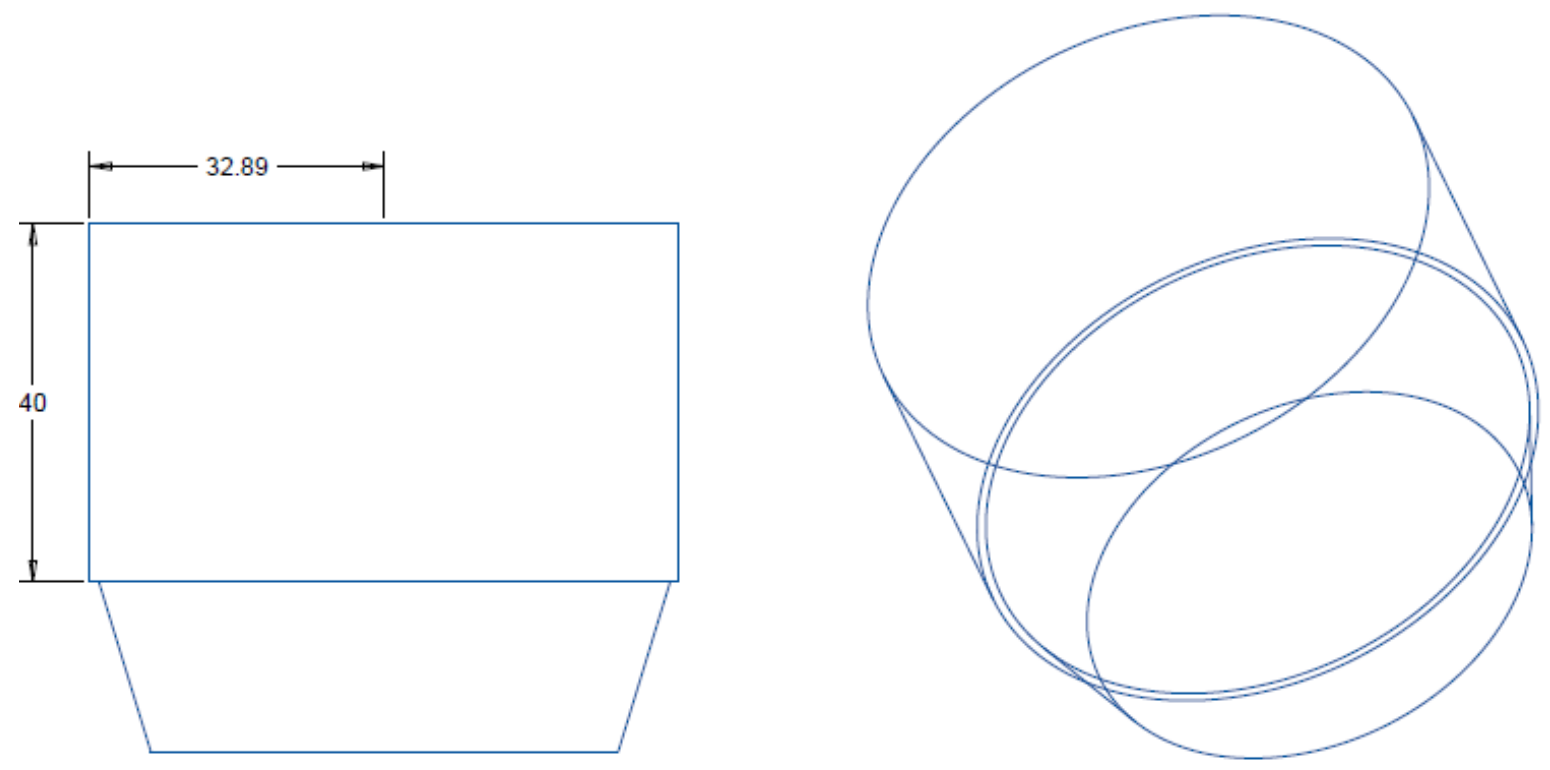

Figure 3.7: Dimensions of fluid bed for calculating volume (units in $\mathrm{mm}$ ).

$$
V_{\text {fluid }}=V_{\text {fixed }}+\pi r_{2}^{2}\left(Z_{\mathrm{f}}-Z_{\mathrm{o}}\right)
$$

Using Equation 3.2, the volume occupied by the fluidized material in the column at each flow rate was calculated, and the volumes indicated in Table 3.1 were used to calculate the energy density of the fluid bed.

Table 3.1: Volume of fluid bed in column at each flow rate.

\begin{tabular}{ccc} 
Flow Rate $(\mathrm{L} / \mathrm{min})$ & $Z_{\mathrm{f}}(\mathrm{mm})$ & Volume $\left(\mathrm{cm}^{3}\right)$ \\
\hline 10 & 0 & 41.4 \\
15 & 39 & 93.2 \\
20 & 49 & 119 \\
25 & 54 & 132 \\
30 & 59 & 145
\end{tabular}


Figure 3.8 shows the height of the $60 \times 65$ mesh material fluidized at $25 \mathrm{~L} / \mathrm{min}$ in comparison to the fixed bed
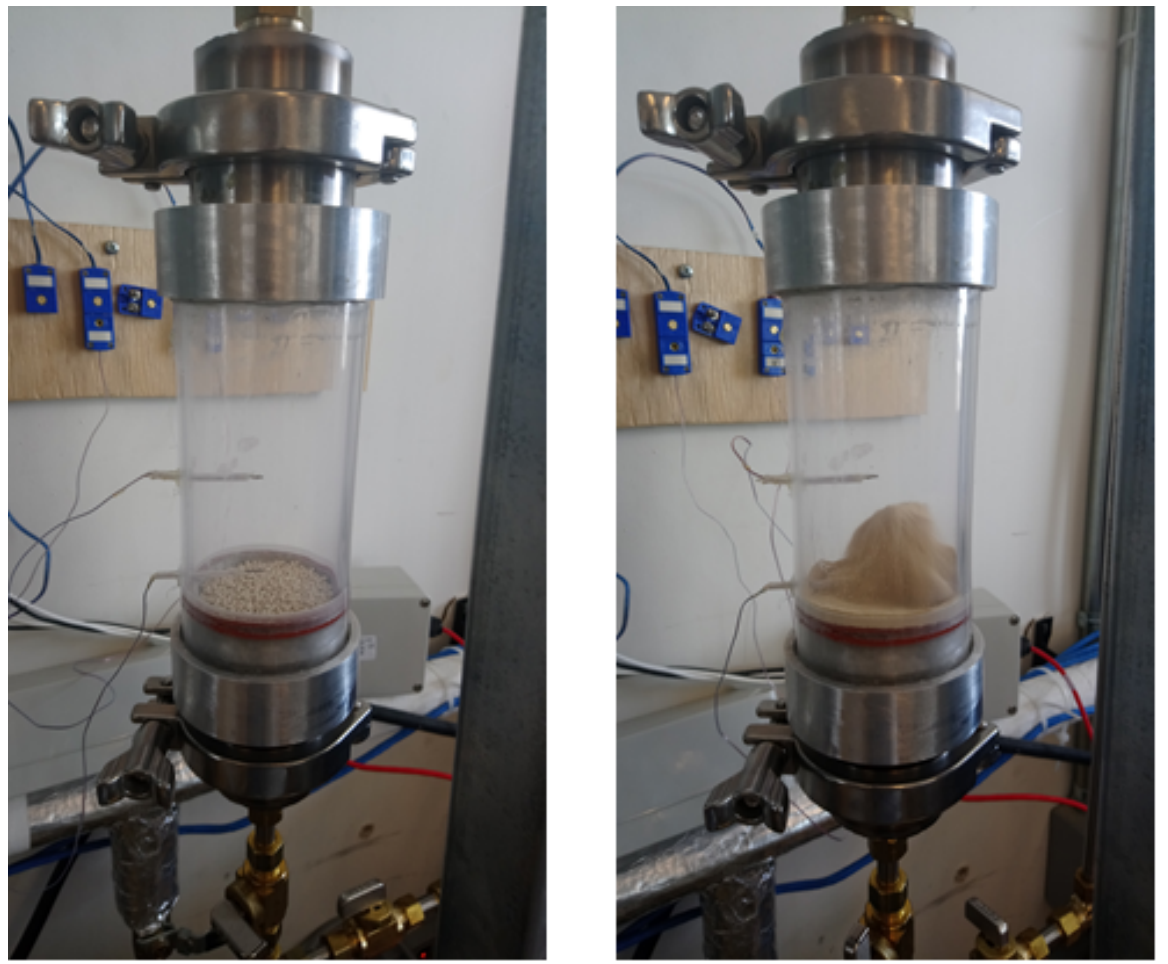

Figure 3.8: A $25 \mathrm{~g}$ sample of $8 \times 12$ zeolite in a fixed bed (left) and $60 \times 65$ zeolite fluidized at $25 \mathrm{~L} / \mathrm{min}$ (right).

\subsubsection{Instrumentation}

The experimental setup shown in Figure 3.1 was equipped with the following instrumentation to measure the adsorption and regeneration processes:

- three pressure transducers with a compound range of -14.7 to 85 psig and an accuracy of $\pm 1 \%$ of the full-scale output (FSO)

- two mass flow controllers (MFC) with a range of 0 to 100 standard L/min (SLM), and an accuracy of $\pm 1.5 \%$ FSO $( \pm 1.5 \mathrm{SLM})$

- two high-temperature relative humidity transmitters $(\mathrm{RH})$ with an accuracy of $\pm 0.05 \% \mathrm{RH} /{ }^{\circ} \mathrm{C}$ for -40 to $150^{\circ} \mathrm{C}\left( \pm 2 \% \mathrm{RH}\right.$ for 3 to $95 \%$ at $\left.25^{\circ} \mathrm{C}\right)$ for relative humidity and $\pm 0.5^{\circ} \mathrm{C}$ for temperatures of -40 to $180^{\circ} \mathrm{C}$

- T-type thermocouples within the adsorption column to measure the outlet temperature of the fixed and fluidized adsorbent beds with an uncertainty of $\pm 0.49^{\circ} \mathrm{C}$ 
A more detailed description of each instrument and the uncertainty analysis applied to each experiment is available as Appendix D.

\subsubsection{Data Acquisition}

To monitor all of the instrumentation installed, as well as to provide the control signals during experimental tests to the MFC and in-line air heater, an existing National Instruments NI cRIO 9024 CompactRIO chassis was wired to all of the devices and instruments through swappable I/O modules (cards) that make specific measurements or perform control functions. The configuration of the cards installed in the NR cRIO 9024 are listed in Table 3.2

Table 3.2: Configuration of I/O modules for the NI cRIO 9204.

\begin{tabular}{|c|c|c|c|l|}
\hline $\begin{array}{c}\text { I/O } \\
\text { Module }\end{array}$ & Function & $\begin{array}{c}\text { Number } \\
\text { of Modules }\end{array}$ & $\begin{array}{c}\text { Total } \\
\text { Number } \\
\text { of Channels }\end{array}$ & Purpose \\
\hline NI 9214 & $\begin{array}{c}\text { Isothermal } \\
\text { Thermocouple Input }\end{array}$ & 1 & 16 & $\begin{array}{l}\text { measure } \\
\text { thermocouples }\end{array}$ \\
\hline NI 9207 & $\begin{array}{c}4-20 \text { mA and 0-10 V } \\
\text { Analog Input }\end{array}$ & 1 & 16 & $\begin{array}{l}\text { meausure RH, } \\
\text { pressure, and } \\
\text { flowrate }\end{array}$ \\
\hline NI 9265 & $\begin{array}{c}4-20 \mathrm{~mA} \\
\text { Analog Output }\end{array}$ & 1 & 4 & control flowrate \\
\hline
\end{tabular}

The data acquisition system communicated with a software called LabVIEW that allowed the signals to be read into and sent out from a program referred to as a virtual instrument (VI).

\subsubsection{Inlet Humidity PID Control}

Using the measured relative humidity at the inlet as feedback for controlling the wet and dry MFCs, it was possible to maintain a set relative humidity at the inlet of the adsorption column. Figure 3.9 shows the response of this control as the inlet relative humidity value of the LabVIEW VI was set to 30,50 , and $70 \%$ at a total flow rate of $25 \mathrm{~L} / \mathrm{min}$. The flow rate of the wet and dry MFC are indicated on the primary y-axis, and the measured $\mathrm{RH}$ is indicated by the secondary y-axis. 


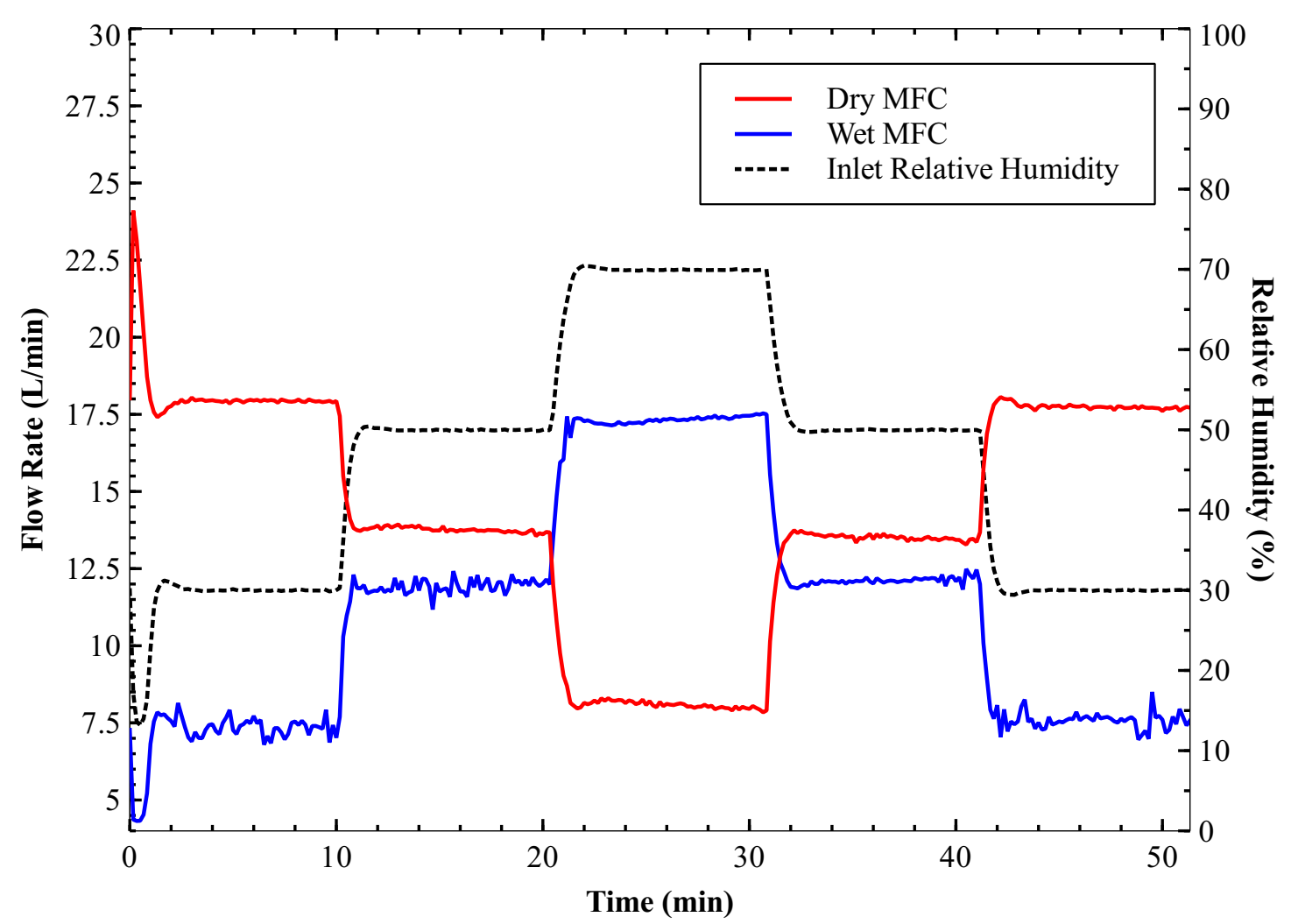

Figure 3.9: Response of MFCs to change in inlet relative humidity signal.

A plunge in the measured $\mathrm{RH}$ of the inlet air was a typical response to the the start of the VI and is why the column is bypassed for the first 5 min of every experiment. As the flows of the wet and dry MFC converge over the first $20 \mathrm{~min}$, the measured relative humidity of the mixed flows increases and stabilizes at each setpoint value from $30 \rightarrow 50 \rightarrow 70 \% \mathrm{RH}$. Likewise as the two flows begin to diverge at $30 \mathrm{mins}$, the measured inlet relative humidity decreases from 70 back to $30 \% \mathrm{RH}$.

\subsection{Material Preparation}

The TCM chosen for this work was a zeolite 13X molecular sieve adsorbent purchased from Delta Adsorbents (see Appendix B for manufacturer specifications and MSDS). The material was received as a $5 \mathrm{lb}$ pail of $8 \mathrm{x} 12$ mesh beads $(1.41-2.38 \mathrm{~mm})$. To obtain a 60x65 (Tyler) mesh adsorbent sample for bubbling fluidization, a mortar and pestle were used to crush portions of the $8 \times 12$ mesh material, which were then shaken in a stack of No. 50, 60, and 70 U.S. size sieves for 30 minutes. The particles collected from 
the No. 70 (65 Tyler mesh) sieve were assumed to be smaller than the No. 60 (60 Tyler mesh) sieve size and therefore have a particle diameter of $212-250 \mu \mathrm{m}$.

Per the manufacturer's specifications, the zeolite was packaged with $\leq 1.5 \%$ wt. moisture, which could be up to $1.5 \mathrm{~g}$ of water for a $100 \mathrm{~g}$ sample. Prior to weighing a sample for adsorption, batches of each mesh size were dehydrated in a kiln at $350^{\circ} \mathrm{C}$ for 4 hours. Samples of $25 \mathrm{~g}$ were measured out while the material was still hot from coming out of the kiln, and placed in a sealed container labeled according to the test it was to be used for. These containers were placed in a larger sealed container of silica gel to inhibit the unintentional adsorption of atmospheric water vapour present in the laboratory prior to starting an experiment.

\subsection{Procedure}

\subsubsection{Adsorption (Discharge)}

Two adsorption experiments were conducted to evaluate fixed and fluidized beds of zeolite as components in thermochemical energy storage systems using the configuration of Figure 3.2.

1. Variation of air flow rate from $10-30 \mathrm{~L} / \mathrm{min}$ at $25^{\circ} \mathrm{C}$ and $50 \% \mathrm{RH}$ using $25 \mathrm{~g}$ samples of $8 \times 12$ and $60 \times 65$ mesh samples of zeolite 13X. This flow rate range was based on the minimum fluidization and terminal velocities of the 60x65 mesh calculated in Appendix C.

2. Variation of inlet relative humidity from $30-70 \% \mathrm{RH}$ at $25^{\circ} \mathrm{C}$ and an air flow rate of $25 \mathrm{~L} / \mathrm{min}$ using $25 \mathrm{~g}$ samples of 8x12 and 60x65 mesh samples of zeolite 13X.

To allow for the humidity and temperature controls to stabilize, the flow was directed through the bypass for the first 5 minutes of each experiment; at the 5 minute mark, the flow was re-directed through the column according to Figure 3.2. The resulting temperature lift of each experiment was a transient process and peaked before saturation of the material (see Figure 3.10). Execution of the program was determined to be complete when the outlet humidity was constant within $0.01 \mathrm{~g} / \mathrm{kg}$. 
After an initial adsorption trial for each of the samples that had been regenerated in the kiln, five subsequent trials followed in which the same samples were regenerated in a toaster oven at $200^{\circ} \mathrm{C}$ for one hour. Each sample was weighed before and after each adsorption run to measure the amount of water adsorbed and therefore compare the measured heat of adsorption to that specified by the manufacturer.

\section{Variation of Flow Rate}

For adsorption experiments in which the total flow rate of air was the varied parameter from 10 to $30 \mathrm{~L} / \mathrm{min}$ (LPM), five $25 \mathrm{~g}$ samples were prepared according to section 3.2 and are listed in Table 3.3.

Table 3.3: Labels of samples for tests varying flow rate.

\begin{tabular}{|c|c|c|}
\hline \multirow{2}{*}{ Air Flow Rate at $50 \% \mathrm{RH}$ and $25^{\circ} \mathrm{C}(\mathrm{L} / \mathrm{min})$} & \multicolumn{2}{|c|}{ Sample Label } \\
\cline { 2 - 3 } & $8 \mathrm{x} 12$ Mesh $(25 \mathrm{~g})$ & $60 x 65$ Mesh $(25 \mathrm{~g})$ \\
\hline 10 & $8 \times 12 \_25 \mathrm{~g} \_10 L P M$ & $60 x 65 \_25 g \_10 L P M$ \\
\hline 15 & $8 \times 12 \_25 \mathrm{~g} \_15 \mathrm{LPM}$ & 60x65_25g_15LPM \\
\hline 20 & 8x12_25g_20LPM & 60x65_25g_20LPM \\
\hline 25 & 8x12_25g_25LPM & 60x65_25g_25LPM \\
\hline 30 & 8x12_25g_30LPM & 60x65_25g_30LPM \\
\hline
\end{tabular}

\section{Variation of Relative Humidity}

For adsorption experiments in which the relative humidity of the air was varied from 30 to $70 \%$, three $25 \mathrm{~g}$ samples were prepared according to section 3.2 and are listed in Table 3.4.

Table 3.4: Labels of samples for tests varying inlet relative humidity.

\begin{tabular}{|c|c|c|c|}
\hline \multirow{2}{*}{$\mathrm{RH}$ at $25^{\circ} \mathrm{C}(\%)$} & Humidity $\left(\mathrm{g}_{\mathrm{H}_{2} \mathrm{O}} / \mathrm{kg}_{a}\right)$ & \multicolumn{2}{|c|}{ Sample Label } \\
\cline { 3 - 4 } & 5.85 & $8 \mathrm{x} 12$ Mesh $(25 \mathrm{~g})$ & $60 \times 65$ Mesh $(25 \mathrm{~g})$ \\
\hline 30 & 9.78 & $8 \mathrm{x} 12 \_25 \mathrm{~g} \_30 \mathrm{RH}$ & $60 \mathrm{x}$ _50RH_25g_30RH \\
\hline 50 & 13.7 & 8x12_25g_70RH & 60x65_25g_50RH \\
\hline 70 & & & \\
\hline
\end{tabular}




\subsubsection{In-Situ Regeneration \& Repeated Cycling}

The regeneration experiments performed differ from the adsorption experiments in that the zeolite samples were regenerated in the column itself (i.e., regenerated in-situ) instead of the toaster oven. This set of experiments was conducted on a single $25 \mathrm{~g}$ sample of each of the $8 \times 12$ and $60 \times 65$ zeolite batches to evaluate the drying aspects of fixed and fluidized beds as components in thermochemical energy storage systems.

Using the configuration of Figure 3.3, the setpoints of the VI were set to provide $0 \%$ $\mathrm{RH}$ air at $150^{\circ} \mathrm{C}$ and $20 \mathrm{~L} / \mathrm{min}$. After 5 minutes of bypass, the air was introduced to the column, resulting in a spike in the outlet $\mathrm{RH}$ of the column as water was released from the adsorbent. Regeneration of the adsorbent was determined to be complete when the outlet temperature of the column reached a plateau and the outlet RH returned to zero. The setpoint for the inlet air temperature was then set to $25^{\circ} \mathrm{C}$ and the column was allowed to cool to ambient conditions.

After this regeneration step, adsorption experiments were subsequently performed on the samples to the determine the effect of repeated regeneration-adsorption (cycling) on the energy density of the beds. The two samples were each repeatedly cycled for a total of 25 adsorption runs at $25 \mathrm{~L} / \mathrm{min}$ and $50 \% \mathrm{RH}$.

\subsubsection{In-Situ Regeneration Under Partial Vacuum}

For these experiments, two samples of the 8x12 mesh zeolite were studied, one for $90^{\circ} \mathrm{C}$ and the other for $150^{\circ} \mathrm{C}$ at the inlet for a flow rate of $20 \mathrm{~L} / \mathrm{min}$. Each sample was first regenerated under atmospheric conditions, then subject to adsorption with inlet conditions of $50 \% \mathrm{RH}, 25^{\circ} \mathrm{C}$ and $25 \mathrm{~L} / \mathrm{min}$. The same samples were then regenerated again with the same inlet temperatures under partial vacuum conditions of approximately $90 \mathrm{kPa}$ (absolute) using the setup configuration shown in Figure 3.4. The samples were then subject to adsorption again to compare the energy released between the two temperatures and pressures. 


\subsection{Calculation of Various Adsorption Parameters}

\subsubsection{Adsorption Parameters}

\section{Concentration Breakthrough and Mass of Water Adsorbed}

The concentration of water vapour in the air at the inlet and outlet of the column was noted with time to produce breakthrough curves similar to Figure 3.10 that plot the ratio of the concentration of water vapour at the outlet $(C)$ to that of the inlet $\left(C_{\mathrm{o}}\right)$. Breakthrough $\left(t_{\mathrm{b}}\right)$ is the point in time during adsorption that $C / C_{\mathrm{o}}>0$ as the adsorbent can no longer adsorb all of the water vapour entering the system, and the concentration of that gas at the outlet begins to increase. For adsorption TES systems, the point of breakthrough generally coincides with the peak temperature of the system, indicating when a majority of the active sites of the adsorbent have been covered. Exhaustion time $\left(t_{\mathrm{e}}\right)$ is the point at which the concentration of water vapour at the outlet reaches that of the inlet concentration at a point of saturations (i.e., $C / C_{\mathrm{o}}=1.0$ ).

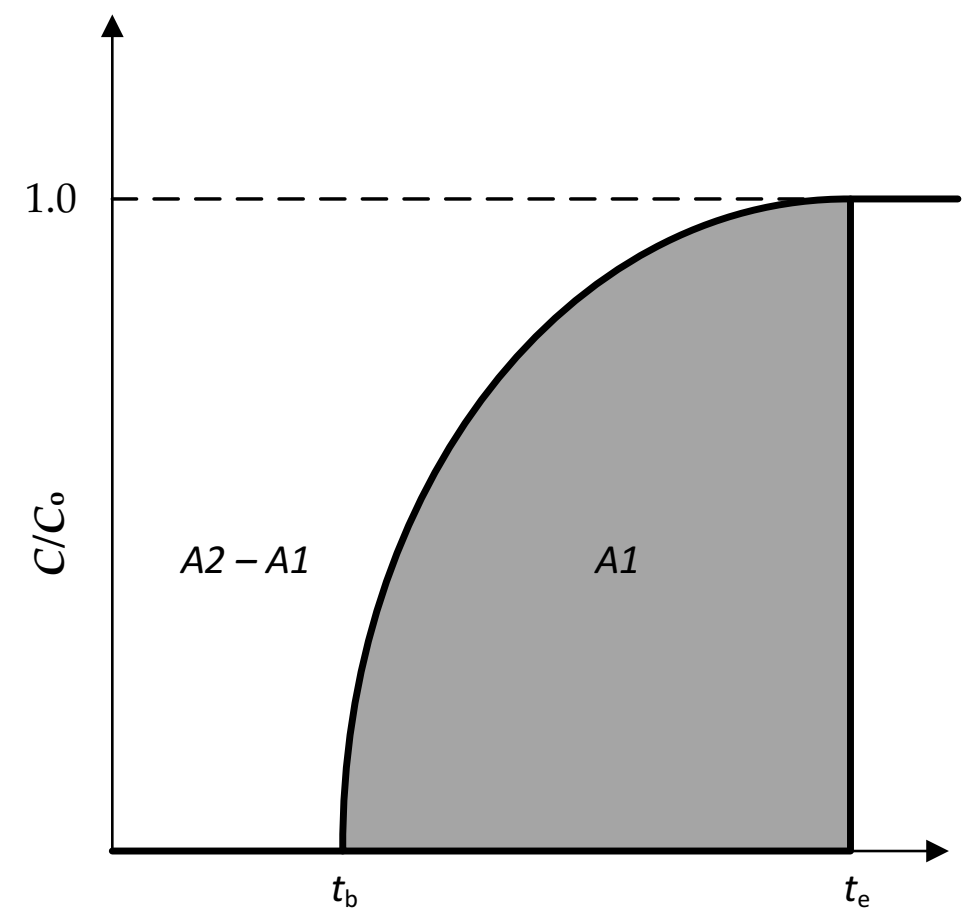

Figure 3.10: Subtraction of areas for calculating mass of water adsorbed. 
In Figure 3.10, $A 1$ represents the area under the curve from breakthrough to exhaustion $\left(A_{1}=\int_{t_{b}}^{t_{\mathrm{e}}} C d t\right)$, and the rectangular area of $A 2=C_{\mathrm{o}} t_{e}$ is the total mass of of water $\operatorname{vapour}\left(m_{\mathrm{tot}}\right)$ to enter the system:

$$
m_{\mathrm{tot}}=C_{o} \dot{V} t_{e}
$$

The difference in the two areas is the amount of water adsorbed within the bed $\left(m_{\mathrm{w}}\right.$ according to:

$$
m_{\mathrm{w}}=\dot{V}(A 2-A 1)
$$

The concentration of water vapour was obtained by multiplying the humidity of the air $\left(\mathrm{kg}_{\mathrm{H}_{2} \mathrm{O}} / \mathrm{kg}_{a}\right)$ by the density of dry air $\left(\mathrm{kg} / \mathrm{m}^{3}\right)$; humidity $(\omega)$ was calculated from the relative humidity, pressure, and temperature of the air:

$$
\omega=0.622\left[\frac{\phi p_{\mathrm{ws}}}{p-\phi p_{\mathrm{ws}}}\right]
$$

\section{Adsorption Capacity (Loading)}

The equilibrium water vapour uptake by the zeolite or loading $\left(q_{\mathrm{eq}}\right)$ is a ratio of the mass of water adsorbed to the mass of the sample $(X)$ :

$$
q_{\mathrm{eq}}=\frac{m_{\mathrm{w}}}{X}
$$

The loading of an adsorbent bed indicates how close it is to reaching saturation and therefore could be used in determining the state of charge of the system.

\section{Mass Transfer Zone}

Mass transfer zone $(M T Z)$ is a function of hydraulic loading rate and defined as the length of a fixed adsorbent bed (of height, $Z$ ) where adsorption takes place:

$$
M T Z=Z \times\left(1-\frac{t_{\mathrm{b}}}{t_{\mathrm{e}}}\right)
$$

Adsorption breakthrough occurs when the $M T Z$ has passed the furthest part of the bed, and therefore indicates how much of the adsorbent is saturated and needs to be replaced by regenerated material in an external adsorber via material transport. 


\section{Chapter 4}

\section{Results \& Discussion}

This chapter presents the results of the adsorption and regeneration experiments that were obtained using the setup and methods described in Chapter 3. The results for the adsorption of water vapour onto the zeolite 13X samples for different conditions of the adsorbate (i.e., flow rate and relative humidity) are evaluated and discussed in terms of parameters considered for scaling up the system.

\subsection{Variation of Air Flow Rate}

The flow rate is an important design parameter for sizing the turbomachinery (i.e., compressors, fans, or blowers) in terms of the power required to drive air through the adsorber in an adsoprtion based TES system. The flow rates used in pilot scale systems are generally determined by the ventilation rate of the space that they are heating based on floor area and air changes per hour $(\mathrm{ACH} / \mathrm{h})$; the STAID prototype is a notable example in which a flow rate of $120-180 \mathrm{~m}^{3} / \mathrm{h}$ was used based on heating a building with a floor area of $100 \mathrm{~m}^{2}$ and an air change rate of $0.6-0.7 \mathrm{ACH} / \mathrm{h}$ 30. Using flow rates of 10 to $30 \mathrm{~L} / \mathrm{min}$ at an inlet relative humidity of $50 \%$ at $25^{\circ} \mathrm{C}$, the following results were obtained for the adsorption breakthrough, mass transfer zone, mass of water adsorbed, and thermal energy released by the fixed and fluidized adsorbent beds. 


\subsubsection{Adsorption Breakthrough}

Monitoring the temporal change in the concentration of water vapour in the air exiting the column during adsorption produced breakthrough curves shown as Figure 4.1. Each of the five lines in Figure 4.1 is the average concentration of water vapour in the outlet air of the column $(C)$ for a flow rate of 10 to $30 \mathrm{~L} / \mathrm{min}$ (repeated 5 times per flow rate) for an inlet humidity of air of $9.78 \mathrm{~g}_{\mathrm{w}} / \mathrm{kg}_{\mathrm{a}}\left(50 \% \mathrm{RH}\right.$ and $\left.25^{\circ} \mathrm{C}\right)$. The initial concentration of water in the outlet drops to zero as all of the water is adsorbed by the zeolite $13 \mathrm{X}$ and the air exiting the column is dry until the point of breakthrough $\left(t_{\mathrm{b}}\right)$, when the concentration ratio $\left(C / C_{\mathrm{o}}\right)$ becomes greater than zero. As the zeolite $13 \mathrm{X}$ reaches its adsorption capacity, the concentration ratio becomes 1 , indicating that equilibrium for the adsorption process has been reached.

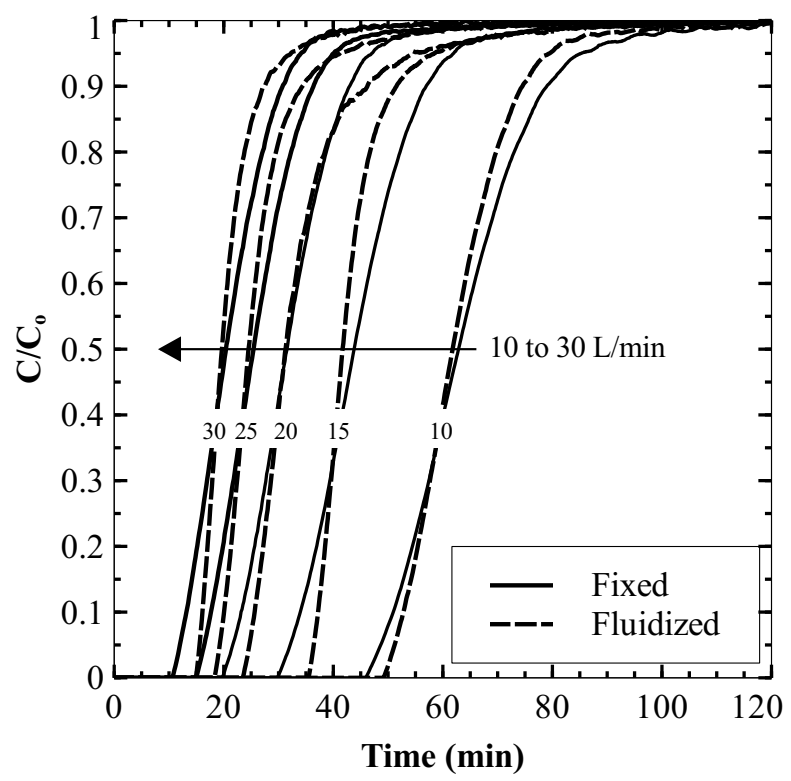

Figure 4.1: Concentration breakthrough of the outlet for the fixed and fluidized bed for a flow rate of $10-30 \mathrm{~L} / \mathrm{min}$.

The results of Figure 4.1 show that breakthrough time for both beds decreased as the flow rate of the air increased due to a higher volume of water passing through the column per unit of time. The earlier point of breakthrough seen for the fixed bed was attributed to both the difference in particle size as well as other phenomena introduced by the axial mixing of solids in the fluidized bed for which the outlet concentration experienced a steeper gradient. 
Considering that adsorption occurs at sites on the adsorbent that are accessed through its pores, as the particle diameter of the adsorbent increases, its adsorption sites are less accessible to the gas stream and a higher resistance to intra-particle mass transfer leads to an earlier breakthrough. Additionally, as the particle diameter is decreased, the boundary layer through which the water vapour must diffuse to reach the surface of the zeolite is also decreased, resulting in lower resistance to interphase mass transfer and a later breakthrough. These results agree with a similar parametric study conducted by Lefebvre et al. in which particle diameters of 0.5 to $2.3 \mathrm{~mm}$ were considered and the longer breakthrough period of the smaller particles was determined to be a predictor of better energy storage performance if more water is adsorbed [46].

Research on adsorption for thermochemical storage seldom focuses on the breakthrough behaviour of adsorbent beds; however, this information can be useful for monitoring the progress of the adsorption process as it moves through the adsorption column and therefore influence design considerations. By knowing or estimating the breakthrough and exhaustion time of an adsorbent bed, the length of the zone where adsorption occurs can be calculated or estimated.

\subsubsection{The Mass Tranfer Zone}

In a packed bed with uniform flow, the mass transfer zone, $M T Z$, or the volume in the column where adsorption occurs, is generally considered to be well defined at any point in time and vapour is adsorbed in this zone (see Figure 4.2 56.

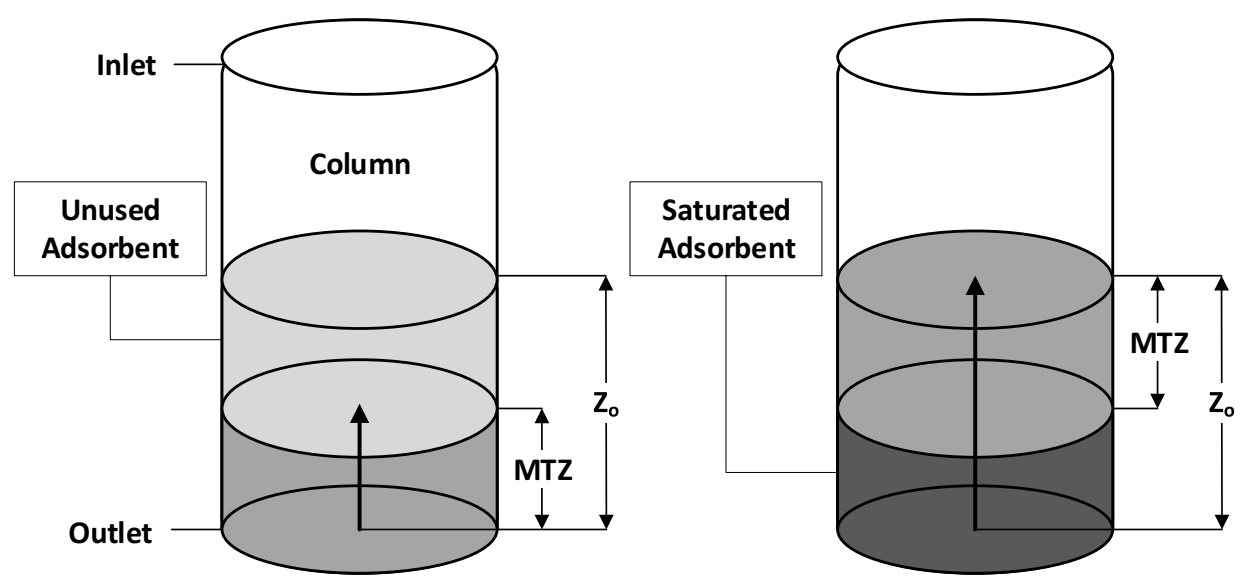

Figure 4.2: Illustration of MTZ Concept in a fixed adsorbent bed. 
As adsorption progresses from the inlet to the outlet of the fixed bed in Figure 4.2, the $M T Z$ propagates upward until breakthrough, when it passes through the the farthest point in the bed, or the static bed height $\left(Z_{o}\right)$. In a fluidized bed however, water vapour is adsorbed to all zeolite particles simultaneously and a defined adsorption zone ceases to exist, (i.e., the entire fluidized bed is the adsorption zone) 57].

Figure 4.3 shows the increase in the $M T Z$ of each adsorbent bed with flow rate. The $M T Z$ of the fixed bed was calculated according to Equation 3.7 using $t_{\mathrm{b}}$ and $t_{\mathrm{e}}$, while that of the fluidized bed is equal to the height of its bubbles in the column $\left(Z_{\mathrm{f}}\right)$, and increases proportionally with flow rate.

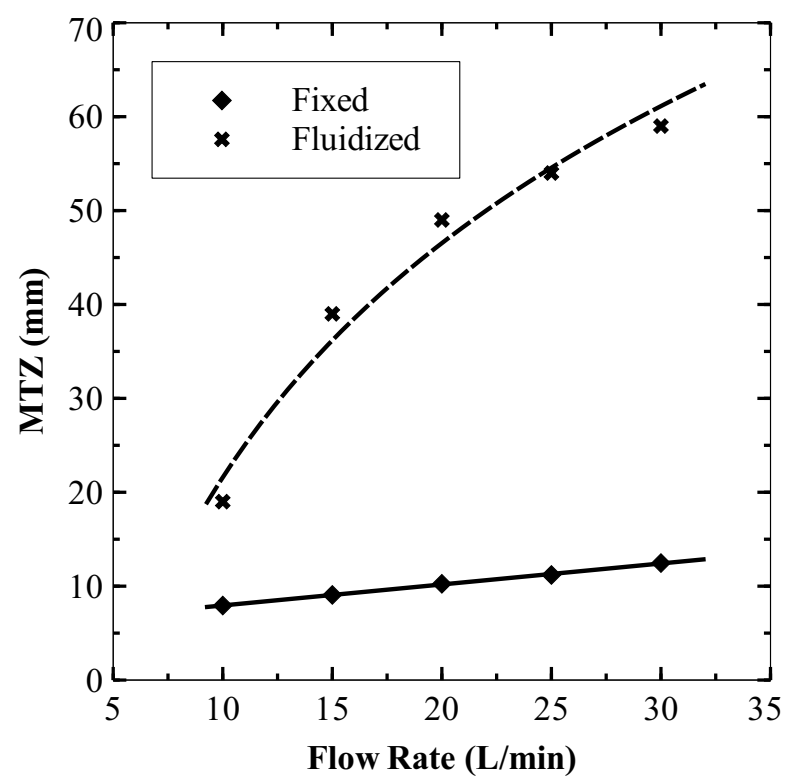

Figure 4.3: Mass transfer zone of fixed and fluidized bed with flow rate.

The results of Figure 4.3 highlight the difference in the fraction of the fixed bed where adsorption occurs compared to the entire volume of the fluidized bed at each flow rate. For example, at $10 \mathrm{~L} / \mathrm{min}$, the $M T Z$ of the fixed bed is approximately half of the static bed height $(19 \mathrm{~mm})$. As the flow rate increases, the depth of the $M T Z$ increases, as increased mass transfer allows water to diffuse further into the bed. The $M T Z$ is therefore an important parameter for sizing an adsorption column as it suggests how much of the material will initially be discharged before breakthrough and therefore how much charged material is left (unused adsorbent in Figure 4.2. 


\subsubsection{Mass of Water Adsorbed}

Using the calculation method described in subsection 3.4.1 as well as weighing the samples before and after adsorption, the mass of water adsorbed $\left(m_{\mathrm{w}}\right)$ by each of the samples in Table 3.3 was determined for each of the five trials conducted per flow rate. Figure 4.4 presents the results of calculating the mass of water adsorbed for each test, and the average change in mass measured using a scale for the five runs performed for each flow rate. The uncertainty of the weighed mass of water adsorbed was approximated as up to $-0.25 \mathrm{~g}$ with adsorbing up to this much water prior to starting the adsorption run.

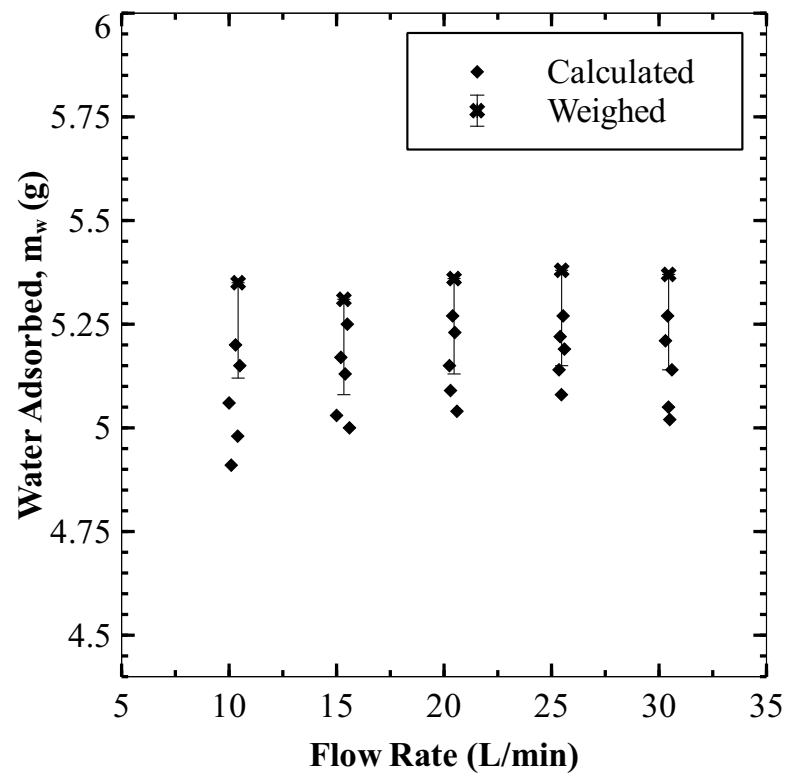

(a) fixed bed (8x12 mesh)

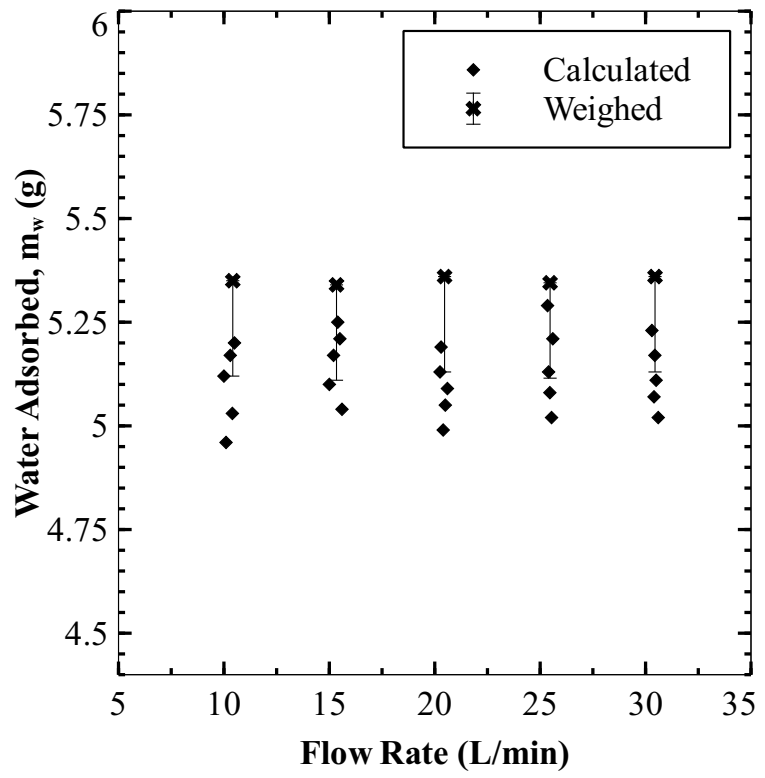

(b) fluidized bed (60x65 mesh)

Figure 4.4: Mass of water adsorbed by the (a) fixed and (b) fluidized beds.

The water uptake of both adsorbent beds varied slightly, with samples adsorbing 4.9 - $5.4 \mathrm{~g}$ of water. This result was expected as the adsorption equilibrium of the zeolite $13 \mathrm{X}$-water vapour pair is independent of air flow rate [58]. The amount of water uptake observed indicates that the zeolite samples reached an average adsorption capacity $\left(q_{\mathrm{eq}}\right)$ of $0.19-0.22 \mathrm{~g}_{\mathrm{H}_{2} \mathrm{O}} / \mathrm{g}_{13 \mathrm{X}}$ which is typical of the adsorption isotherm for zeolite $13 \mathrm{X}$ and identical to the study conducted by Zhang et al., in which $0.18-0.20 \mathrm{~g}_{\mathrm{H}_{2} \mathrm{O}} / \mathrm{g}_{13 \mathrm{X}}$ of loading was measured by their experimental setup [59]. Based on an enthalpy of adsorption of $4.2 \mathrm{~kJ} / \mathrm{g}_{\mathrm{H}_{2} \mathrm{O}}\left(1,800 \mathrm{BTU} / \mathrm{lb}_{\mathrm{H}_{2} \mathrm{O}}\right)$ provided by the manufacturer in Appendix $\mathrm{B}, 20.2$ to $22.7 \mathrm{~kJ}$ of heat per $25 \mathrm{~g}$ sample would be expected from this amount of loading. 


\subsubsection{Thermal Energy Released}

The amount of thermal energy $(\mathrm{kJ})$ calculated from the adsorption of water onto each zeolite sample is shown as Figure 4.5. The five data points that form the higher trendline for each graph represent the heat released from the adsorption of each sample after regeneration in the kiln at $350^{\circ} \mathrm{C}$ as part of material preparation; this was performed once per flow rate. The cluster of five data points for each flow rate represent the heat released from the adsorption of each sample after regeneration at $200^{\circ} \mathrm{C}$. These temperatures are quite high for the application of storing solar thermal energy, although Wang et al. [60] were able to achieve air temperatures up to $200^{\circ} \mathrm{C}$ in their evacuated tubular solar air heater.

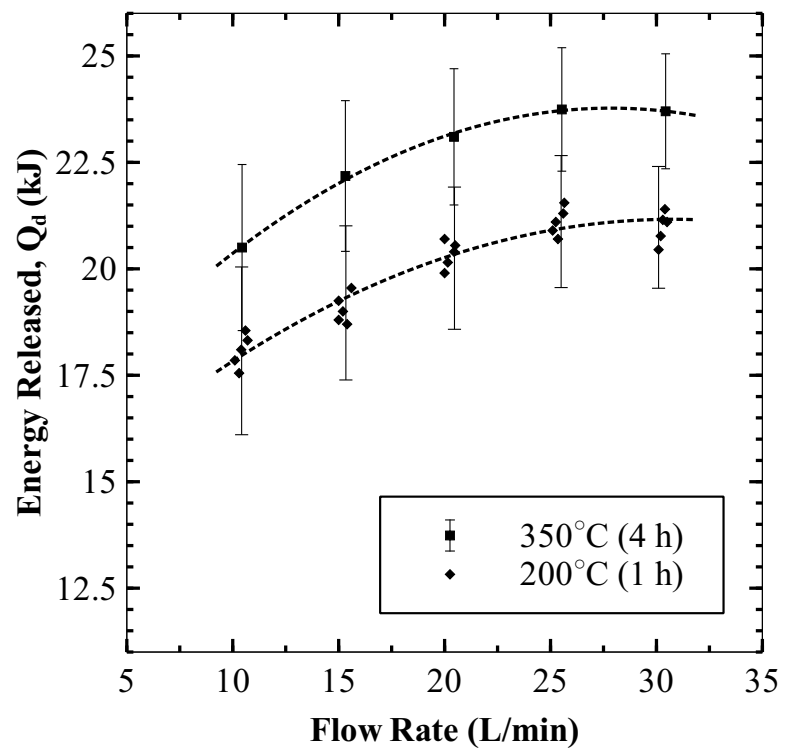

(a) fixed bed (8x12 mesh)

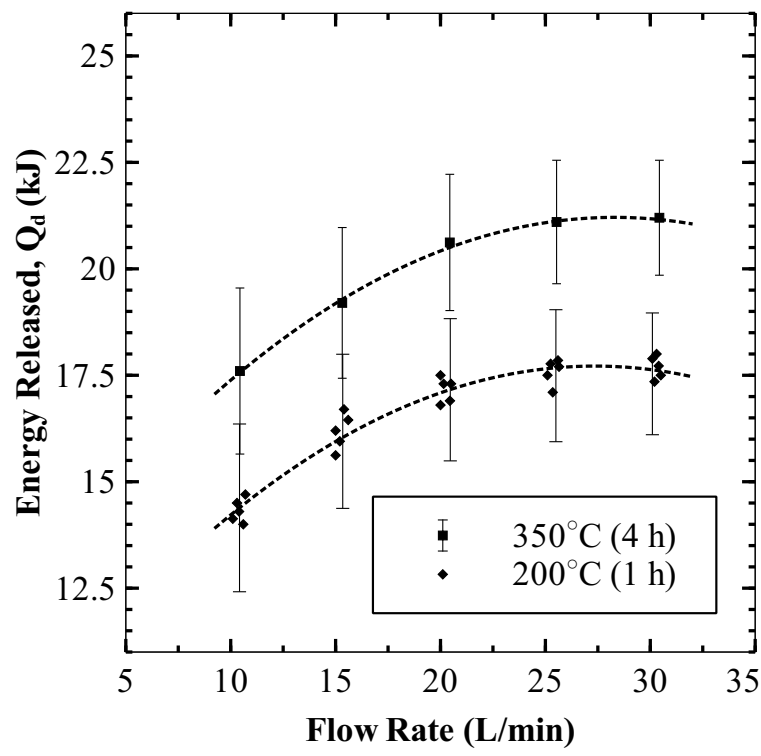

(b) fluidized bed (60x65 mesh)

Figure 4.5: Heat released by $25 \mathrm{~g}$ of zeolite $13 \mathrm{X}$ in a (a) fixed and (b) fluidized beds.

The results of Figure 4.5 show that the measured amount of thermal energy released is determined by both the adsorption equilibrium and the effect of flow rate on Equation 2.5. A sufficient flow rate is required for interphase heat transfer between the zeolite and the air where neglecting radiative effects, the energy released would be zero at no flow. The polynomial fit suggests that a flow rate between 25 and $30 \mathrm{~L} / \mathrm{min}$ was optimal, where the measured thermal energy released may begin to decrease beyond $30 \mathrm{~L} / \mathrm{min}$, possibly due to turbulence in the column accompanied by heat losses. 
The systematic error on the calculation of thermal energy discharged was in the range of $\pm 1.4-1.95 \mathrm{~kJ}$ for all fifty of the adsorption experiments run between the two beds which represents a systematic uncertainty of 6 to 14\%. The method used to calculate the systematic uncertainty on the thermal energy equation from the measurement uncertainties of the instrumentation is presented in Appendix $D$.

The calculated amount of heat from adsorption is considered in terms of energy storage capacity (per unit mass) and energy density (per unit volume) in Figure 4.6. The difference between Figure 4.6 and Figure 4.6 b points out the significance of the added volume on reducing the relative energy density of the column in terms of the additional height required for fluidization. At higher flow rates the energy density of the fluidized bed at higher flow rates was comparable to a sensible heat storage using liquid water at $30-50 \mathrm{kWh} / \mathrm{m}^{3}$.

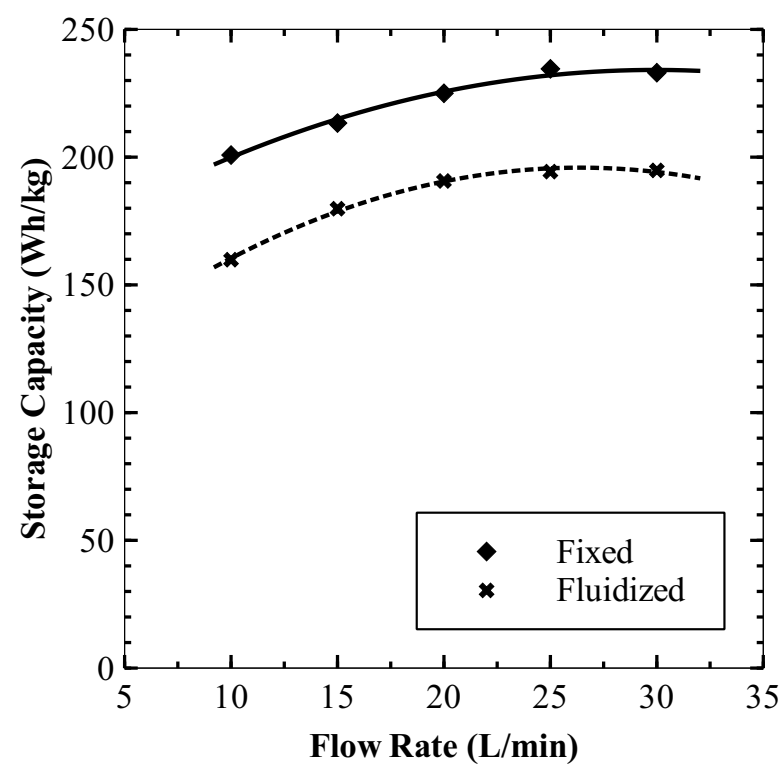

(a) storage capacity

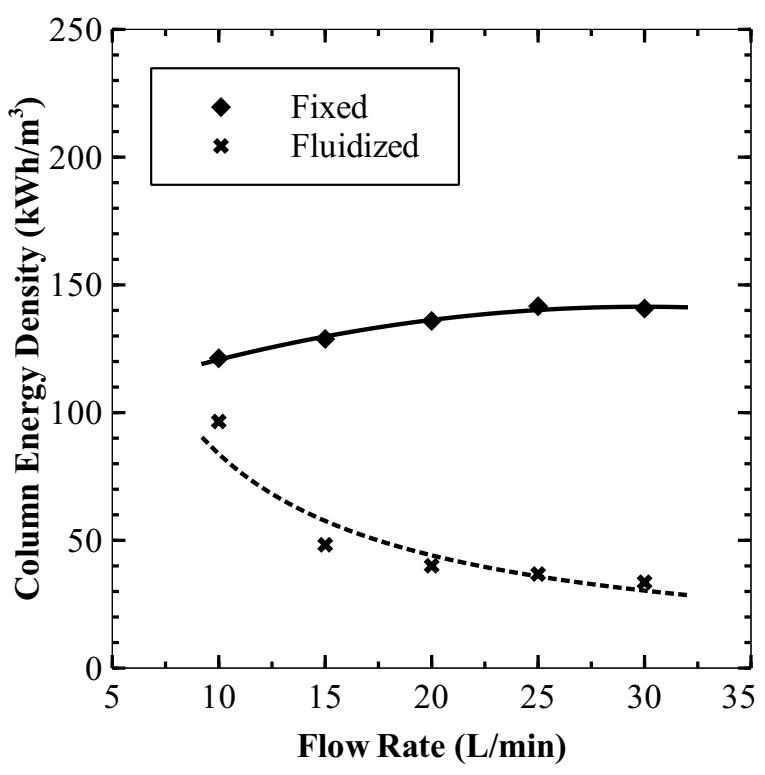

(b) column energy density

Figure 4.6: The (a) storage capacity and (b) energy density of the fixed and fluidized beds.

In terms of storage capacity, both adsorbent beds produced comparable values to the literature, particularly the 150 - $220 \mathrm{Wh} / \mathrm{kg}$ range obtained by Lass-Seyoum et al. [53]. The energy density of the fixed bed was also comparable to experiments performed by Zhang et al. [59] that obtained $115-137 \mathrm{kWh} / \mathrm{m}^{3}$ for flow rates of $17-50 \mathrm{~m}^{3} / \mathrm{h}[59]$. In the design of an adsorption TES for a home, the storage capacity would determine the 
minimum amount of material required per charge/discharge cycle for a seasonal storage system based on the annual demand of the heating load, whereas the column energy density would dictate the volume of the adsorber required for meeting the demand on a shorter time-scale (e.g., hourly), as the adsorber is only a fraction of the whole system including the material storage.

\subsection{Variation of Relative Humidity}

From the results of section 4.1, the thermal energy released by the fixed and fluidized bed reaches a plateau at $25 \mathrm{~L} / \mathrm{min}$; this variable was fixed while the concentration of water vapour at the inlet was varied for these experiments. The data presented in this section is the average of five adsorption runs performed on each sample and includes the average breakthrough, temperature lift, discharge rate, and cumulative thermal energy released by the beds for inlet relative humidities of 30 to $70 \%$.

\subsubsection{Adsorption Breakthrough}

Similar to subsection 4.1.1, the breakthrough of the fixed and fluidized beds for an inlet relative humidity of $30-70 \%$ was obtained and is shown by Figure 4.7 .

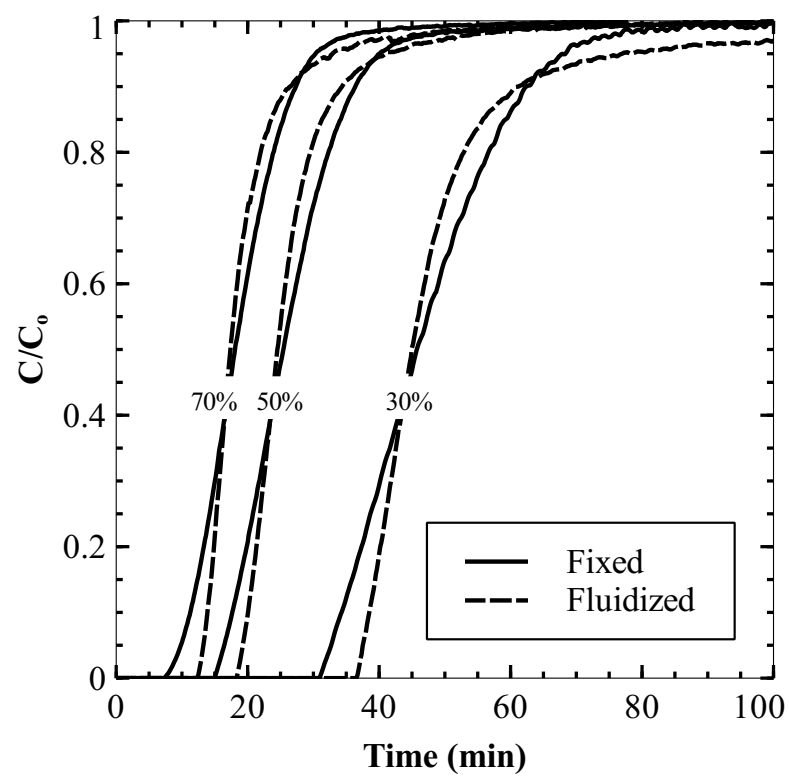

Figure 4.7: Concentration breakthrough of the outlet for the fixed and fluidized bed for $30-70 \% \mathrm{RH}$ at inlet. 
These curves show that the rate of adsorption increases as the relative humidity increases, resulting in shorter breakthrough times for each bed. In terms of material transport for an external adsorber concept where adsorption is separate from material storage, the inlet concentration of water vapour would determine how often material would need to be cycled in and out of the adsorber, where this rate would increase with higher inlet concentrations of water vapour. Compared to Figure 4.1, the breakthrough for each bed at $50 \% \mathrm{RH}$ is identical to the data for $25 \mathrm{~L} / \mathrm{min}$ in which the inlet relative humidity was also 50\%. Because these tests were conducted at essentially atmospheric pressure, the adsorption equilibrium was not affected by the concentration of water and therefore similar amounts of water were adsorbed as those obtained in Figure 4.4.

\subsubsection{Temperature Lift}

The temperature lift, or the difference in temperature between the outlet thermocouple of each bed and the inlet RTD (RH1) measured during adsorption at 30, 50, and $70 \% \mathrm{RH}$ is provided by Figure 4.8. Exposed and ungrounded T-type thermocouples were used within the column because they offer the highest response time $(0.25 \mathrm{~s})$ for and are most appropriate for non-corrosive gases in the range of temperatures measured in the transient regime of this experiment.

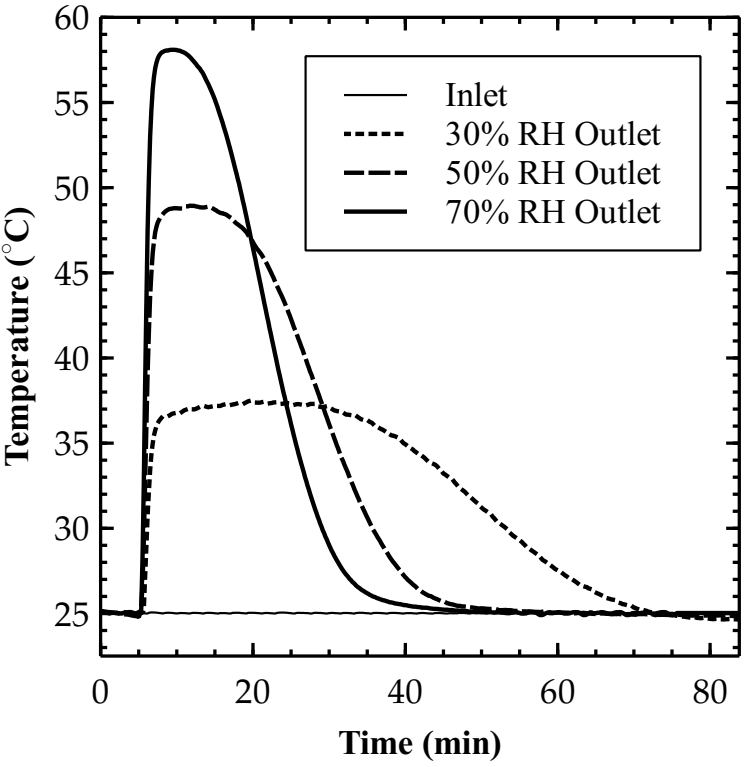

(a) fixed bed (8x12 mesh)

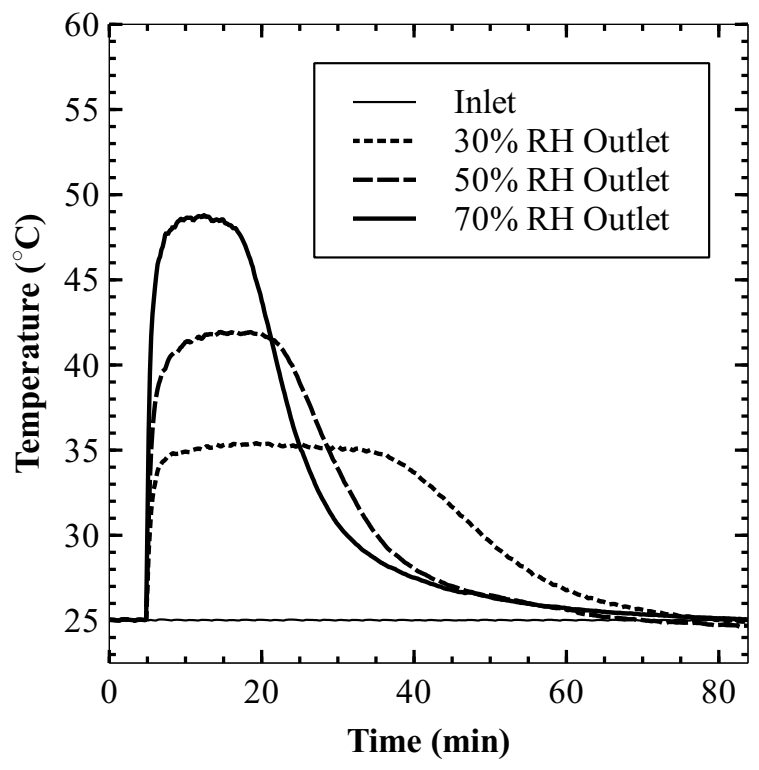

(b) fluidized bed (60x65 mesh)

Figure 4.8: Outlet temperature lift of the (a) fixed and (b) fluidized bed. 
The peak temperature at the outlet for each bed increased proportionally to relative humidity due to the larger amount of water vapour at the inlet in the presence of a higher partial pressure of the water vapour adsorbate. The optimal relative humidity of the air to be used in practice would depend on the required delivery temperature of the system. Discharging air at a temperature more than $8^{\circ} \mathrm{C}$ above the temperature of a room in conventional overhead heating systems has been found to result in significant unwanted stratification of air temperature 61. If these results were scaled to directly supplying space heat to a building with a similar overhead system, a relative humidity of $30 \%$ should be used to supply heated air to a room that is normally maintained at $25^{\circ} \mathrm{C}$. A lower relative humidity of the inlet air provides a more sustained temperature lift, and would require less frequent cycling of the adsorbent. Therefore the inlet concentration of water vapour should be considered in the design of an adsorption TES should be based on the delivery temperature of the air for space heating.

Higher peak temperatures were measured in the fixed bed of 8x12 mesh zeolite for each level of relative humidity, which is in contrast with the packed bed study conducted by Lefebvre et al. [46] that reported higher temperature lifts for smaller particles. In this present study however, different dispersion mechanisms influenced heat transfer between the adsorbent and the air. Fluidized beds can exhibit backmixing in which the products of adsorption (initially dry and warmer air) re-enter the adsorbent bed, effectively causing partial desorption which would reduce the temperature of the gas phase.

\subsubsection{Discharge Rate \& Thermal Energy Released}

The distribution of the rate of heat released in Figure 4.9 follows that of Figure 4.8 as Equation 2.5 is driven by the temperature lift. The same trends are therefore seen in that the peak discharge rate of heat released increases with higher relative humidity, and a higher discharge rate is measured from the fixed bed of $8 \times 12$ mesh zeolite. The rate of heat discharged by the fixed and fluidized beds increased by 6 and $4 \mathrm{~W}$ respectively, per $20 \%$ increase in relative humidity. From this observation, the rate of heat output can effectively be controlled by the concentration of water vapour entering the column. Therefore within a period of time before the breakthrough point, the rate of 
heat provided by adsorption can be ramped up or down based on demand by adjusting the inlet concentration of water vapour at the inlet.

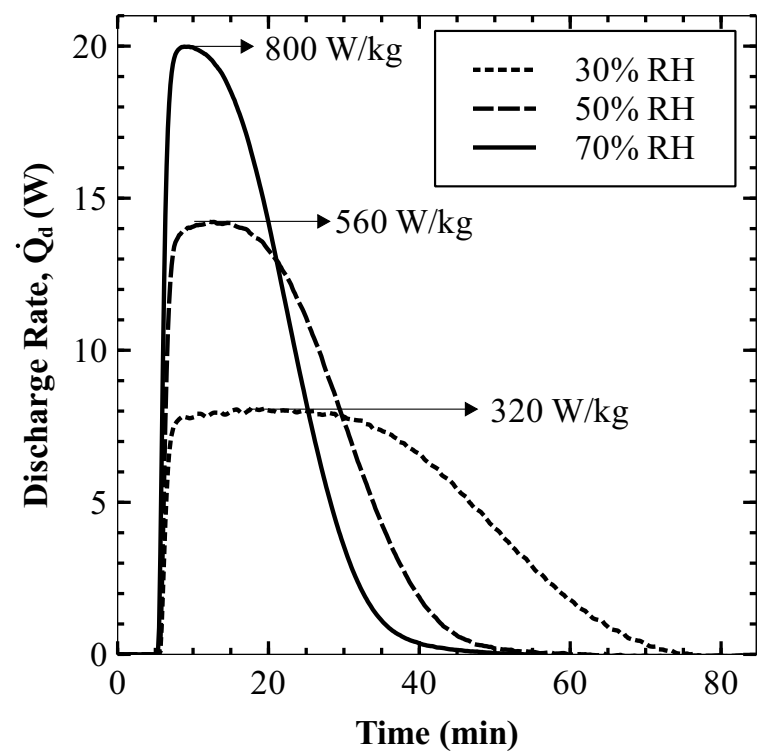

(a) fixed bed (8x12 mesh)

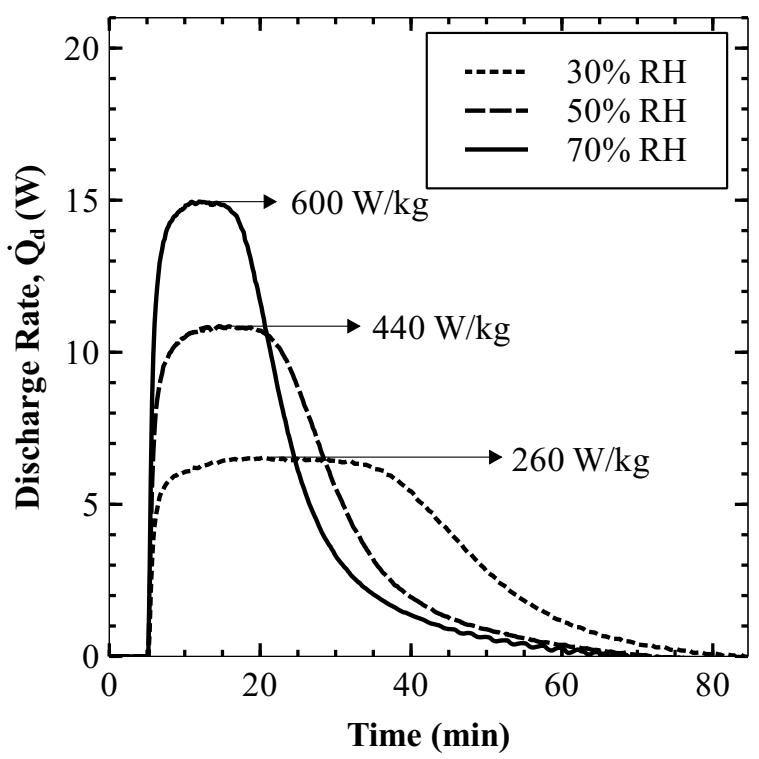

(b) fluidized bed (60x65 mesh)

Figure 4.9: Rate of heat and specific power discharged by the (a) fixed and (b) fluidized beds.

The rate of thermal energy discharged from thermochemical storage systems is often quantified in terms of its specific power for scaling purposes. The specific power of the $25 \mathrm{~g}$ fixed and fluidized beds is indicated in Figure 4.9 by the peak heat discharge rate measured per $\mathrm{kg}$ of zeolite. Compared to those reported in the literature, the values of specific power obtained in these experiments were quite high for both beds, ranging from 260 to $800 \mathrm{~W} / \mathrm{kg}$. The study of the STAID prototype conducted by Johannes et al. for example, reported a specific power of $27.5 \mathrm{~W} / \mathrm{kg}$, commensurate to a $2.25 \mathrm{~kW}$ rate of discharge with $80 \mathrm{~kg}$ of zeolite making up the entire storage system 30. Lass-Seyoum et al. reported progressively lower values of specific power as the volume of their test rigs were increased from $1.5 \mathrm{~L}$ to $750 \mathrm{~L}$ [49]. This indicates that there is a limit in terms of how the specific power scales when comparing the integrated vs. external types of systems.

For a residential heating application in which the discharge component of the storage system is cycled on and off similar to the schedule of a natural gas furnace, the size of the adsorber should be optimized based on the specific power and the mass of material 
required for meeting the peak space heating load $\left(\mathrm{W} / \mathrm{m}^{2}\right)$. This strategy was adopted by Gaeini et al. [52] in the design of a system scaled to meet the demand of a passive house with a peak power requirement of $1 \mathrm{~kW}$. Each of the four segments in their system weighed $42.5 \mathrm{~kg}$ and produced $0.9 \mathrm{~kW}$ of power or $21 \mathrm{~W} / \mathrm{kg}$. This system however was designed to operate continuously for up to 10 hours, owing its large size to meeting the entire load without the transport of material.

By taking the area under the curves of Figure 4.9, the cumulative thermal energy released for each inlet water vapour concentration was obtained and is shown as Figure 4.10.

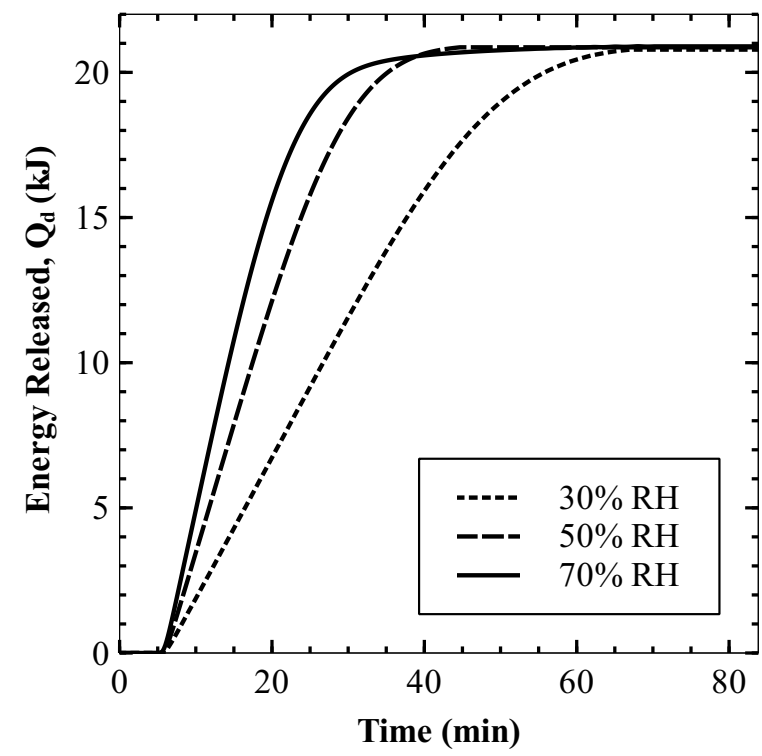

(a) fixed bed (8x12 mesh)

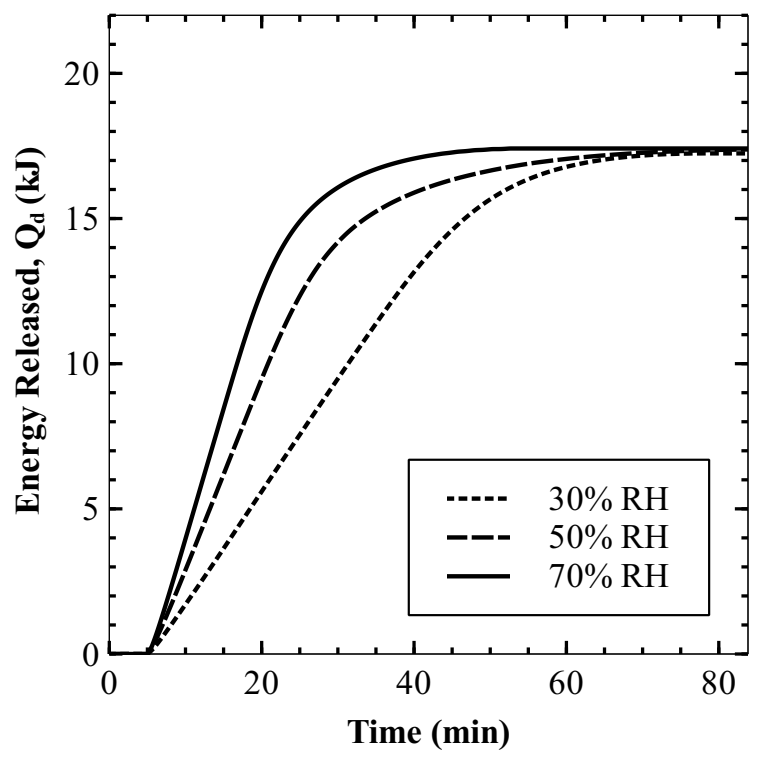

(b) fluidized bed (60x65 mesh)

Figure 4.10: Cumulative energy released by the (a) fixed and (b) fluidized beds.

The results of Figure 4.10 agree with observations made in the literature that the total amount of heat released from adsorption is independent of the concentration of water vapour at the inlet; Johannes et al. [30] found that a higher outlet temperature and rate of discharge occurred for an inlet of $70 \%$ relative humidity than $50 \%$, but the total energy released was the same. Similarly, Zhang et al. 59 found that output power increased with relative humidity of 60 to $80 \%$ but the total energy released by adsorption for each test was within their experimental error of 11.4\%. By comparing Figure 4.10 with Figure 4.6, it can be seen that the same amount of thermal energy was released 
at $25 \mathrm{~L} / \mathrm{min}$ between the separate set of experiments using different samples. Therefore for this experiment, the fixed and fluidized beds would have the same energy storage capacity and column energy densities at $25 \mathrm{~L} / \mathrm{min}$ in Figure 4.6.

\subsection{Adsorption-Regeneration Cycling}

These are the results of regenerating the saturated adsorbent beds in the column with $150^{\circ} \mathrm{C}$ air at $20 \mathrm{~L} / \mathrm{min}$, followed by adsorption at $25^{\circ} \mathrm{C}$ and $50 \%$ with a flow rate of $25 \mathrm{~L} / \mathrm{min}$ (repeated 25 times).

\subsubsection{Regeneration Step}

Figure 4.11 and Figure 4.11b show the temperatures measured in the system and the outlet relative humidity for a typical regeneration run as a function of time, respectively. The inlet temperature of the air in Figure 4.11 a was steady at $150^{\circ} \mathrm{C}$ when it was introduced to the column 5 minutes into the regeneration run. The outlet RH of both beds peak at $19.5 \% \mathrm{RH}$, followed by a gradual decrease to $0 \%$ in Figure $4.11 \mathrm{~b}$.

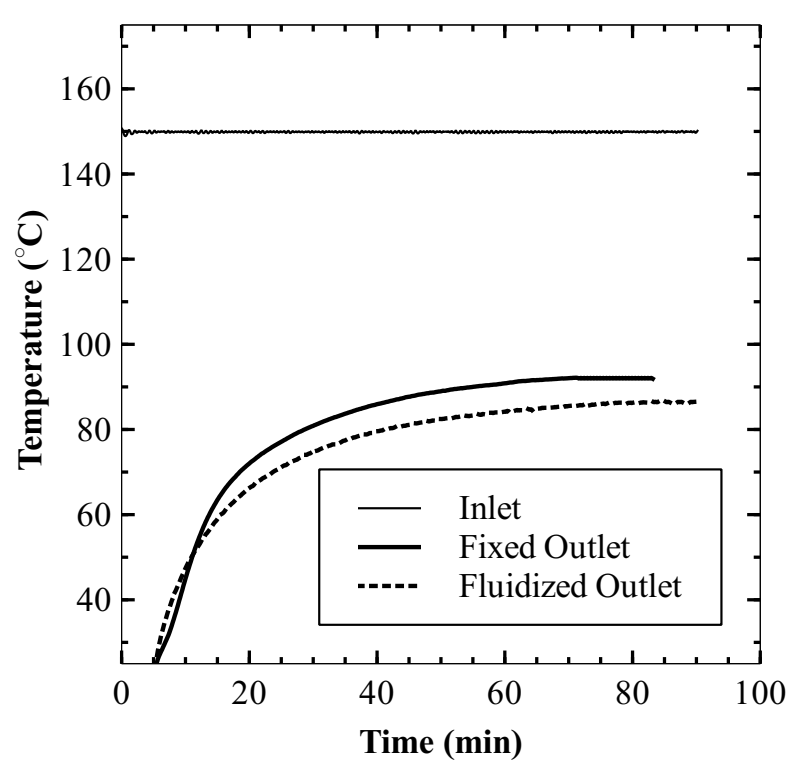

(a) system temperatures

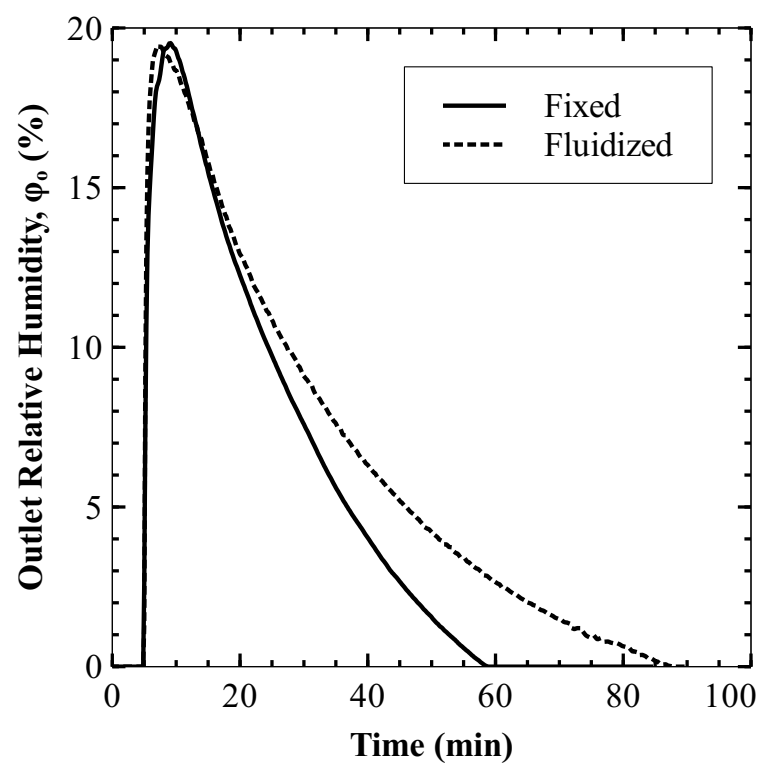

(b) outlet relative humidity

Figure 4.11: The average (a) system temperatures and (b) outlet relative humidity for the in-situ regeneration step. 
For the first 5 minutes of regeneration, the fluidized bed heats up faster than the fixed bed as shown by Figure 4.11 , after which the temperature of the fixed bed overtakes and reaches a temperature of $92^{\circ} \mathrm{C}$ by the time the concentration of its outlet in Figure 4.11 reaches zero. The slight delay in the fixed bed was due to heating the components of the adsorption column which occurred faster in the fluidized bed in which a higher heat transfer co-efficient would exist between the material and the interior of the column. Higher material-wall heat transfer is also attributed to the lower peak temperature of the fluidized bed which reached $87^{\circ} \mathrm{C}$ by the time its outlet $\mathrm{RH}$ reached zero. Both beds peaked at the same relative humidity, with the fluidized taking longer to release all of its absorbed water.

\subsubsection{Adsorption Step}

Figure 4.12 shows the average outlet temperature and discharge rate of the fixed and fluidized bed for an adsorption run following the regeneration step as part of the repeated cycling of the adsorbent.

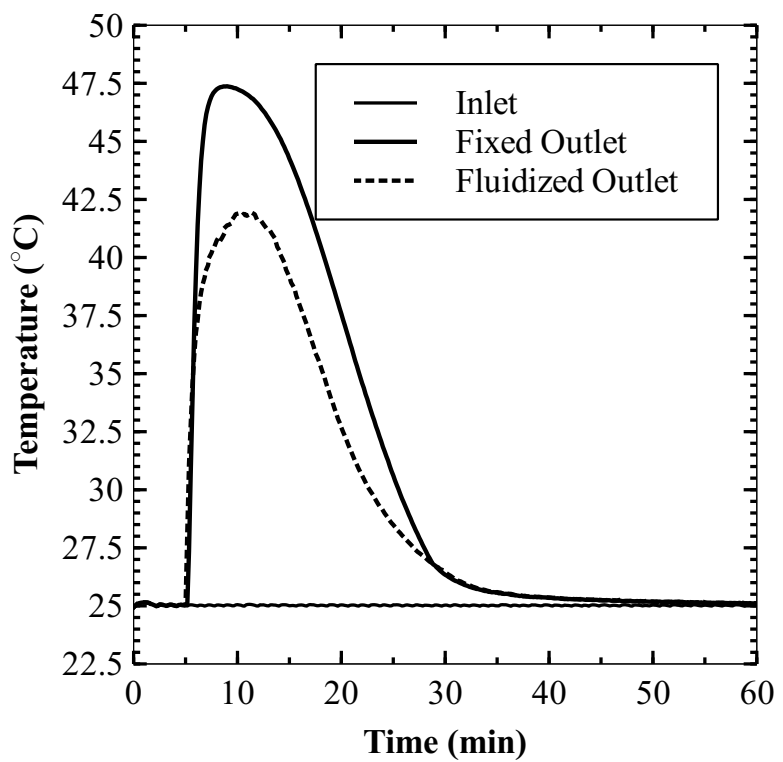

(a) temperature lift

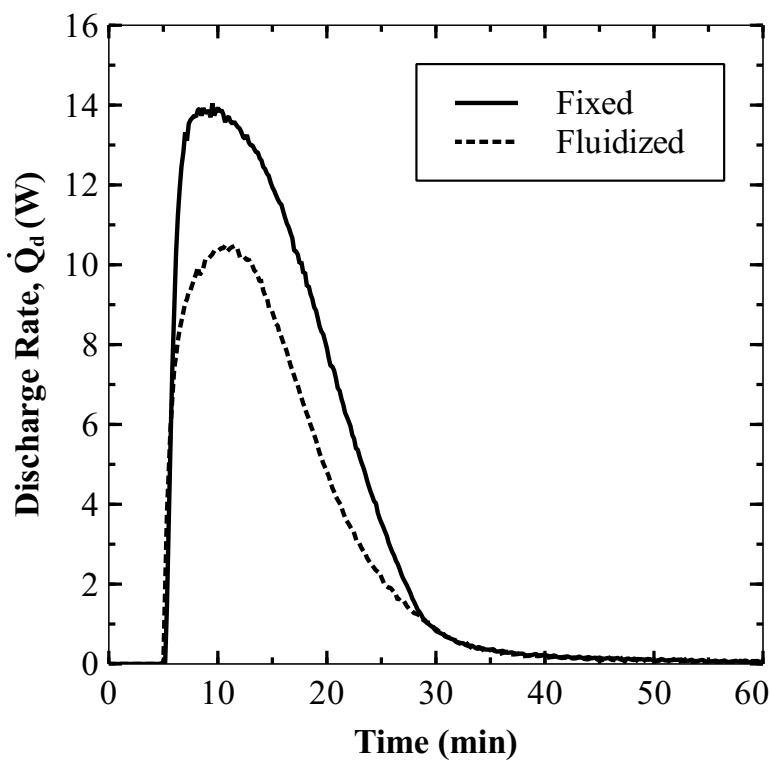

(b) rate of heat discharge

Figure 4.12: The average (a) temperature lift and (b) discharge rate of cycled fixed and fluidized beds during adsorption.

Referring to the results of Figure 4.8 for which the samples were regenerated at $200^{\circ} \mathrm{C}$ in the toaster oven, it can be seen that the outlet temperatures of both adsorbent 
beds in Figure 4.12a reach identical values despite being regenerated at much lower temperatures. An identical observation was made for the STAID prototype in which the outlet temperature peaked at $57.5^{\circ} \mathrm{C}$ for a shorter time when regenerated at $120^{\circ} \mathrm{C}$ than at $180^{\circ} \mathrm{C}[30]$. The discharge rates of both beds in Figure 4.12 are therefore similar to Figure 4.9, albeit the duration of the peak is less than that of the beds that were regenerated at a higher temperature, resulting in less energy released per Figure 4.13 .

The average energy densities of the fixed and fluidized bed were determined to be $86 \pm 8.1 \mathrm{kWh} / \mathrm{m}^{3}$ and $18 \pm 1.9 \mathrm{kWh} / \mathrm{m}^{3}$, respectively. The repeatability of the energy densities measured and shown as Figure 4.13 shows that the zeolite $13 \mathrm{X}$ can be recharged after multiple cycles without losing performance. Twenty-five cycles were considered sufficient for this test considering that the literature reports lifetimes on the order 2,000 cycles for synthetic zeolites 62 .

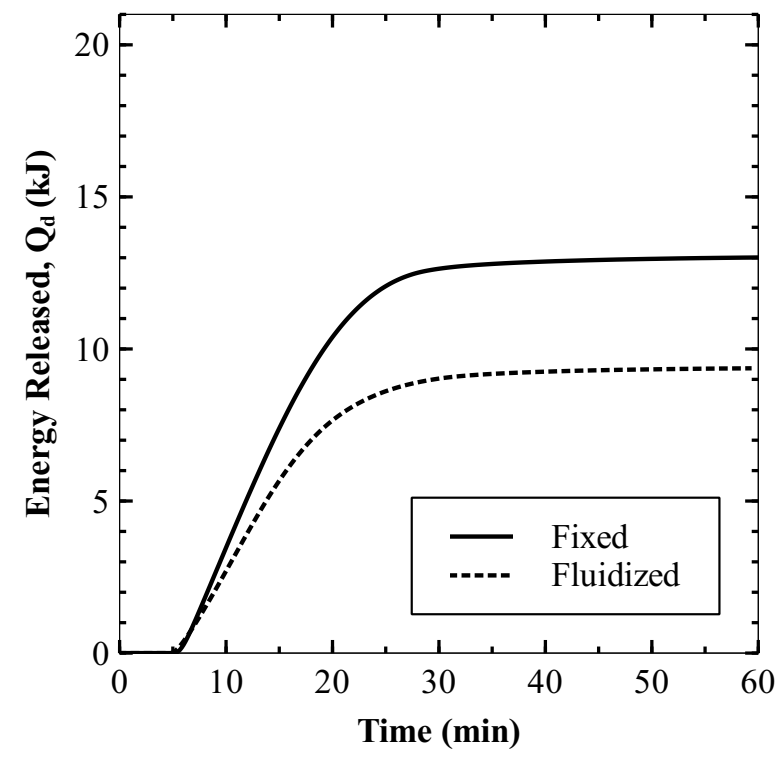

(a) average energy released

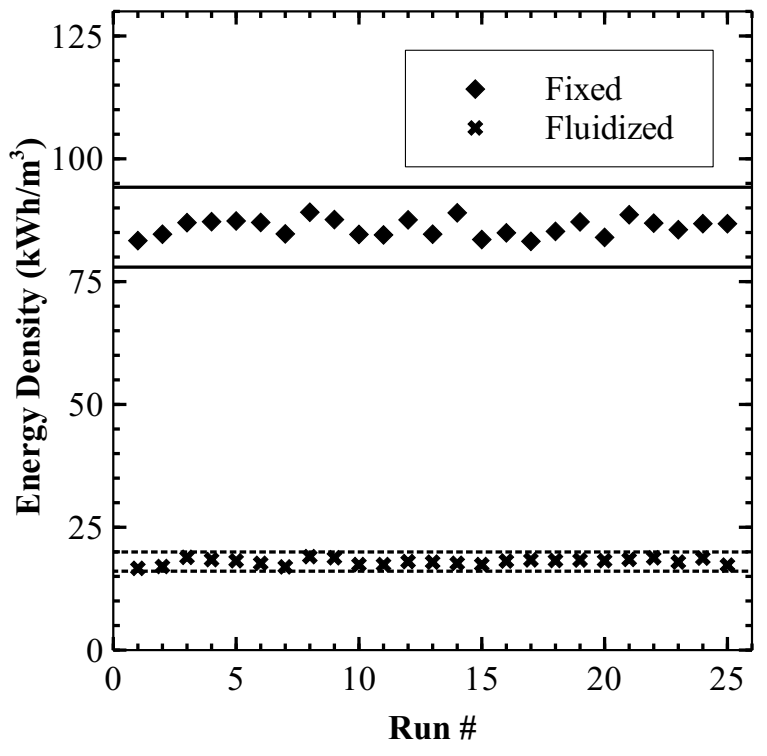

(b) cycle energy density

Figure 4.13: The (a) average energy released per cycle and (b) cycle energy densities of the fixed and fluidized bed.

\subsection{In-Situ Regeneration Under Partial Vacuum}

Tests were performed to investigate the effect of a partial vacuum on the regeneration of the zeolite and its corresponding energy released from adsorption. Two samples of $8 \times 12$ mesh zeolite were regenerated at 90 and $150^{\circ} \mathrm{C}$ under the pressure of the air supplied 
directly to the apparatus from the compressed air line, as well as under partial vacuum conditions using a material conveying vacuum pump. These tests were only performed on the 8x12 mesh zeolite because the smaller 60x65 mesh zeolite particles were sucked out of the column due to the proximity of the vacuum pump. It was hypothesized that under sub-atmospheric pressures, the samples could be equivalently regenerated at lower temperatures in comparison to the near atmospheric conditions present when the air is supplied directly. Figure 4.14 shows the average absolute pressure measured across the adsorption column under a partial vacuum (vac) and conditions slightly above atmospheric pressure (atm) for inlet temperatures of 90 and $150^{\circ} \mathrm{C}$ at an air flow rate of $20 \mathrm{~L} / \mathrm{min}$.

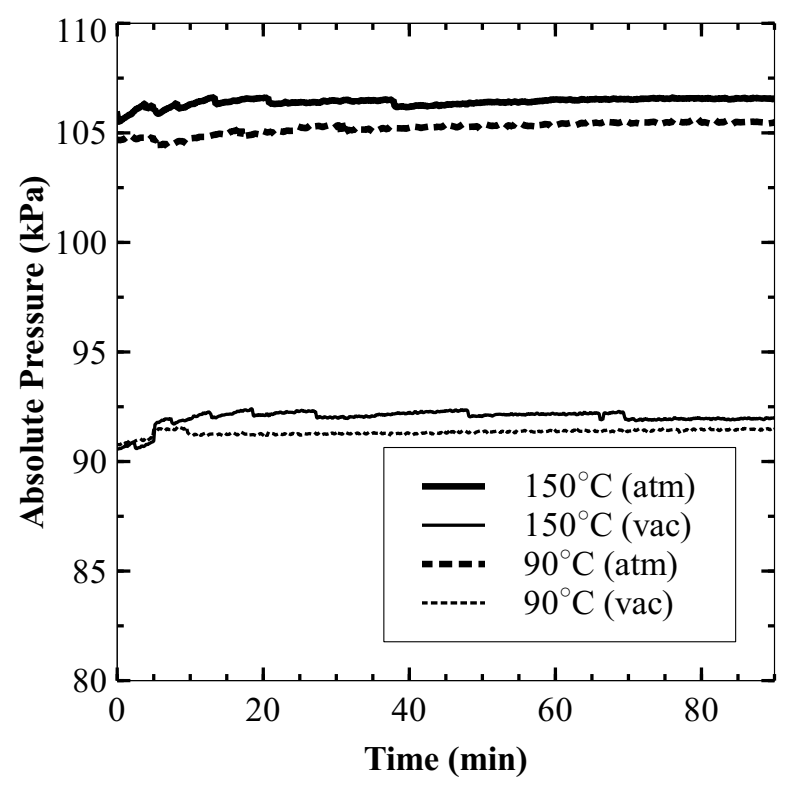

Figure 4.14: Average absolute pressure of the column for regeneration under partial vacuum and atmospheric conditions.

The thicker lines represent the atmospheric condition and the thinner lines represent the partial vacuum condition. The largest vacuum that could be achieved in the column was approximately $10 \mathrm{kPa}$ below a standard atmospheric pressure of $101.325 \mathrm{kPa}$. A greater vacuum could have been obtained with a lower air flow rate; however, this was a design tradeoff as the apparatus could not reach inlet temperatures as high as $150^{\circ} \mathrm{C}$ below $20 \mathrm{~L} / \mathrm{min}$. Under both atmospheric and partial vacuum conditions, a lower pressure was observed at a lower temperature of $90^{\circ} \mathrm{C}$ compared to $150^{\circ} \mathrm{C}$. This observation abides by the ideal gas law, which states that for a gas at constant volume, 
or in this case volumetric flow rate, the temperature of the gas is directly proportional to its pressure 63.

An equivalent observation was made for the outlet temperature of the adsorption column, in which lower temperatures were measured for the partial vacuum condition according to Figure 4.15a. The corresponding release of water vapour at the outlet of the column is shown as Figure $4.15 \mathrm{~b}$. At $150^{\circ} \mathrm{C}$, significantly faster regeneration of the zeolite occurred under atmospheric pressure than for the partial vacuum case despite reaching similar peaks in $\mathrm{RH}$ at the outlet. For the sample regenerated at $90^{\circ} \mathrm{C}$ however, water was released at an identical rate under both pressures.

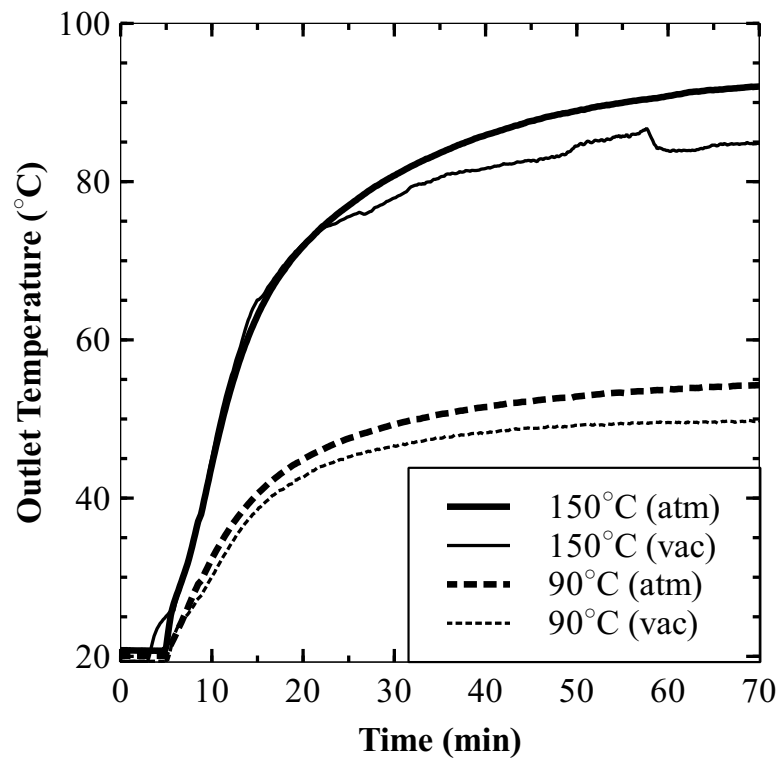

(a) column temperature

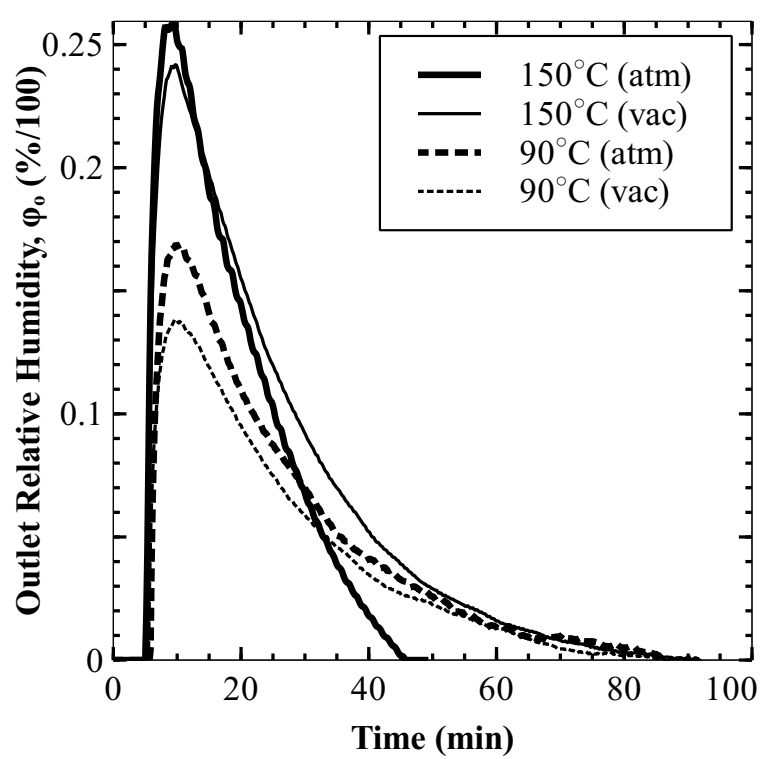

(b) outlet relative humidity

Figure 4.15: The (a) outlet temperatures and (b) relative humidity of adsorption column for regeneration under partial vacuum and atmospheric conditions.

The results of the corresponding adsorption run after each regeneration condition is presented as Figure 4.16a, which shows the temperature lift of the column and the cumulative energy released. 


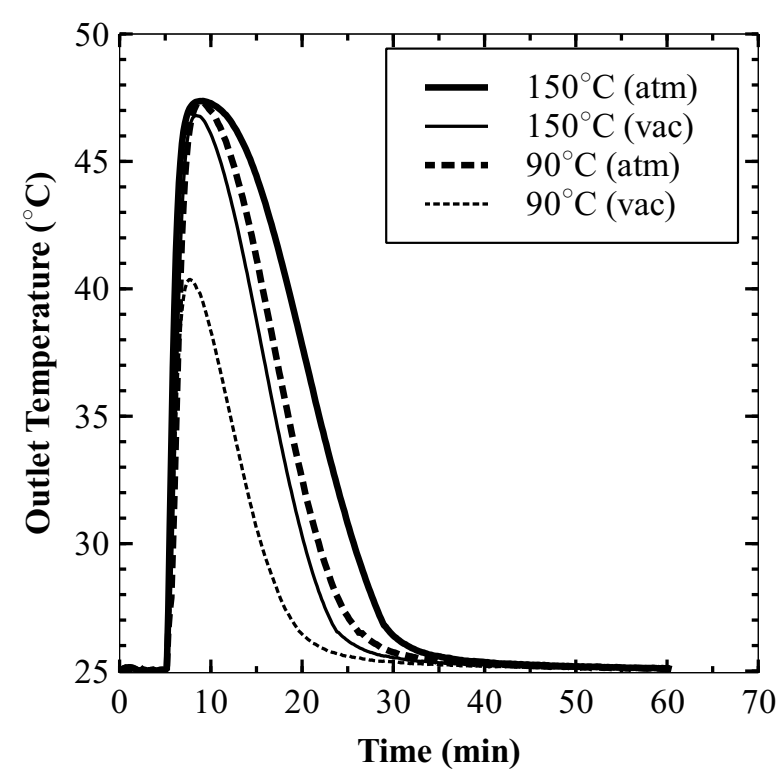

(a) temperature lift

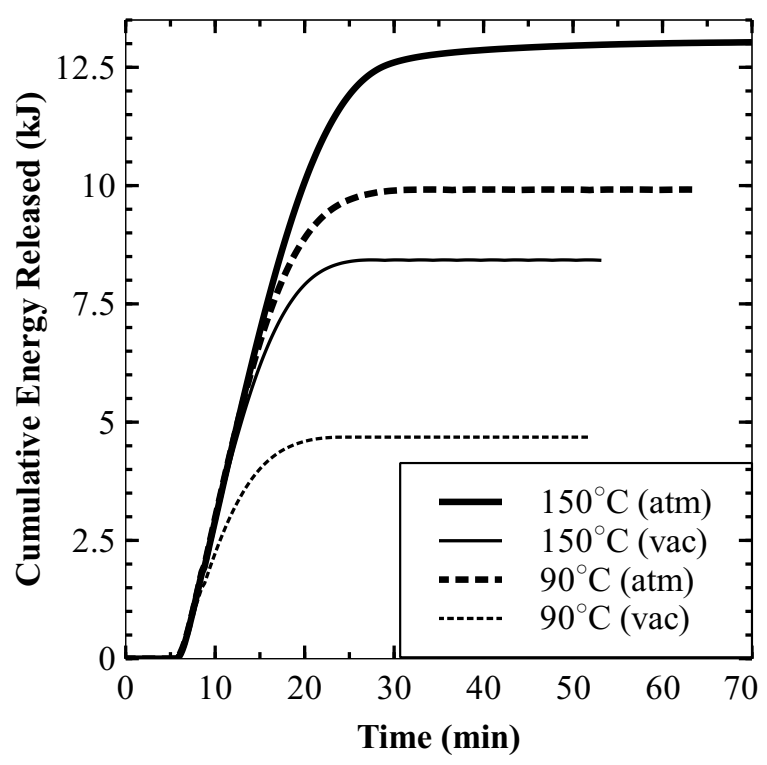

(b) energy released

Figure 4.16: The (a) temperature lift and (b) energy released for regeneration under partial vacuum and atmospheric conditions.

It is interesting to see that both pressure conditions for a regeneration temperature of $150^{\circ} \mathrm{C}$ and the atmospheric case at $90^{\circ} \mathrm{C}$ yielded identical results in terms of the peak outlet temperatures shown in Figure 4.16a. This result is consistent with temperature lift of the $8 \times 12$ mesh zeolite bed for all adsorption runs performed with air at 50\% RH and $25 \mathrm{~L} / \mathrm{min}$. The longer temperature peaks of the samples regenerated under atmospheric conditions however, resulted in greater amounts of energy released per Figure 4.16b. The $90^{\circ} \mathrm{C}$ atmospheric case however, released more energy than the $150^{\circ} \mathrm{C}$ vacuum case.

\subsection{Scaling Considerations}

From the experimental results obtained in section 4.1 and section 4.2 , the following methodology is proposed to develop a scaled adsorption-based TES for seasonal use given the annual and peak space heating loads of a home. An annual residential heating load of $15-300 \mathrm{kWh} / \mathrm{m}^{2}$ and peak load of $10-60 \mathrm{~W} / \mathrm{m}^{2}$ were considered to represent the space heating demand of Canada's residential building stock, from ultra-low energy homes built to the Passive House standard, to much older and less energy efficient vintages $[2,64]$. 


\subsubsection{Scaling the Volume of Material Storage}

The minimum mass and volume of zeolite required to supply the annual space heating load can be calculated from the storage capacity of the material (Wh/kg). Figure 4.17a shows how the total mass of zeolite would scale per $\mathrm{m}^{2}$ of floor area based on the results of Figure 4.6a for $25 \mathrm{~L} / \mathrm{min}$. Given a floor area of $100 \mathrm{~m}^{2}\left(1,076 \mathrm{ft}^{2}\right)$, Figure $4.17 \mathrm{~b}$ shows the volume of zeolite storage that would be required based on the scaling of Figure $4.17 \mathrm{a}$ and the $640 \mathrm{~kg} / \mathrm{m}^{3}$ bulk density of the zeolite. Compared to the BTES system of the DLSC that occupied a volume of over $650 \mathrm{~m}^{3}$ per home, even the largest volume of storage for a fluidized bed is over 2.5 times more compact, occupying $240 \mathrm{~m}^{3}$ for the storage of the material alone. Natural Resources Canada has suggested that up to $10 \mathrm{~m}^{3}$ of space in R-2000 homes could be allocated to the entirety of a thermochemical energy storage system $[8]$.

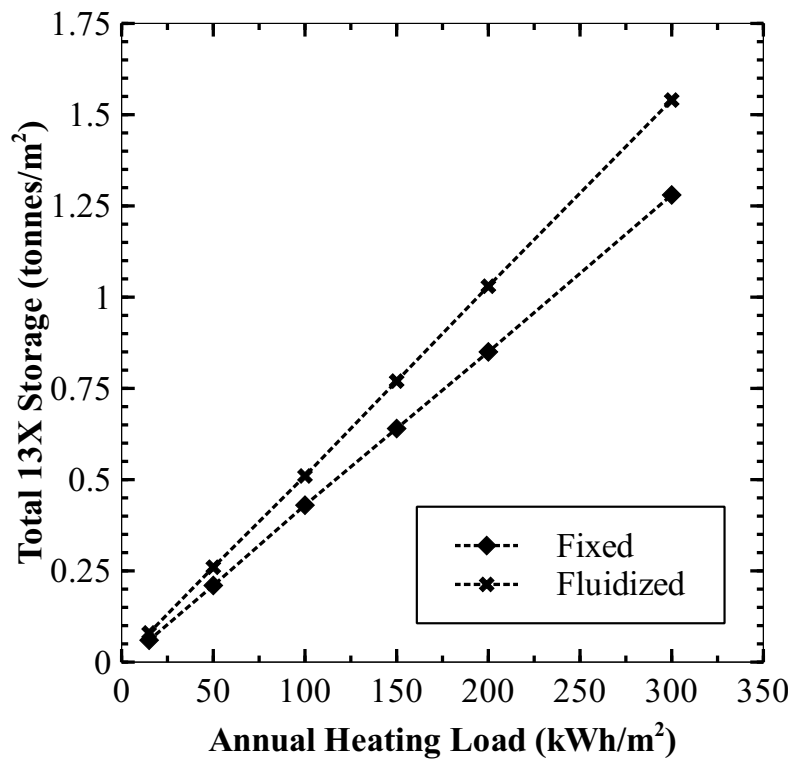

(a) mass scaling factor

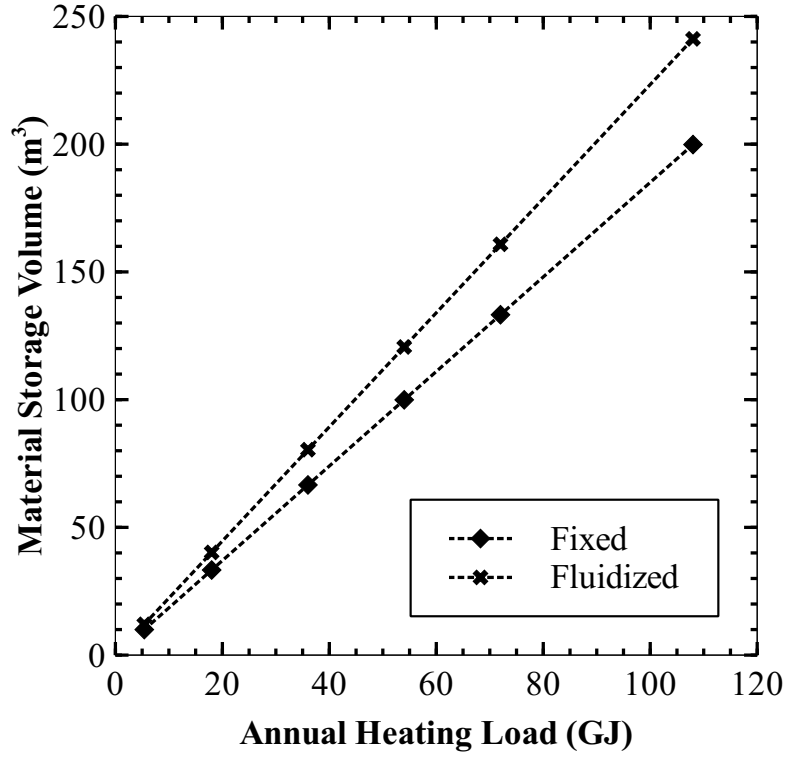

(b) scaled material storage volume

Figure 4.17: The (a) total storage mass and (b) volume of zeolite required based on annual heating load and a floor area of $100 \mathrm{~m}^{2}$.

To conceive a volume this small would require a passive house with an annual space heating load of less than 5 GJ which is not representative of Canada's building stock. Most homes in Canada also have a larger floor area of $200 \mathrm{~m}^{2}$ which would double the calculated scaled storage volume of material calculated in Figure 4.17p [2]. Because it was assumed that the system would be charged and discharged as a single cycle in a 
given year, the volume of storage calculated could be artificially high, where smaller volumes of material would be required for a system that can charge during the winter as well. Where it has been demonstrated that zeolites offer a high rate of discharge, it would seem more appropriate to pursue an application with a shorter timescale such as peak and diurnal energy storage, which would require more conceivable volumes of material.

\subsubsection{Scaling the Adsorber Volume}

The minimum mass and volume of the adsorbent beds required to supply a peak heating load was calculated from the specific power of the material $(\mathrm{W} / \mathrm{kg})$ in Figure 4.18 .

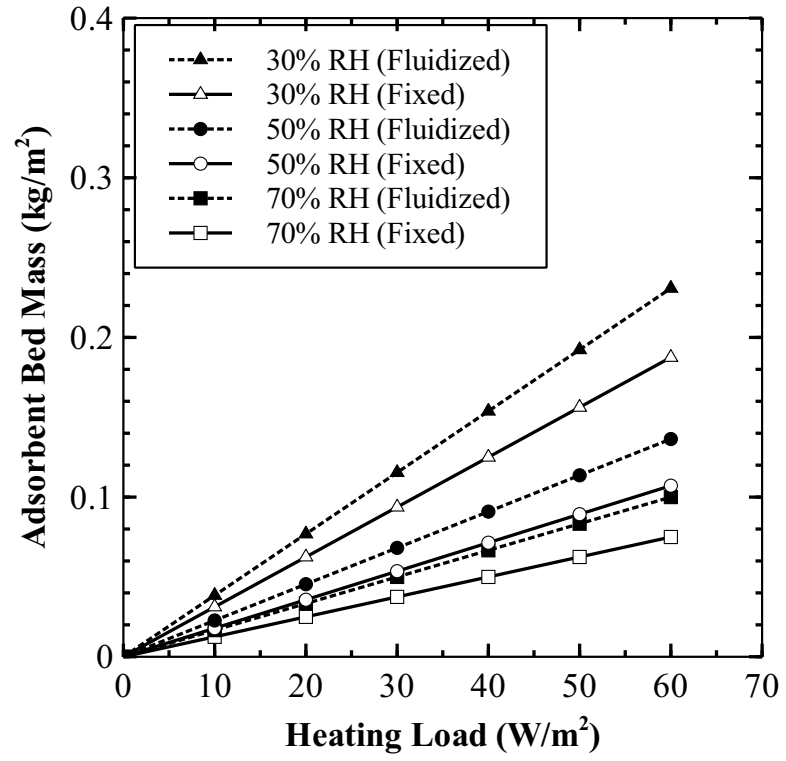

(a) mass scaling factor

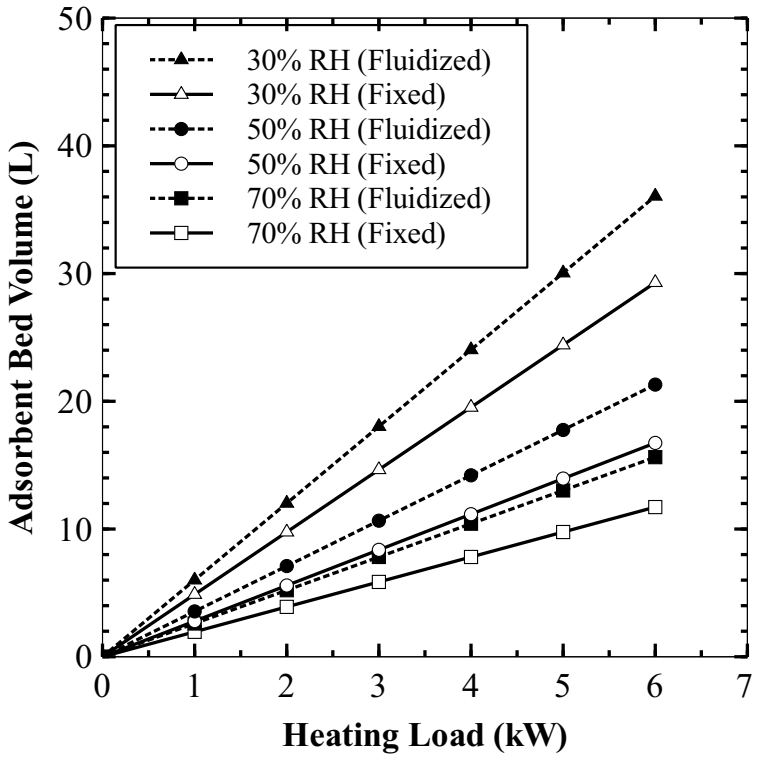

(b) scaled adsorbent bed volume

Figure 4.18: Adsorbent bed volume of (a) the fixed bed and (b) the fluidized bed, based on a floor area of $100 \mathrm{~m}^{2}$.

Similar to finding the total volume of material for such a system, a scaling factor in $\mathrm{kg}$ per $\mathrm{m}^{2}$ of floor area was calculated from the specific power of each bed for inlet water vapour concentrations of $30-70 \% \mathrm{RH}$ in Figure 4.18a. This scaling factor was used to determine the volume of an adsorber required for a $100 \mathrm{~m}^{2}$ floor area in Figure 4.18. Notwithstanding the difference in the concentration of water vapour at the inlet of the column for each test in section 4.2, the same amount of thermal energy was released for each level of relative humidity. Therefore the lower and more dispersed specific power 
of the $30 \% \mathrm{RH}$ run for each bed requires more zeolite to supply equivalent heating loads as those met by higher specific power for 50 and $70 \% \mathrm{RH}$ at the inlet. Heating a $100 \mathrm{~m}^{2}$ floor area, as shown by Figure 4.18b would require between 2 and $36 \mathrm{~L}$ of zeolite in the adsorber at a time depending on the bed type and the concentration of water vapour at the inlet. The volume of the whole fixed bed adsorber could be approximated as the volume of the adsorbent alone; however, the volume of the fluidized bed adsorber would of course go beyond the volume scaled in Figure 4.18b due to the bubble height of the adsorbent material. The expansion of the fluidized bed observed in this work as shown by the $M T Z$ in Figure 4.3 could be considered in a model to estimate the height of the zeolite bubbles in a scaled model as shown by Zhang et al. 65.

Having an approximation of the volume of the adsorber, an assumption can then be made about its shape to define dimensions such as the diameter and static bed height of a cylinder, for which an optimal height to diameter ratio of 1.5 has been found optimal [52]. From the scaled static bed, the breakthrough and exhaustion times of the scaled system can be estimated [57]. An estimation of the breakthrough time is necessary to determine the state of charge of the adsorbent bed as it essentially indicates when the rate of heat released by adsorption has peaked. Using the breakthrough times and static bed height, the $M T Z$ of the scaled adsorber can be established which indicates the amount of material to be replaced in continuous operation of the external type system. From these preliminary calculations and experimental data, a numerical model could be built with which a parametric study could be conducted to optimize the dimensions of the system based on heating load and inlet conditions. 


\section{Chapter 5}

\section{Conclusions and Future Work}

\subsection{Conclusions}

This thesis represents the establishment of research initiatives on thermochemical storage at Carleton University, and aimed to experimentally evaluate and compare fixed and fluidized beds as components in such storage systems. The evaluation was based on the results of a series of adsorption experiments that observed the effects of flow rate, relative humidity, and regeneration temperature on the thermal energy storage capacities of an 8x12 and 60x65 mesh zeolite 13X molecular sieve. The energy released by both beds was not affected by the air flow rate, and this parameter can be limited to the rate required for supplying the space heat of a scaled application. The concentration of water vapour at the inlet was shown to be a significant parameter in terms of controlling the delivery temperature of the system, with relatively values of high specific power calculated for both the fixed and fluidized beds. Greater axial dispersion and zeolite-wall heat transfer in the fluidized bed however, potentially resulted in the lower temperature response observed from the 60x65 mesh samples which reduced the amount of thermal energy they released for all of the tests performed. The bubbles of the fluidized bed of 60x65 mesh zeolite also required a greater volume at higher air flow rates, which reduced its energy density even more in comparison to the fixed 8x12 mesh beds that had an equivalent mass.

This work also explored the use of a vacuum pump to purge saturated beds of $8 \times 12$ zeolite during regeneration. While it was hypothesized that a lower pressure would 
reduce the vapour pressure of the air and therefore be more favourable for regeneration in comparison to atmospheric conditions, the temperatures obtained in the column were proportional to the lower pressure and therefore less energy could be stored in the samples regenerated under a partial vacuum. Therefore, the use of a vacuum for this application of regeneration at higher flow rates is not recommended.

The goal of the scaling methodology was to further consider the results in terms of how the column used in this work might scale to supply realistic residential heating loads. The most feasible scenario to pursue for R\&D of seasonal compact thermal energy storage included the use of a fixed adsorbent bed which would require $9.9 \mathrm{~m}^{3}$ of storage material to meet the heating load of a passive house with a load of $15 \mathrm{kWh} / \mathrm{m}^{2} /$ year. Higher heating loads could be feasibly met however, if higher energy densities could be achieved with advanced TCM. In terms of focusing efforts on R\&D for integrating compact TES systems into buildings, investigating peak load applications would allow researchers to develop technologies for smaller systems that are more conceivable, using data from this and other fundamental studies that consider the behaviour of solid TCMgas pairs.

\subsection{Future Work}

Given these initial results, future work comparing fixed and fluidized beds with the present experimental setup could continue in the following research directions.

\subsubsection{Internal Heat Transfer and DHW}

The fluidized bed was inferior to the fixed bed for the application of space heating due to the reduced outlet temperatures in the presence of higher axial dispersion of the particles. This higher degree of mixing however may be better suited to transfer heat within the bed itself which would be advantageous for the application of thermal storage of a buffer tank or domestic hot water (DHW). Investigating this claim could involve quantifying the rate of axial and radial heat transfer in each bed. This would require larger sample sizes and additional thermocouples along the axis and radii of each bed. The addition of thermocouples to the interior and exterior wall of the column may also 
help determine if the fluidized bed experienced greater heat losses through the column than the fixed bed.

\subsubsection{Material Transport \& State of Charge}

It appears that to date, the mechanical transport of thermochemical material in and out of an external adsorber has not been realized at any scale let alone attempted in a model. An investigation of the frequency of material transport could be carried out starting with estimation of breakthrough time and the length of the mass transfer zone for a given scope of the system's size based on the scaling analysis provided in this work. The experimental data obtained from this research could be implemented in the development of a new TRNSYS component for TES through adsorption, following a similar method to how Type 1270 was developed for a PCM wall. 


\section{References Cited}

[1] Ibrahim Dinçer and Marc A. Rosen. Exergy: Energy, Environment and Sustainable Development. Elsevier Ltd., 2 edition, 2013.

[2] Natural Resources Canada - Office of Energy Efficiency. Energy Use Data Handbook 1990 - 2010. Ottawa, Canada: Her Majesty the Queen in Right of Canada, 2013.

[3] Gerald Faninger. The potential of solar thermal technologies in a sustainable energy future. IEA Solar Heating and Cooling Programme, 2010.

[4] Natural Resources Canada - Office of Energy Efficiency. Heating with natural gas. Ottawa, Canada: Her Majesty the Queen in Right of Canada, 2012.

[5] Bob Sibbit, Doug McClenahan, Reda Djebbar, Jon Thornton, Bill Wong, Jarred Carriere, and Jo Kokko. The performance of a high solar fraction seasonal storage district heating systemfive years of operation. Energy Procedia, 30:856 - 865, 2012.

[6] Trevor Letcher. Storing Energy. Elsevier Inc., 2016.

[7] Ibrahim Dincer and Marc Rosen. Thermal energy storage: systems and applications. John Wiley \& Sons, 2002.

[8] Science Applications International Corporation (SAIC Canada) and Wim van Helden Renewable Heat B.V. Compact Thermal Energy Storage Assessment Report. 2012.

[9] Cynthia Cruickshank and Stephen Harrison. An experimental test apparatus for the evaluation of multi-tank thermal storage systems. In Proceedings of the Joint Conference of the Canadian Solar Buildings Research Network and Solar Energy Society of Canada Inc.(SESCI). Citeseer, 2006.

[10] Sarah Wert, Cynthia A Cruickshank, and Dominic Groulx. Characterization of an air-pcm energy storage design for air handling unit applications. In ASME 2017 Heat Transfer Summer Conference, pages V001T09A005-V001T09A005. American Society of Mechanical Engineers, 2017.

[11] Motoyuki Suzuki. Adsorption Engineering. Elsevier Science Publishing Company, Inc., 1990.

[12] VM Van Essen, HA Zondag, J Cot Gores, LPJ Bleijendaal, M Bakker, R Schuitema, WGJ Van Helden, Z He, and CCM Rindt. Characterization of mgso4 hydrate for thermochemical seasonal heat storage. Journal of Solar Energy Engineering, 131(4):041014, 2009. 
[13] HA Zondag, VM Van Essen, LPJ Bleijendaal, BWJ Kikkert, and M Bakker. Application of $\mathrm{MgCl}_{2} \cdot 6 \mathrm{H}_{2} \mathrm{O}$ for thermochemical seasonal solar heat storage. In Proceedings IRES 2010 conference, Berlin, 2010.

[14] Lewis G Harriman III. The dehumidification handbook, 1989.

[15] UR Fischer. What is the best possible heat storage density for a seasonal adsorptive thermal energy storage. In 11th International Conference on Thermal Energy Storage, Stockholm, 2009.

[16] Ralph T Yang. Adsorbents: fundamentals and applications. John Wiley \& Sons, 2003.

[17] Douglas Morris Ruthven. Principles of Adsorption and Adsorption Processes. John Wiley \& Sons, New York, 1984.

[18] Benot Stutz, Nolwenn Le Pierres, Frdric Kuznik, Kevyn Johannes, Elena Palomo Del Barrio, Jean-Pierre Bdcarrats, Stphane Gibout, Philippe Marty, Laurent Zalewski, Jerome Soto, Nathalie Mazet, Rgis Olives, Jean-Jacques Bezian, and Doan Pham Minh. Storage of thermal solar energy. Comptes Rendus Physique, 18(7):401 - 414, 2017. Demain lnergie.

[19] Matthias Rommel, Andreas Hauer, and Wim van Helden. Iea shc task 42 / eces annex 29 compact thermal energy storage. Energy Procedia, 91(Supplement C):226 - 230, 2016. Proceedings of the 4th International Conference on Solar Heating and Cooling for Buildings and Industry (SHC 2015).

[20] Kokouvi Edem N'Tsoukpoe, Thomas Schmidt, Holger Urs Rammelberg, Beatriz Amanda Watts, and Wolfgang KL Ruck. A systematic multi-step screening of numerous salt hydrates for low temperature thermochemical energy storage. Applied Energy, 124:1-16, 2014.

[21] Holger U Rammelberg, Malte Myrau, Thomas Schmidt, and Wolfgang Ruck. An optimization of salt hydrates for thermochemical heat storage. In Proceedings of the International Symposium on Innovative Materials for Processes in Energy Systems 2013, September 4-6, 2013, Fukuoka, Japan.

[22] Kathrin Korhammer, Maria Druske, Armand Fopah-Lele, Holger Urs Rammelberg, Nina Wegscheider, Oliver Opel, Thomas Osterland, and Wolfgang Ruck. Sorption and thermal characterization of composite materials based on chlorides for thermal energy storage. Applied Energy, 162:1462-1472, 2016.

[23] Aran Solé, Laia Miró, Camila Barreneche, Ingrid Martorell, and Luisa F Cabeza. Corrosion of metals and salt hydrates used for thermochemical energy storage. Renewable Energy, 75:519-523, 2015.

[24] Camila Barreneche, A Inés Fernández, Luisa F Cabeza, and Ruud Cuypers. Thermophysical characterization of sorption tcm. Energy Procedia, 48:273-279, 2014. 
[25] Thomas H Herzog, Jochen Jänchen, Eythymius M Kontogeorgopoulos, and Wolfgang Lutz. Steamed zeolites for heat pump applications and solar driven thermal adsorption storage. Energy Procedia, 48:380-383, 2014.

[26] J. Jänchen, T. Herzog, K. Schumann, A. Brandt, and B. Unger. Properties of a novel binderless y-type zeolite for thermal adsorption storage applications. Proceedings of the 17th International Zeolite Conference, Moscow, Russia, July 5-6, 2013.

[27] Claire Ferchaud, HA Zondag, Robert de Boer, and CCM Rindt. Characterization of the sorption process in thermochemical materials for seasonal solar heat storage application. In Proceedings of the 12th international conference on energy storage (Innostock 2012), pages 16-19, 2012.

[28] S.V. Gaastra-Nedea, C.C.M. Rindt, A. König-Haagen, R.R. Kasibhatla, D. Brüggemann, P. Dolado, A. Lazaro, and E. Franquet. Advanced numerical modelling techniques to tune the properties of heat storage materials for optimal reactor performance. Proceedings of SHC 2015 International Conference on Solar Heating and Cooling for Buildings and Industry, Istanbul, Turkey, Dec 2-4, 2015.

[29] Wim van Helden, Motoi Yamaha, Christoph Rathgeber, Andreas Hauer, Fredy Huaylla, Nolwenn Le Pierrs, Benoit Stutz, Barbara Mette, Pablo Dolado, Ana Lazaro, Javier Mazo, Mark Dannemand, Simon Furbo, Alvaro Campos-Celador, Gonzalo Diarce, Ruud Cuypers, Andreas Knig-Haagen, Stephan Hhlein, Dieter Brggemann, Benjamin Fumey, Robert Weber, Rebekka Kll, Waldemar Wagner, Xavier Daguenet-Frick, Paul Gantenbein, and Frdric Kuznik. Iea shc task 42 / eces annex 29 working group b: Applications of compact thermal energy storage. Energy Procedia, 91(Supplement C):231 - 245, 2016. Proceedings of the 4th International Conference on Solar Heating and Cooling for Buildings and Industry (SHC 2015).

[30] Kévyn Johannes, Frédéric Kuznik, Jean-Luc Hubert, Francois Durier, and Christian Obrecht. Design and characterisation of a high powered energy dense zeolite thermal energy storage system for buildings. Applied Energy, 159:80-86, 2015.

[31] Andreas Krnauer, Eberhard Lvemann, Sarah Brckner, and Andreas Hauer. Mobile sorption heat storage in industrial waste heat recovery. Energy Procedia, 73(Supplement C):272 - 280, 2015. 9th International Renewable Energy Storage Conference, IRES 2015 .

[32] Christoph Rathgeber, Stefan Hiebler, Eberhard Lvemann, Pablo Dolado, Ana Lazaro, Jaume Gasia, Alvaro de Gracia, Laia Mir, Luisa F. Cabeza, Andreas Knig-Haagen, Dieter Brggemann, lvaro Campos-Celador, Erwin Franquet, Benjamin Fumey, Mark Dannemand, Thomas Badenhop, Jan Diriken, Jan Erik Nielsen, and Andreas Hauer. Iea shc task 42 / eces annex 29 a simple tool for the economic evaluation of thermal energy storages. Energy Procedia, 91(Supplement C):197 206, 2016. Proceedings of the 4th International Conference on Solar Heating and Cooling for Buildings and Industry (SHC 2015).

[33] Barbara Mette, Henner Kerskes, and Harald Drück. Process and reactor design for thermo-chemical energy stores. In ISES Solar World Congress, volume 28, 2011. 
[34] Frank M. White. Fluid Mechanics. McGraw-Hill, 7 edition, 2011.

[35] Daizo Kunii and Octave Levenspiel. Fluidization Engineering. John Wiley \& Sons, Inc., 1969.

[36] D. Geldart. Types of gas fluidization. Powder Technology, 7(5):285 - 292, 1973.

[37] Mooson Kwauk, Jinghai Li, and Dejin Liu. Particulate and aggregative fluidization 50 years in retrospect. Powder Technology, 111(1):3 - 18, 2000.

[38] Semion Shaul, Evgeny Rabinovich, and Haim Kalman. Typical fluidization characteristics for geldart's classification groups. Particulate Science and Technology, 32(2):197-205, 2014.

[39] CY Wen and YH Yu. A generalized method for predicting the minimum fluidization velocity. AIChE Journal, 12(3):610-612, 1966.

[40] Armand Fopah Lele, Kokouvi Edem N'Tsoukpoe, Thomas Osterland, Frédéric Kuznik, and Wolfgang KL Ruck. Thermal conductivity measurement of thermochemical storage materials. Applied Thermal Engineering, 89:916-926, 2015.

[41] Barbara Mette, Henner Kerskes, Harald Drck, and Hans Mller-Steinhagen. Experimental and numerical investigations on the water vapor adsorption isotherms and kinetics of binderless zeolite 13x. International Journal of Heat and Mass Transfer, $71: 555-561,2014$.

[42] F. B. Cortés, F. Chejne, F. Carrasco-Marín, C. Moreno-Castilla, and A. F. PérezCadenas. Water adsorption on zeolite 13x: comparison of the two methods based on mass spectrometry and thermogravimetry. Adsorption, 16(3):141-146, Aug 2010.

[43] Lalhmingsanga Hauchhum and Pinakeswar Mahanta. Carbon dioxide adsorption on zeolites and activated carbon by pressure swing adsorption in a fixed bed. International Journal of Energy and Environmental Engineering, 5(4):349-356, 2014.

[44] Lalhmingsanga Hauchhum and Pinakeswar Mahanta. Performance enhancement of $\mathrm{CO}_{2}$ capture from flue gas in a bubbling fluidized bed. Journal of the Energy Institute, 2016.

[45] Daniel Dicaire and F. Handan Tezel. Regeneration and efficiency characterization of hybrid adsorbent for thermal energy storage of excess and solar heat. Renewable Energy, 36(3):986 - 992, 2011.

[46] Dominique Lefebvre, Patrice Amyot, Burcu Ugur, and F. Handan Tezel. Adsorption prediction and modeling of thermal energy storage systems: A parametric study. Industrial \&5 Engineering Chemistry Research, 55(16):4760-4772, 2016.

[47] Thomas Nonnen, Steffen Beckert, Kristin Gleichmann, Alfons Brandt, Baldur Unger, Henner Kerskes, Barbara Mette, Sebastian Bonk, Thomas Badenhop, Frank Salg, and Roger Glser. A thermochemical long-term heat storage system based on a salt/zeolite composite. Chemical Engineering 65 Technology, 39(12):2427-2434, 2016. 
[48] Herbert Zondag, Benjamin Kikkert, Simon Smeding, Robert de Boer, and Marco Bakker. Prototype thermochemical heat storage with open reactor system. Applied energy, 109:360-365, 2013.

[49] Asnakech Lass-Seyoum, Mike Blicker, Dimitry Borozdenko, Thomas Friedrich, and Timo Langhof. Transfer of laboratory results on closed sorption thermo- chemical energy storage to a large-scale technical system. Energy Procedia, 30(Supplement C):310 - 320, 2012. 1st International Conference on Solar Heating and Coolingfor Buildings and Industry (SHC 2012).

[50] Benoit Michel, Pierre Neveu, and Nathalie Mazet. Comparison of closed and open thermochemical processes, for long-term thermal energy storage applications. Energy, 72(Supplement C):702 - 716, 2014.

[51] Benoit Michel, Nathalie Mazet, and Pierre Neveu. Experimental investigation of an innovative thermochemical process operating with a hydrate salt and moist air for thermal storage of solar energy: Global performance. Applied Energy, 129:177-186, 2014.

[52] M Gaeini, MR Javed, H Ouwerkerk, HA Zondag, and CCM Rindt. Realization of a $4 \mathrm{kw}$ thermochemical segmented reactor in household scale for seasonal heat storage. Energy Procedia, 135:105-114, 2017.

[53] Asnakech Lass-Seyoum, Dmitry Borozdenko, Thomas Friedrich, Timo Langhof, and Simone Mack. Practical test on a closed sorption thermochemical storage system with solar thermal energy. Energy Procedia, 91:182 - 189, 2016. Proceedings of the 4th International Conference on Solar Heating and Cooling for Buildings and Industry (SHC 2015).

[54] Christian Finck, Hans vant Spijker, Ard-Jan de Jong, Ellemieke Henquet, Henk Oversloot, and Ruud Cuypers. Design of a modular $3 \mathrm{kwh}$ thermochemical heat storage system for space heating application. In 2nd International Conference on Sustainable Energy Storage, June, volume 19, page 21, 2013.

[55] Christian Finck, Ellemieke Henquet, Christiaan van Soest, Henk Oversloot, ArdJan de Jong, Ruud Cuypers, and Hans vant Spijker. Experimental results of a 3 kwh thermochemical heat storage module for space heating application. Energy Procedia, 48:320-326, 2014.

[56] H Hori, I Tanaka, and T Akiyama. A simple estimation method of breakthrough time on fixed-bed adsorption column of activated carbon. Nippon Kagaku Kaishi, (5):961-969, 1985.

[57] Hajime Hori, Isamu Tanaka, and Takashi Akiyama. Breakthrough time on activated carbon fluidized bed adsorbers. JAPCA, 38(3):269-271, 1988.

[58] Young Ki Ryu, Seung Ju Lee, Jong Wha Kim, and Chang-Ha Leef. Adsorption equilibrium and kinetics of $\mathrm{h} 2 \mathrm{o}$ on zeolite 13x. Korean Journal of Chemical Engineering, 18(4):525-530, 2001. 
[59] YN Zhang, RZ Wang, and TX Li. Experimental investigation on an open sorption thermal storage system for space heating. Energy, 141:2421-2433, 2017.

[60] Pin-Yang Wang, Hong-Yang Guan, Zhen-Hua Liu, Guo-San Wang, Feng Zhao, and Hong-Sheng Xiao. High temperature collecting performance of a new all-glass evacuated tubular solar air heater with u-shaped tube heat exchanger. Energy Conversion and Management, 77:315-323, 2014.

[61] Daniel Int-Hout III. Overhead heating: revisiting a lost art. ASHRAE Journal, 49(3):56, 2007.

[62] Charles K Hersh. Molecular sieves. Technical report, Reinhold Pub.,, 1961.

[63] George Antonoff and Duncan Randall. The ideal gas laws. School Science and Mathematics, 48(2):118-121.

[64] Jürgen Schnieders, Wolfgang Feist, and Ludwig Rongen. Passive houses for different climate zones. Energy and Buildings, 105:71-87, 2015.

[65] YM Zhang, CX Lu, and MX Shi. A practical method to estimate the bed height of a fluidized bed of fine particles. Chemical Engineering 85 Technology: Industrial Chemistry-Plant Equipment-Process Engineering-Biotechnology, 31(12):1735-1742, 2008.

[66] Theodore L Bergman, Frank P Incropera, David P DeWitt, and Adrienne S Lavine. Fundamentals of heat and mass transfer. John Wiley \& Sons, 2011.

[67] George Granger Brown, Alan Shivers Foust, George Martin Brown, and Richard Schneidewind. Unit operations. 1951.

[68] Sympatec QICPIC Particle Size Analysis. https://mfix.netl.doe.gov/ wp-content/uploads/2016/04/Size-Analysis-Zeolite-4x8-v2.pdf. Accessed: 2016-02-22.

[69] Christopher Baldwin. Design and construction of an experimental apparatus to assess the performance of a solar absorption chiller with integrated thermal storage. Carleton University, Ottawa, ON, Canada, 2013.

[70] Zoran Morvay and Dušan Gvozdenac. Applied industrial energy and environmental management, volume 2. John Wiley \& Sons, 2008. 
Appendices 


\section{Appendix A}

\section{Adsorption Column Drawings}

This appendix contains the assembly and working drawings of the adsorption column built as part of this research project. The drawings are organized as follows:

- Figure A1 is the full assembly of the column

- Figure A2 is the inlet sub-assembly of the column

- Figures A2.1 - A2.8 are the working drawings of the components for the inlet sub-assembly

- Figure A3 is a working drawing of the acrylic column

- Figure A4 is the outlet sub-assembly of the column (made of the components shown for Figure A2) 


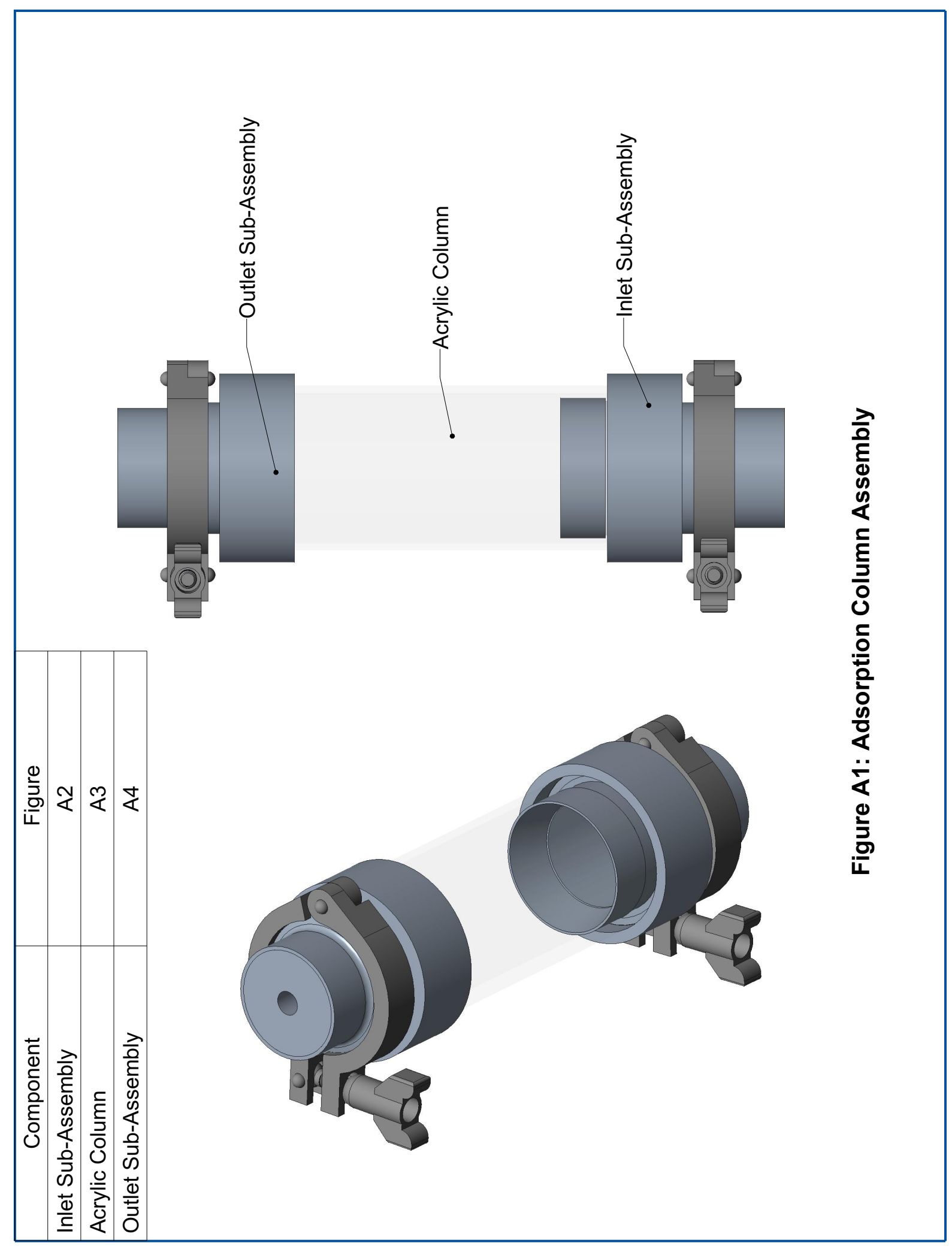




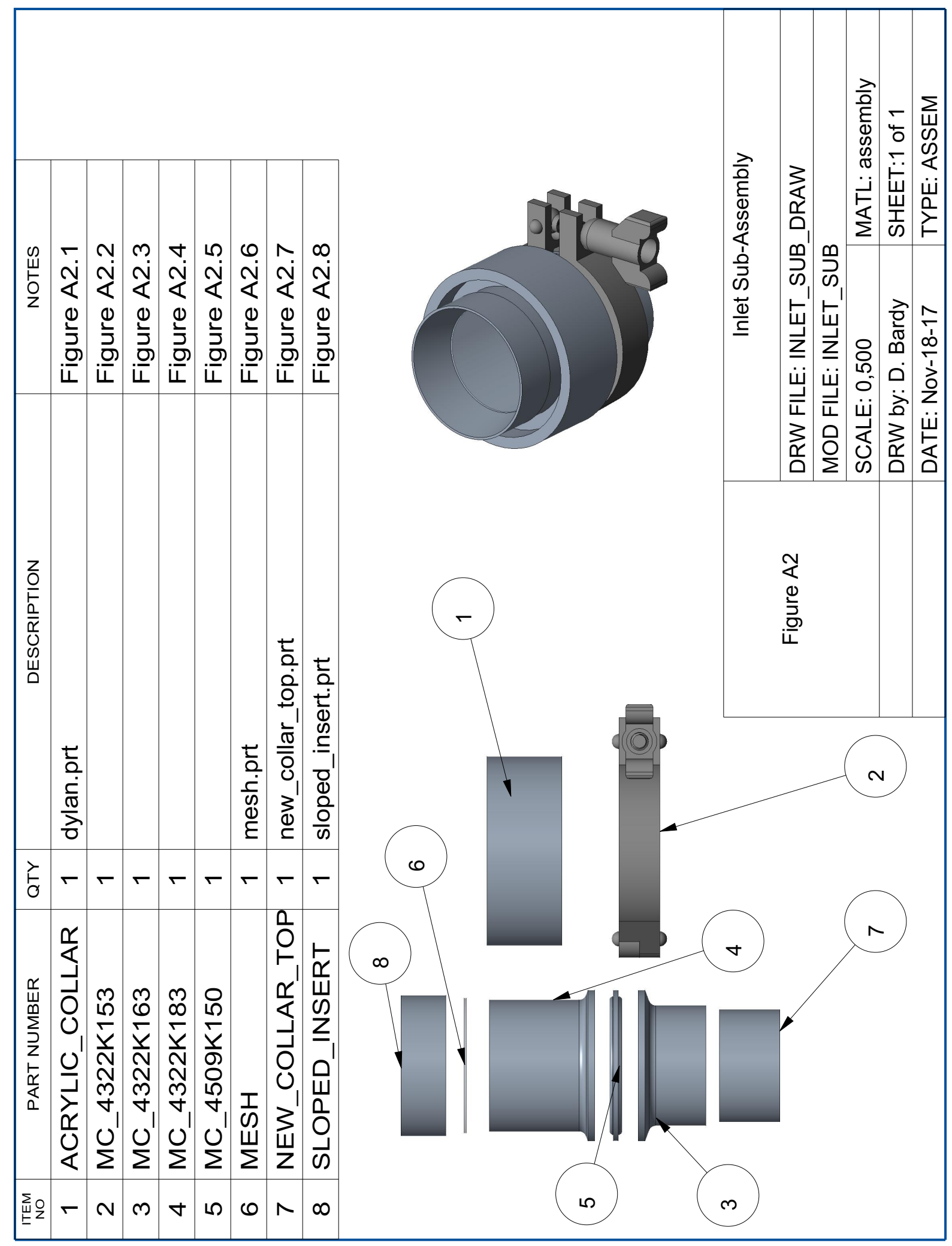




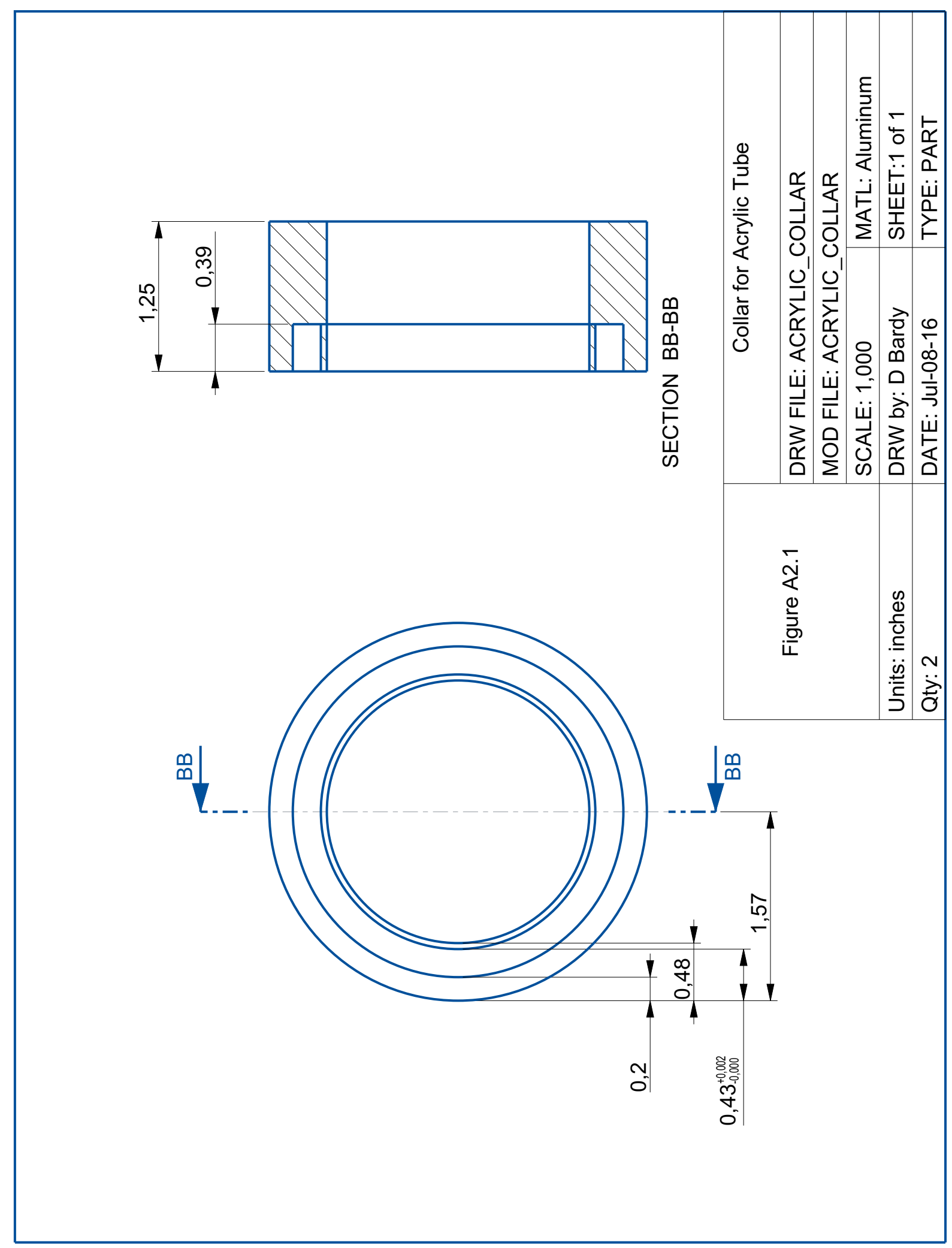




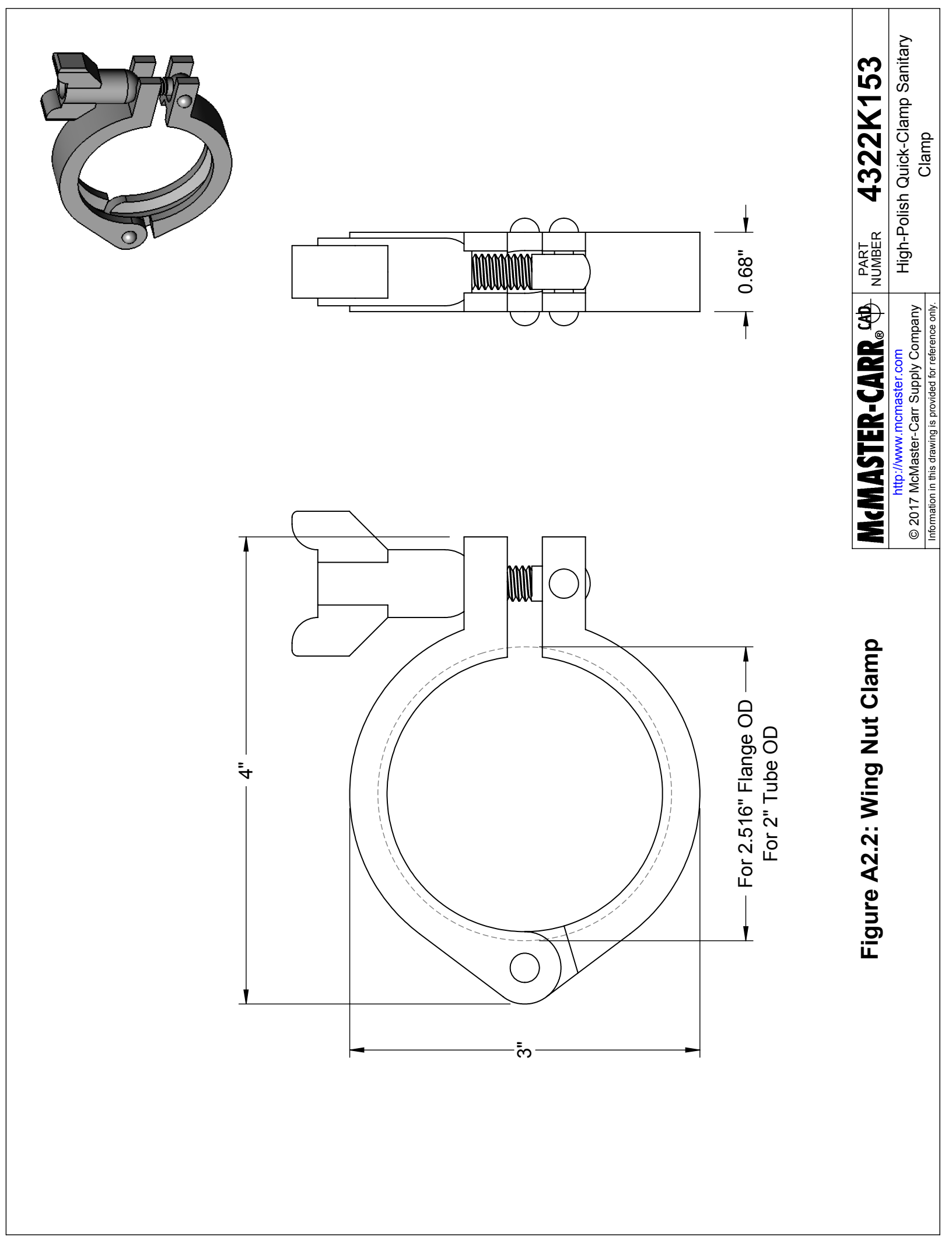




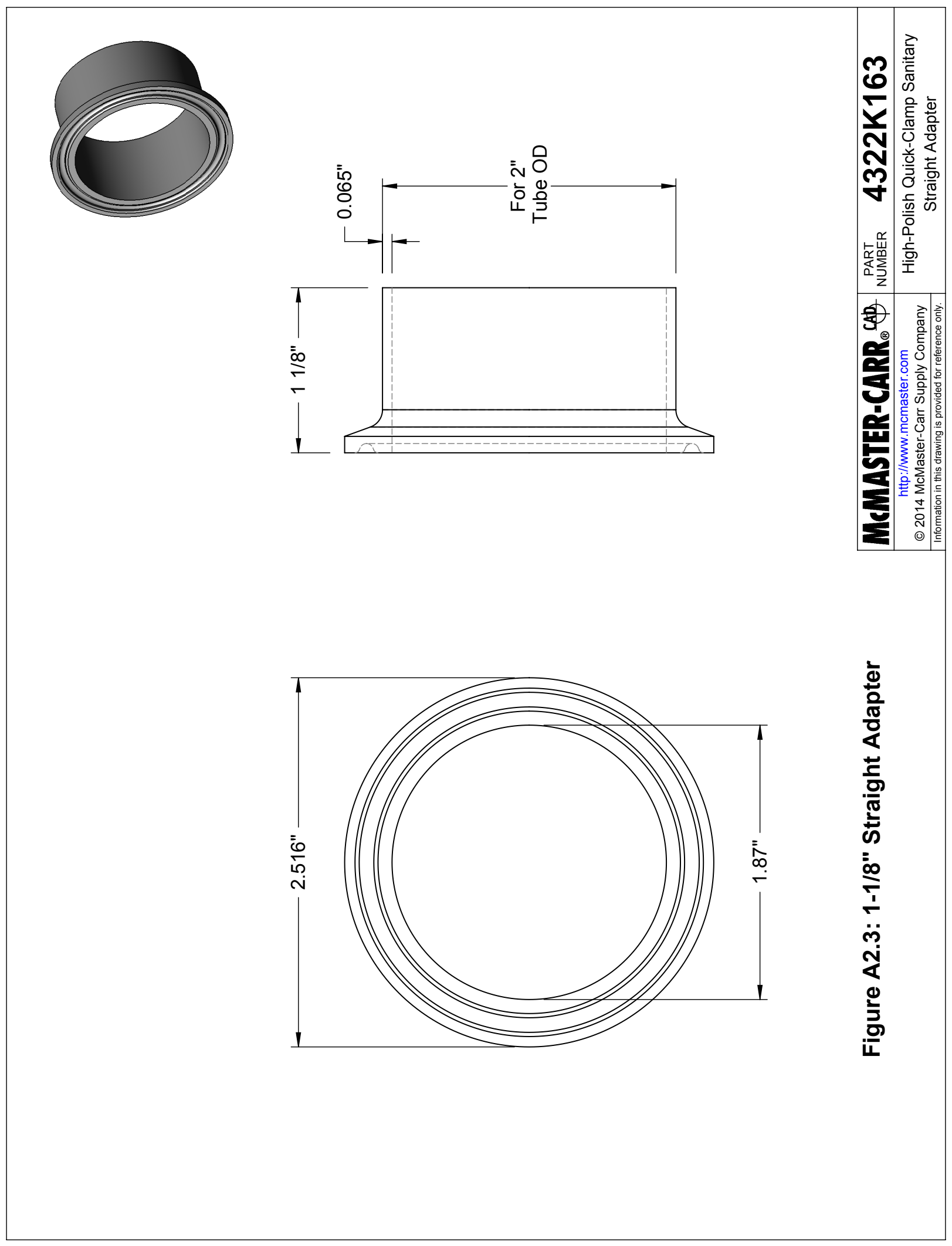




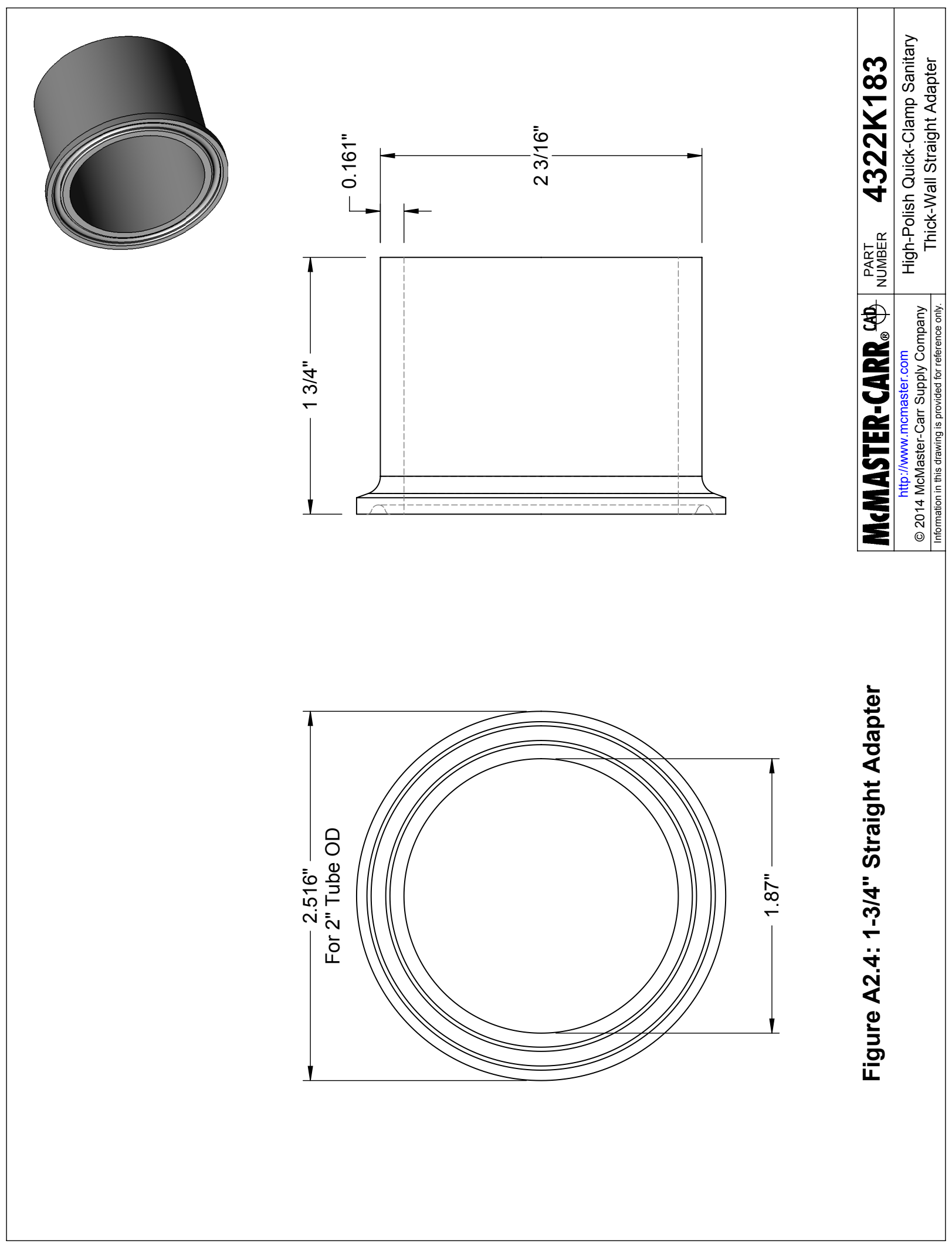




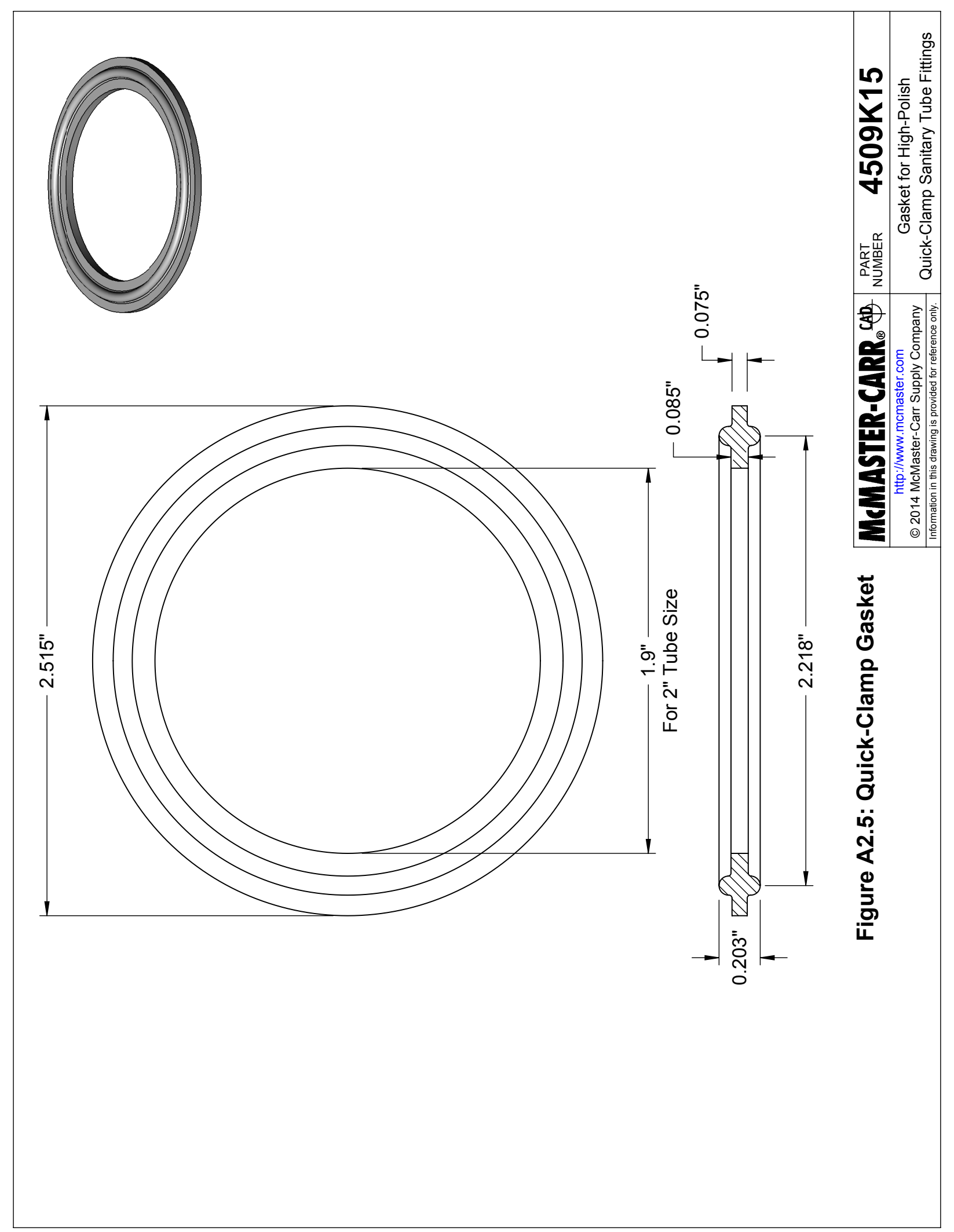




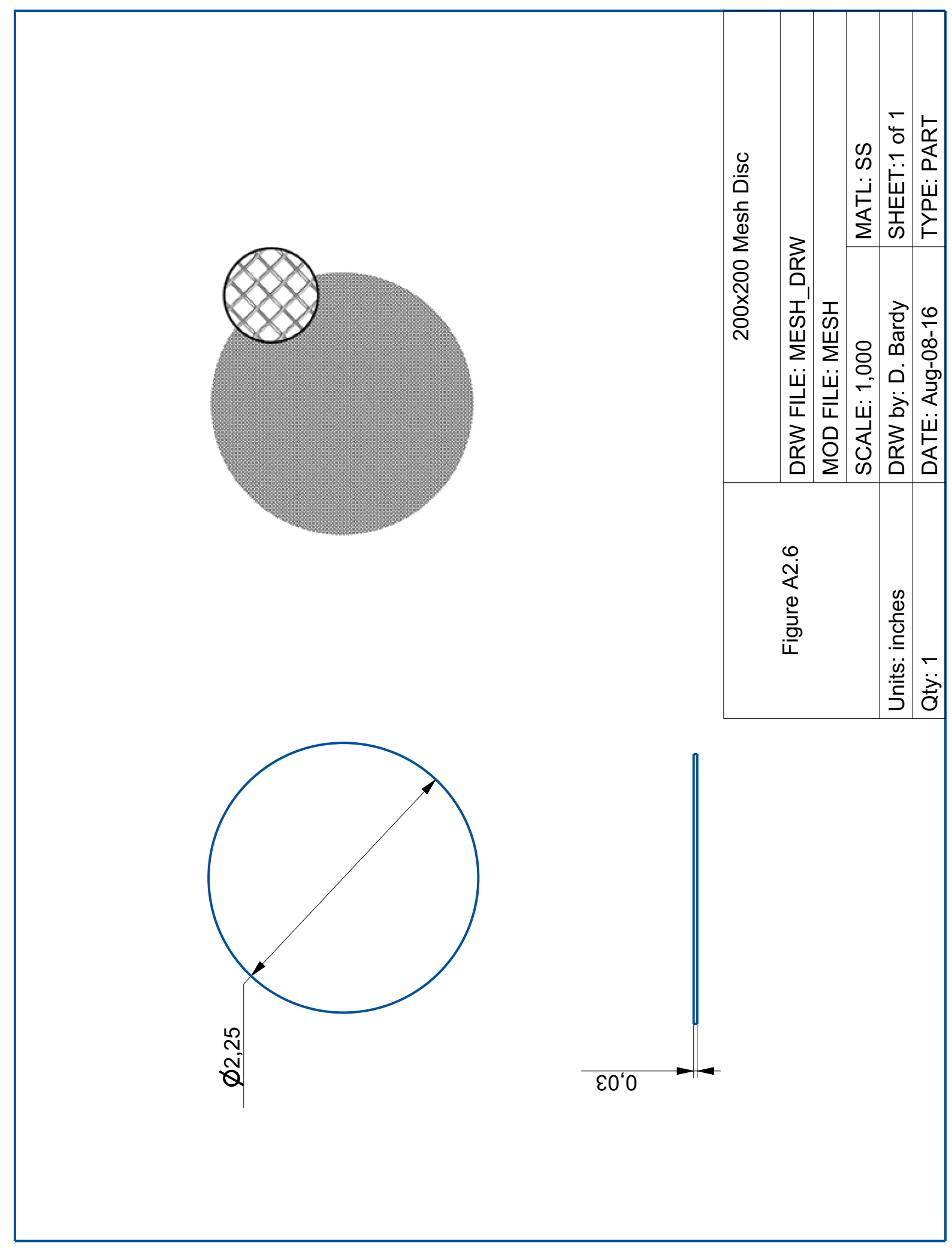




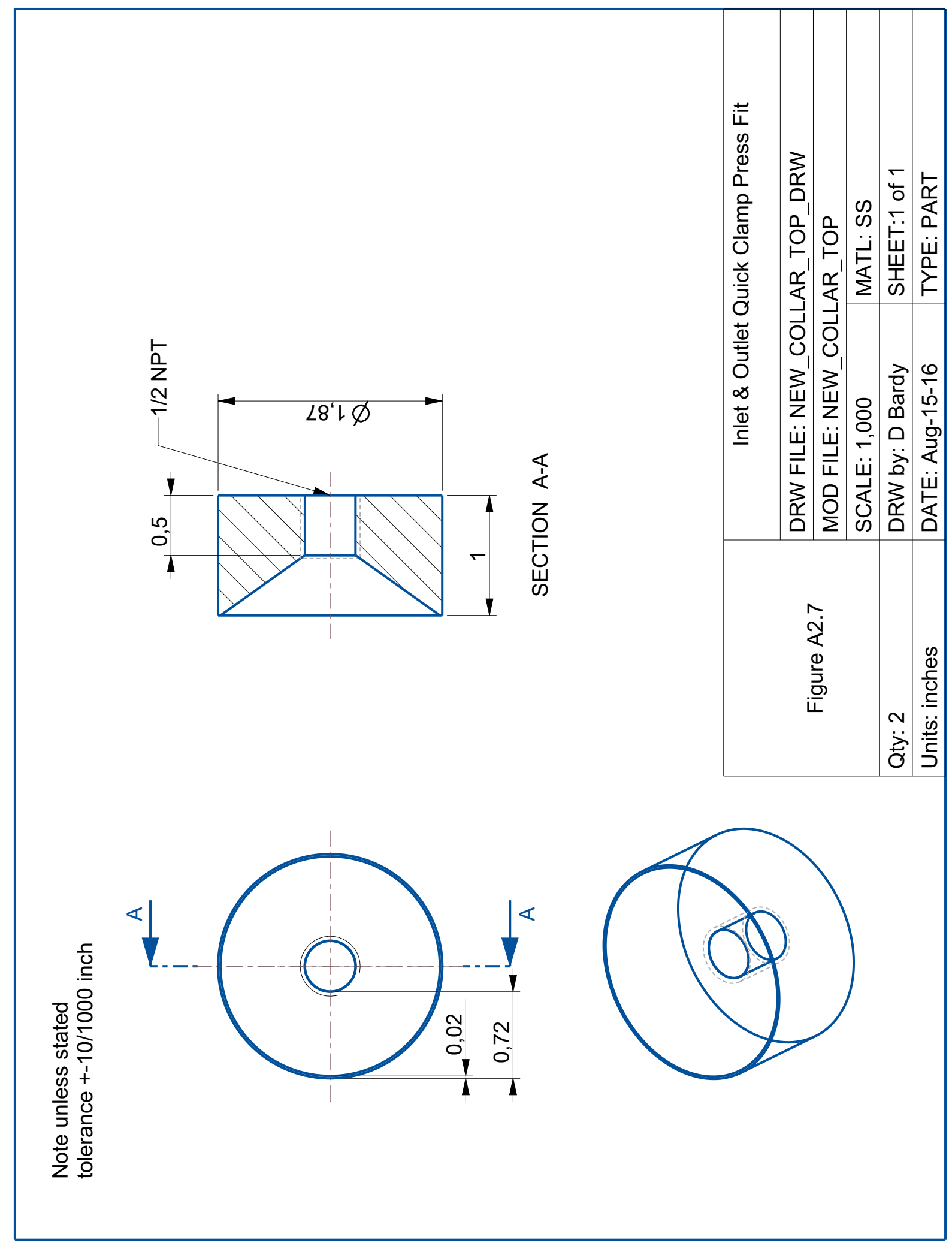




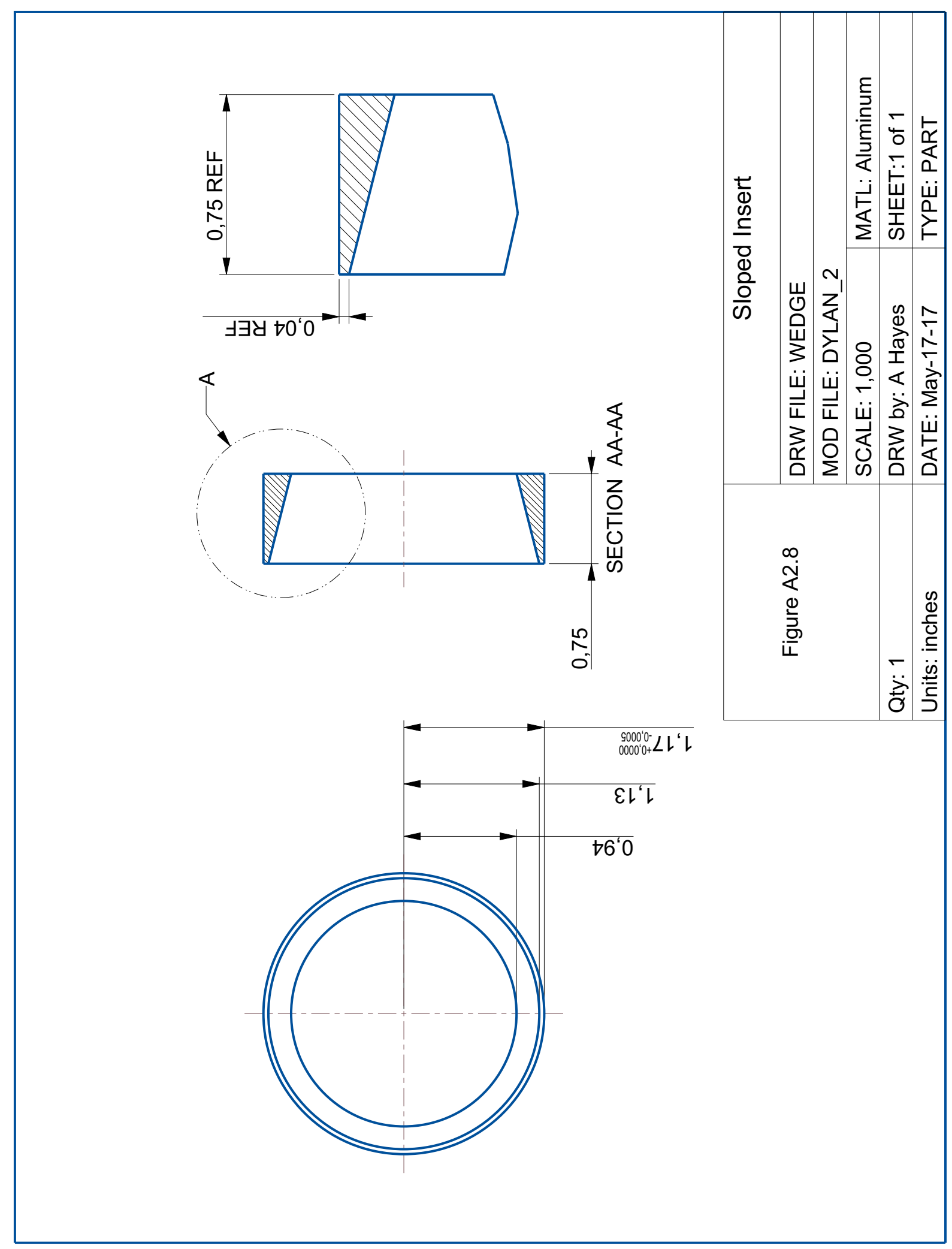




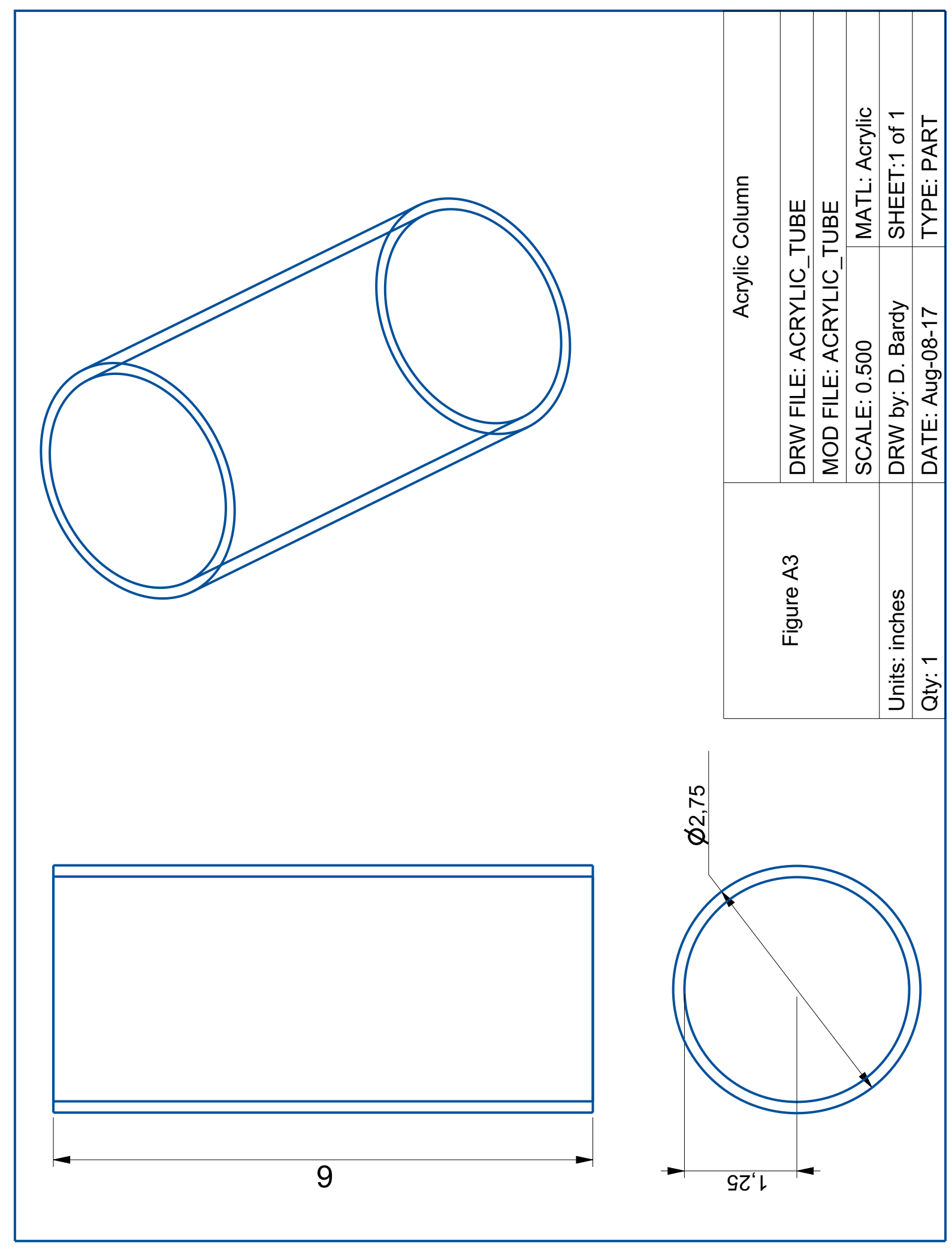




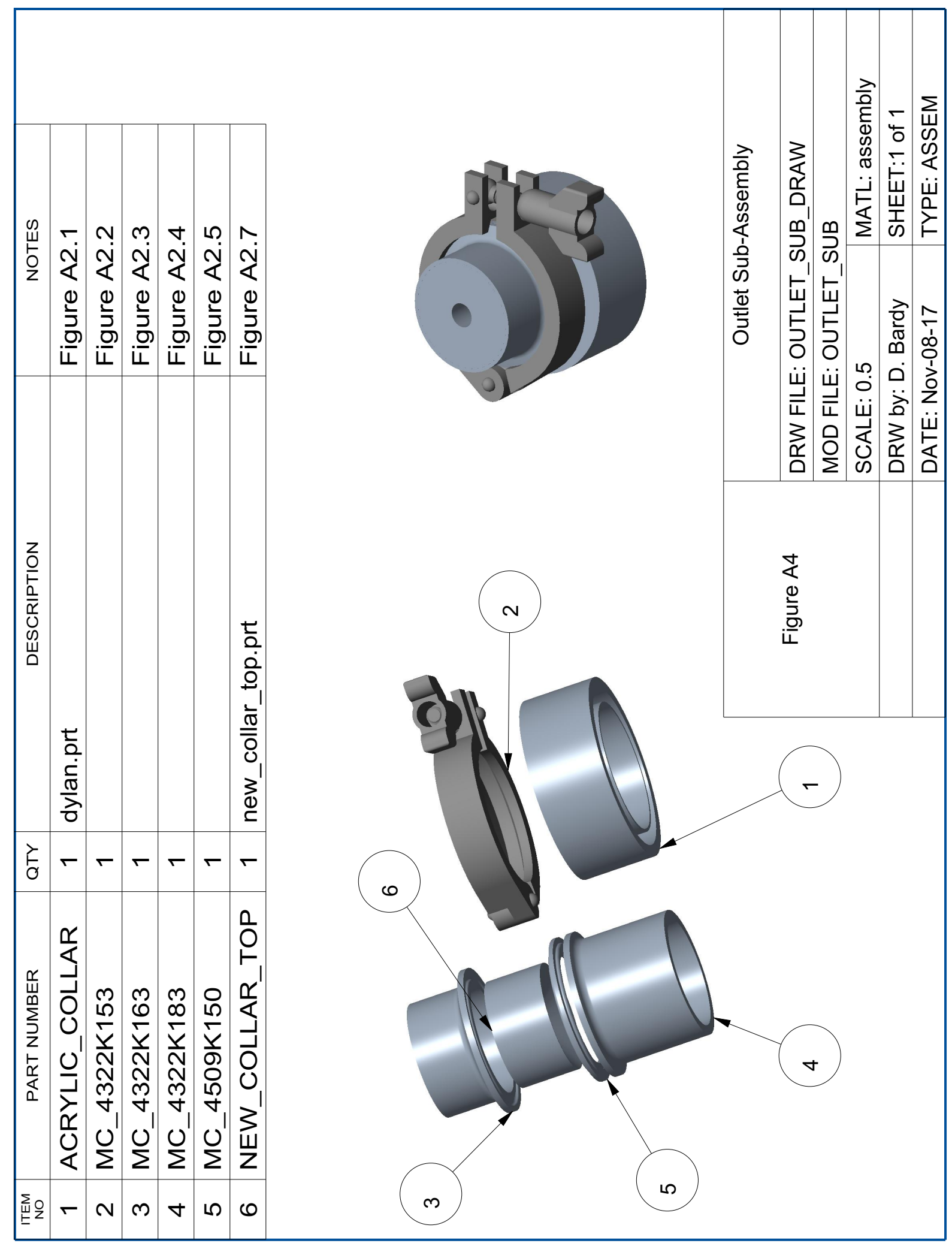


Appendix B

Manufacturer Specifications \&

MSDS for Zeolite 13X 


\section{X Molecular Sieve 8x12 Mesh, Beaded}

Revised 2015

CHEMICAL FORMULA Na86[(AIO2)86(SiO2)106] $\cdot \mathrm{nH} 2 \mathrm{O}$

\section{PRODUCT DESCRIPTION}

DelSORB $₫ 13$ X812B molecular sieve is a multiple purpose, highly porous, high capacity alkali metal alumino-silicate in the spherical form. It is the sodium form of the Type X crystal structure with pore diameters of approximately $10 \AA$. It can adsorb all molecules that can be adsorbed on 3A, 4A, and 5A molecular sieve. Type 13X can also adsorb molecules such as aromatics and branched-chain hydrocarbons, which have large critical diameters.

\section{SPECIFICATIONS}

$\begin{array}{lll}\text { Property } & \text { Value } & \text { Unit } \\ \text { Bead Size } & 8 \times 12 & \text { Mesh } \\ \text { Nominal Pore Opening } & 10 & \text { Angstroms } \\ \text { Equilibrium Water Capacity @ } 25^{\circ} \mathrm{C} & \geq 26 & \% \text { Weight } \\ \text { CO2 Adsorption Capacity } & \geq 18 & \% \text { Weight } \\ \text { Heat of Adsorption } & 1800 & \mathrm{BTU} / \mathrm{lb} \text { of } \mathrm{H} 2 \mathrm{O} \\ \text { Bulk Density } & \geq .64 & \mathrm{~g} / \mathrm{ml} \\ & \geq 40 & \mathrm{lbs} / \mathrm{ft} 3 \\ \text { Crush Strength } & \geq 8 & \mathrm{lbs} \\ & \geq 35 & \mathrm{~N} \\ \text { Size Qualification } & \geq 97 & \% \\ \text { Package Moisture } & \leq 1.5 & \% \text { Weight }\end{array}$

TYPICAL APPLICATIONS

General gas drying; concurrent removal of $\mathrm{H} 2 \mathrm{O}$ and $\mathrm{CO} 2$ from gas and air streams; sweeten natural gas and liquid hydrocarbon streams by removing $\mathrm{H} 2 \mathrm{~S}$ and Mercaptans; separation of N2 from O2; PSA oxygen units.

\section{PACKAGING INFORMATION}

Drums $135 \mathrm{kgs} / 300 \mathrm{lbs}$ Super Sacks Fill weights to order specification

\section{HANDLING \& STORAGE RECOMMENDATIONS}

Store DeISORB尺 molecular sieve in a dry location to prevent premature water adsorption. Reseal packages after opening to prevent contamination and unintended water adsorption. We recommend that you rotate stock so oldest material is used first.

HEALTH \& SAFETY INFORMATION

Health and Safety Information is available on product MSDS, which can be downloaded from our web site unw.deltaadsorbents.com or by contacting Delta Adsorbents at 630.980.5286. 


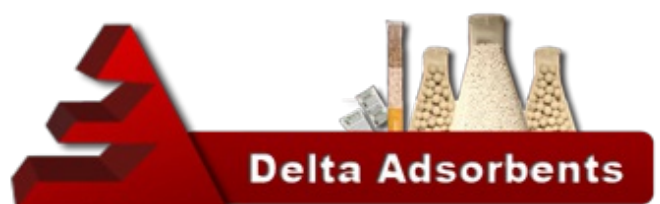

Delta Adsorbents Div. of Delta Enterprises, Inc.

24 Congress Circle W.

Roselle, IL 60172

Phone: 630.980 .5205

Molecular Sieve SDS

Updated 2017

\section{Section 1: CHEMICAL PRODUCT \& COMPANY IDENTIFICATION}

Chemical Name: Molecular Sieve; 3a,4a,5a,13x

Product Name: DelSORB 3A, 4A, 5A, 13X

Synonym: Zeolite, Synthetic

Emergency Assistance:

USA:

Telephone: + 1.847.292.8600

Fax: +1.847 .292 .8601$

Supplier Information:

Interra Global Corporation 800 Busse Highway, Ste 101 Park Ridge, IL 60068

USA

\section{Section 2: HAZARDS IDENTIFICATION}

Potential Acute Health Effects: Slightly hazardous in case of skin contact (irritant), of eye contact (irritant), of ingestion or inhalation.

Potential Chronic Health Effects: 3 (Not classifiable for human.) by IARC

Carcinogenic Effects: Not available.

Mutagenic Effects: Not available.

Teratogenic Effects: Not available.

Developmental Toxicity: Not available.

The substance may be toxic to lungs.

Repeated or prolonged exposure to the substance can produce target organs damage.

\section{Section 3: COMPOSITION \& INFORMATION ON INGREDIENTS}

CAS Number:

3A: $1318-02-1$

4A: $1344-00-9$

5A: 69912-79-4

13X: 63231-69-6

\section{Section 4: FIRST AID MEASURES}

Eye Contact: Check for and remove any contact lenses. In case of contact, immediately flush eyes with plenty of water for at least 15 minutes. Get medical attention if irritation occurs.

Skin Contact: Wash with soap and water. Cover the irritated skin with an emollient. Get medical attention if irritation develops.

Serious Skin Contact: Not available.

Inhalation: If inhaled, remove to fresh air. If not breathing, give artificial respiration. If breathing is difficult, give oxygen. Get medical attention.

Serious Inhalation: Not available.

Ingestion: Do not induce vomiting unless directed to do so by medical personnel. Never give anything by mouth to an unconscious person. If large quantities of this material are swallowed, get medical attention immediately. Loosen tight clothing such as a collar, tie or belt. 


\section{Section 5: FIRE \& EXPLOSION DATA}

Flammability of the Product: Non-flammable.

Auto-Ignition Temperature: Not applicable.

Flash Points: Not applicable.

Flammable Limits: Not applicable.

Products of Combustion: Not available.

Fire Hazards in Presence of Various Substances: Not applicable.

Explosion Hazards in Presence of Various Substances

Risks of explosion of the product in presence of mechanical impact: Not available.

Risks of explosion of the product in presence of static discharge: Not available.

Fire Fighting Media and Instructions: Not applicable.

Special Remarks on Fire Hazards: Powerful oxiders may cause fire. [Quartz]

Special Remarks on Explosion Hazards: Powerful oxiders or metals may cause explosions.[Quartz]

\section{Section 6: ACCIDENTAL RELEASE MEASURES}

Small Spill: Use appropriate tools to put the spilled solid in a convenient waste disposal container. Finish cleaning by spreading water on the contaminated surface and dispose of according to local and regional authority requirements.

Large Spill: Use a shovel to put the material into a convenient waste disposal container. Finish cleaning by spreading water on the contaminated surface and allow to evacuate through the sanitary system.

\section{Section 7: HANDLING \& STORAGE}

Storage: Keep container tightly closed. Suitable for any general chemical storage area. Containers of this material may be hazardous when empty since they retain product residues (dust, solids); observe all warnings and precautions listed for the product.

\section{Section 8: EXPOSURE CONTROLS / PERSONAL PROTECTION}

Engineering Controls: Use process enclosures, local exhaust ventilation, or other engineering controls to keep airborne levels below recommended exposure limits. If user operations generate dust, fume or mist, use ventilation to keep exposure to airborne contaminants below the exposure limit.

Personal Protection: Safety glasses. Lab coat. Gloves. Dust respirator. Be sure to use an approved certified respirator or equivalent.

Personal Protection in Case of a Large Spill: Splash goggles. Full suit. Dust respirator. Boots. Gloves. A self contained breathing apparatus should be used to avoid inhalation of the product. Suggested protective clothing might not be sufficient; consult a specialist before handling this product.

Exposure Limits: Not available.

\section{Section 9: PHYSICAL \& CHEMICAL PROPERTIES}

Physical state: Solid (Beads)

Odor: Odorless

Taste: Not available.

Molecular Weight: Not available.

Color: White, Grey

$\mathrm{pH}(1 \%$ soln/water): Not available.

Boiling Point: Not applicable.

Melting Point: Not available.

Critical Temperature: Not available.

Specific Gravity: 2.1 (Water=1)

Vapor Pressure: Not applicable. 
Vapor Density: Not available.

Volatility: Not available.

Odor Threshold: Not available.

H2O/Oil Dist Coeff: Not available.

Ionicity (in Water): Not available.

Dispersion Prop.: Not available.

Solubility: Not available.

\section{Section 10: STABILITY \& REACTIVITY}

Stability: The product is stable.

Instability Temperature: Not available.

Conditions of Instability: Incompatible materials, moisture (absorbs water with evolution of heat), dust generation.

Incompatibility with various substances: Slightly reactive to reactive with moisture.

Corrosivity: Not available.

Special Remarks on Reactivity: Hygroscopic. Reacts with water to evolve heat.

Incompatibility with powerful oxiders: Fluorine, chlorine trifluoride, manganese trioxide, oxygen difluoride, hydrogen peroxide, etc.; Incompatible with acetylene and ammonia. This chemical is attacked by Hydrogen Fluoride. Silica will dissolve in Hydrofluoric Acid and produce the corrosive gas Silicon Tetra fluoride (SiF4). [Quartz]

Special Remarks on Corrosivity: Not available.

Polymerization: Yes.

\section{Section 11: TOXICOLOGICAL INFORMATION}

Routes of Entry: Absorbed through skin. Eye contact. Inhalation. Ingestion.

Toxicity to Animals:

LD50: Not available.

LC50: Not available.

Special Remarks on Toxicity to Animals: Not available.

Chronic Effects on Humans:

CarcinogenicEffects: 3 (Not classifiable for human.) by IARC. May cause damage to the following organs: lungs.

Other Toxic Effects on Humans: Slightly hazardous in case of skin contact, ingestion, or inhalation.

Special Remarks on Chronic Effects on Humans: May contain up to 3\% crystalline quartz which has been determined to be an IARC class 1 carcinogen.

Special Remarks on other Toxic Effects on Humans: Not available.

Acute/Chronic Potential Health Effects:

Skin: May cause skin irritation. The product gets hot as it adsorbs water. Burns to moist or wet skin tissue may result if contact is prolonged.

Eyes: Dust may cause eye irritation.

Ingestion: The product gets hot as it first adsorbs water. Burns to moist body tissues may result if contact is prolonged.

Inhalation: Exposure to dust particles generated from this material may cause irritation of the respiratory tract and may cause lung damage (silicosis, etc.) / cancer. Repeated and prolonged inhalation of crystalline silica in the form of quartz from occupational sources may cause cancer.

\section{Section 12: ECOLOGICAL INFORMATION}

Ecotoxicity: Not available.

BOD5 and COD: Not available.

Products of Biodegradation: Possibly hazardous short term degradation products are not likely. However, long term degradation products may arise.

Toxicity of the Products of Biodegradation: Not available. 


\section{Section 13: DISPOSAL CONSIDERATIONS}

Waste Disposal: Waste must be disposed of in accordance with federal, state and local environmental control regulations.

\section{Section 14: TRANSPORT INFORMATION}

DOT Classification: Not a DOT controlled material (United States).

Identification: Not applicable.

Special Provisions for Transport: Not applicable.

\section{Section 15: OTHER REGULATORY INFORMATION}

Federal and State Regulations: California, Massachusetts, New Jersey, Pennsylvania: Siliporite

Other Classifications:

WHMIS (Canada): Not controlled under WHMIS (Canada).

DSCL (EEC): This product is not classified according to the EU regulations. Not applicable.

HMIS (U.S.A.):

Health Hazard: 1

Fire Hazard: 0

Reactivity: 1

Personal Protection: E

National Fire Protection Association (U.S.A.):

Health: 1

Flammability: 0

Reactivity: 1

Protective Equipment:

Gloves.

Lab coat.

Dust respirator.

Be sure to use an approved/certified respirator or equivalent.

Safety glasses.

\section{Section 16: OTHER INFORMATION}

References: Not available.

Other Special Considerations: Not available.

The purpose of this Safety Data Sheet is to describe the products in terms of their safety requirements. The information above is believed to be accurate and represents the best information currently available to us. However, we make no warrant of merchantability or any other warranty, express or implied, with respect to such information, and we assume no liability resulting from its use. Users should make their own investigations to determine the suitability of the information for their particular purposes. In no event shall DeltaEnterprises, Inc. be liable for an claims, losses, or damages of any third party or for lost profits or any special, indirect, incidental, consequential or exemplary damages, howsoever arising, even if DeltaEnterprises, Inchas been advised of the possibility of such damages. 


\section{Appendix $\mathrm{C}$}

\section{Fluidization Velocity Calculations}

The range of flow rates used in this work was determined by considering the minimum fluidization and terminal velocities for solid particles with a diameter of 210 to $250 \mu \mathrm{m}$

and a density of $640 \mathrm{~kg} / \mathrm{m}^{3}$. The air used to fluidize the particles was assumed to be at $25^{\circ} \mathrm{C}$, and therefore have a density $\left(\rho_{\mathrm{g}}\right)$ and dynamic viscosity $(\mu)$ of $1.2 \mathrm{~kg} / \mathrm{m}^{3}$ and $1.85 \times 10^{-5} \mathrm{~N} \cdot \mathrm{s} / \mathrm{m}^{2}$ respectively 66 . Using a mean particle diameter of $230 \mu \mathrm{m}$, the minimum fluidization velocity was calculated using Equation 2.1.

$$
\begin{aligned}
u_{\mathrm{mf}} & =\frac{\left(230 \times 10^{-6} \mathrm{~m}\right)^{2} \cdot(640-1.2) \mathrm{kg} / \mathrm{m}^{3} \cdot(9.81 \mathrm{~N} / \mathrm{kg})}{1650\left(1.85 \times 10^{-5} \mathrm{~N} \cdot \mathrm{s} / \mathrm{m}^{2}\right)} \times\left|\frac{100 \mathrm{~cm}}{\mathrm{~m}}\right| \\
& =1.1 \mathrm{~cm} / \mathrm{s}
\end{aligned}
$$

Considering the cross-sectional area of mesh disc on which the material rests at the inlet of the column (see Figure A2.6), the flow rate required to provide the minimum fluidization velocity $\dot{V_{m f}}$ was calculated:

$$
\begin{aligned}
\dot{V}_{\mathrm{mf}} & =u_{\mathrm{mf}} \cdot A \\
& =(1.1 \mathrm{~cm} / \mathrm{s}) \cdot\left[\pi(0.94 \mathrm{in})^{2}\right] \times\left|\frac{2.54 \mathrm{~cm}}{\text { in }}\right|^{2} \times\left|\frac{\mathrm{L}}{1000 \mathrm{~cm}^{3}}\right| \times\left|\frac{60 \mathrm{~s}}{\mathrm{~min}}\right| \\
& =1.2 \mathrm{~L} / \mathrm{min}
\end{aligned}
$$


The terminal velocity of the smallest particle can be estimated by Equation C.3. where that particle is assumed to be spherical:

$$
\begin{aligned}
u_{t} & =\left[\frac{4}{225} \frac{\left(\rho_{s}-\rho_{g}\right)^{2} g^{2}}{\rho_{g} \mu}\right]^{\frac{1}{3}} d_{p} \quad 0.4<R e_{p}<500 \\
& =\left[\frac{4}{225} \frac{\left(640 \mathrm{~kg} / \mathrm{m}^{3}-1.2 \mathrm{~kg} / \mathrm{m}^{3}\right)^{2}(9.81 \mathrm{~N} / \mathrm{kg})^{2}}{\left(1.2 \mathrm{~kg} / \mathrm{m}^{3}\left(1.85 \times 10^{-5} \mathrm{~N} \cdot \mathrm{s} / \mathrm{m}^{2}\right)\right.}\right]^{\frac{1}{3}}\left(210 \times 10^{-6} \mathrm{~m}\right) \times\left|\frac{100 \mathrm{~cm}}{\mathrm{~m}}\right| \\
& =66.2 \mathrm{~cm} / \mathrm{s}
\end{aligned}
$$

Determining the terminal velocity of a non-spherical particle, however, requires taking into account its sphericity $\left(\Phi_{s}\right)$, which is defined as the ratio of the surface area of a sphere to the surface area of a particle of the same volume. By this definition, $\Phi_{s}=1$ for spheres, and $0<\Phi_{s}<1$ for all other particle shapes. The terminal velocity of non-spherical shapes can be estimated from experimental correlations of the dimensionless groups $R e_{p}$ vs. $C_{d} R e_{p}{ }^{2}$. Kunii \& Levenspiel 35 plotted these correlations using information from Brown et al. [67] for $0.125<\Phi_{s}<1$. Using Equation 2.4, the velocity independent group was determined to be:

$$
\begin{aligned}
C_{d} R e_{p}{ }^{2} & =\frac{4(9.81 \mathrm{~N} / \mathrm{kg})\left(210 \times 10^{-6} \mathrm{~m}\right)^{3}\left(1.2 \mathrm{~kg} / \mathrm{m}^{3}\right)(640-1.2) \mathrm{kg} / \mathrm{m}^{3}}{3\left(1.85 \times 10^{-5} \mathrm{~N} \cdot \mathrm{s} / \mathrm{m}^{2}\right)^{2}} \\
& =271
\end{aligned}
$$

Using this value for Kunii \& Levenspiel's correlation to determine $R e_{p}$, the terminal velocity and maximum flow rate for the smallest particles was determined for a range of potential particle shapes in Table C.1 
Table C.1: Estimated terminal velocities and flow rates for a $210 \mu \mathrm{m}$ particle.

\begin{tabular}{cccc}
$\Phi_{s}$ & $R e_{p}$ & $u_{t}(\mathrm{~cm} / \mathrm{s})$ & $\dot{V}_{t}(\mathrm{~L} / \mathrm{min})$ \\
\hline 0.125 & 1.8 & 13.2 & 14.2 \\
0.220 & 2 & 14.6 & 15.8 \\
0.600 & 2.5 & 18.3 & 19.7 \\
0.860 & 3 & 22.0 & 23.7 \\
1.00 & 6 & 44.0 & 47.3 \\
1.00 Equation C.3 & - & 66.2 & 70.9
\end{tabular}

The $8 \times 12$ beads used in this work appeared to be nearly spherical; however, the sphericity of these beds was not indicated by the manufacturer. The $60 x 65$ mesh zeolite used was also crushed from $8 \times 12$ beads which made it even less clear as how to approximate the sphericity of the zeolite. The sphericity of a 4x8 mesh zeolite $13 \mathrm{x}$ analyzed for the National Energy Technologies Laboratory (NETL) of the United States Department of Energy was determined to have a sphericity of $\Phi_{s}=0.931$ [68]. The same analysis conducted for NETL also measured $189 \mu \mathrm{m}$ zeolite particles with a sphericity of $\Phi_{s}=0.9$. Taking an average of the $\Phi_{s}$ values in Table C.1 (including the calculation for Equation C.3 returns a sphericity of $\Phi_{s}=0.63$ which is similar to the consistency of sand. The corresponding average of the calculated values for $\dot{V}_{t}$ (from Table C.1) was $31.9 \mathrm{~L} / \mathrm{min}$. The flow rates used to fluidize the $60 \times 65$ mesh bed would therefore have to be between $1.2 \& 31.9 \mathrm{~L} / \mathrm{min}$. Errors from earlier calculations however led to the decision to purchase mass flow controllers (MFC) with a range of 0 to $100 \mathrm{~L} / \mathrm{min}$ and a measurement uncertainty of $\pm 1.5 \mathrm{~L} / \mathrm{min}$, which made it difficult to achieved combined flows of less than $10 \mathrm{~L} / \mathrm{min}$. Earlier tests also revealed that a combined flow rate of at least $10 \mathrm{~L} / \mathrm{min}$ was required between the wet and dry MFC in order to provide an inlet $\mathrm{RH}$ of $50 \%$. 


\section{Appendix D}

\section{Calibration \&Uncertainty Analysis}

\section{D.1 Component Calibration and Uncertainty}

To determine the overall systematic error of the heat of adsorption, the uncertainty on the measurement made by each instrument had to be obtained. This included the uncertainty on the volumetric flow rate read by the two mass flow controllers; the temperatures read by the thermocouples; the temperature and relative humidity read by each relative humidity transmitter; and the pressure read by each pressure transducer.

\section{D.1.1 Mass Flow Controllers}

Two Omega FMA5542A mass flow controllers (MFC) were installed within the system to measure and control the flow rate of air through the wet and dry pathways. Gas flow meters of this type infer flow rate from a temperature dependent electrical resistance as the flow carries heat away from a joule heated coil. Using NIST traceable volumetric calibrators, the mass flow controllers were factory calibrated to $1.5 \%$ of the full scale measurement for normal conidtions of $25^{\circ} \mathrm{C}$ and 1.01 bar absolute. Therefore the uncertainty of the volumetric flow rate $\left(u_{\dot{V}}\right)$ was $\pm 1.5 \mathrm{~L} / \mathrm{min}$ for the $0-100 \mathrm{~L} / \mathrm{min}$ range of the instruments. The only calibration performed after installation was adjusting the zero potentiometer of each MFC; non-zero values were read when no flow was present, and an adjustment was made to force an output signal of $0 \mathrm{Vdc}$ when this was the case. 


\section{D.1.2 Thermocouples}

Thermocouples infer temperature from the voltage induced by the electro motive forces in two dissimilar metals as they experience a change in temperature. The voltage generated as a signal is proportional to the temperature between a measurement junction (soldered end of two metals) and a reference junction of known temperature, or cold junction compensation (CJC).

The T-type thermocouples used in the column were cut from a 30 gauge roll on which a calibration and uncertainty experiment was performed by Baldwin [69 using a constant temperature bath and a resistive temperature detector (RTD). Baldwin determined that the 30 gauge roll used in this experiment had a total uncertainty of $\pm 0.49^{\circ} \mathrm{C}$, where the most significant sources of error were the calibration and experimental error of the cold junction temperature $\left( \pm 0.25^{\circ} \mathrm{C}\right)$ and voltage measurement $\left( \pm 0.175^{\circ} \mathrm{C}\right)$. This $\pm 0.49^{\circ} \mathrm{C}$ measurement error was considered as part of the measurement uncertainty of the temperature lift during adsorption experiments $\left(u_{\delta T}\right)$.

\section{D.1.3 Relative Humidity Transmitters}

Each Omega HX15-W relative humidity transmitter was made up of a $1000 \Omega$ platinum resistance temperature device (Pt1000 RTD) and a thin polymer capacitor.

\section{Pt1000 RTD}

An RTD infers temperature from the change in electrical resistance of a metal probe as it experiences a change in temperature. The transmitters used in the system were specified to have an accuracy of $\pm 0.5^{\circ} \mathrm{C}$ for -40 to $180^{\circ} \mathrm{C}$. This accuracy was also applied to the measurement uncertainty of the inlet temperature as part of the temperature lift of the column during adsorption experiments $\left(u_{\delta T}\right)$.

\section{Thin Polymer Capacitor}

Relative humidity $(\mathrm{RH})$ was inferred from the capacitance of the thin polymer capacitor $(\mu \mathrm{F})$; the increase in the dielectric permittivity of a capacitive sensor is directly proportional to the relative humidity of its environment. 
The transmitters used in the system were specified to have an accuracy of $\pm 2 \%$ for 3 to $95 \% \mathrm{RH}$ at $25^{\circ} \mathrm{C}$, or $\pm 0.05 \% \mathrm{RH} /{ }^{\circ} \mathrm{C}$ for -40 to $150^{\circ} \mathrm{C}$. The former accuracy of $\pm 2 \%$ $\mathrm{RH}$ was used as the uncertainty of the RH measurement $\left(u_{\phi}\right)$ for adsorption experiments in which the inlet conditions were 30 to $70 \% \mathrm{RH}$ at $25^{\circ} \mathrm{C}$.

\section{D.1.4 Pressure Transducers}

Pressure transducers infer pressure from the force measured by a strain gauge over the area of a diaphragm that deforms under non-atmospheric pressure (i.e., positive gauge or vacuum conditions); a strain gauge infers force from a change in electrical resistance as it is lengthened or contracted. The Omega PX209-30V85 pressure transducer measures pressures in the range of -14.7 to 85 psig with a $4-20 \mathrm{~mA}$ signal and has an accuracy of $\pm 1 \%$ full-scale output (FSO) (i.e., $\pm 1 \mathrm{psi}$ ). An uncertainty $\left(u_{p}\right)$ of $6.9 \mathrm{kPa}$ was used in the overall system uncertainty.

\section{D.2 Overall System Uncertainty Analysis}

Having established the uncertainty of instrumentation used to measure volumetric flow rates, temperatures, relative humidity and pressure within the system, the overall uncertainty of the calculations for thermal energy released due to adsorption can be determined.

\section{D.2.1 Uncertainty Calculation Procedure}

Determining the uncertainty of a derived quantity from independent variables requires taking a square root of the sum of squares of the uncertainty of each variable scaled by a sensitivity factor. As an example, for a derived quantity, $Y$, that is a function of variables of $x$, such as Equation D.1.

$$
Y=f\left(x_{1}, x_{2}, x_{3}, \ldots, x_{n}\right)
$$


The sensitivity factor, $\theta$, for any independent variable is derived using a Taylor series expansion and is determined using the partial derivative of Equation D.2.

$$
\theta=\frac{\partial Y}{\partial x_{i}} \quad i=1,2,3, \ldots, N
$$

Once the sensitivity factor is determined for each of the independent variables, the overall uncertainty on the derived quantity, $\mathrm{u}_{Y}$, is calculated using Equation D.3.

$$
u_{Y}=\left[\sum_{i=1}^{N}\left(\theta_{i} u_{i}\right)^{2}\right]^{\frac{1}{2}}
$$

The foregoing procedure was followed in calculating the systematic error on the energy released from the adsorption experiments performed in this research.

\section{D.2.2 Uncertainty of Energy Stored and Released}

Referring to Equation 2.5, the energy released, Q, is a function of the density, volumetric flow rate, heat capacity, and change in temperature of the moist air entering the adsorption column:

$$
Q=f\left(\rho, \dot{V}, c_{p}, \delta T\right)
$$

Therefore the systematic uncertainty on this measurement was calculated according to Equation D.5.

$$
u_{Q}=\sqrt{\left(u_{\rho} \theta_{\rho(Q)}\right)^{2}+\left(u_{\dot{V}} \theta_{\dot{V}(Q)}\right)^{2}+\left(u_{c_{p}} \theta_{c_{p}(Q)}\right)^{2}+\left(u_{\delta T} \theta_{\delta T(Q)}\right)^{2}}
$$

The sensitivity factors were calculated according to Equations A.6 to A.9:

$$
\theta_{\rho(Q)}=\frac{\partial Q}{\partial \rho}=\dot{V} c_{p, m a} \delta T
$$




$$
\begin{gathered}
\theta_{\dot{V}(Q)}=\frac{\partial Q}{\partial \dot{V}}=\rho c_{p, m a} \delta T \\
\theta_{c_{p, m a}(Q)}=\frac{\partial Q}{\partial c_{p}}=\rho \dot{V} \delta T \\
\theta_{\delta T(Q)}=\frac{\partial Q}{\partial \delta T}=\rho \dot{V} C_{p, m a}
\end{gathered}
$$

The volumetric flow rate $\dot{V}$ was measured by the mass flow controllers (MFC), and the temperature change across the column $\delta T$ was measured by a combination of the RTD in the RH transmitter and the thermocouple at the outlet of each bed. The uncertainty of the density $\left(u_{\rho}\right)$ and specific heat capacity $\left(u_{c_{p}}\right)$ of moist air however, which are dependent on temperature and humidity, needed to be calculated as follows.

\section{Uncertainty on Density of Moist Air}

Treating the dry air and water vapour as ideal gases, per Dalton's Law:

$$
\begin{aligned}
\rho & =\rho_{d a}+\rho_{w} \\
& =\frac{\left(p-\phi p_{g}\right) M_{a}+\phi p_{g} M_{w}}{R T}
\end{aligned}
$$

As constants, the uncertainty on $R, M_{w}$, and $M_{a}$ was neglected. Error on $p_{w s}$ and $p_{w s}$ were not considered either as these errors were more than an order of magnitude smaller than the error on the other terms. The sensitivity factors for the error on the density of moist air were calculated as: 


$$
\begin{gathered}
\theta_{p}=\frac{\partial \rho}{\partial p} \\
=\frac{M_{a}}{R T} \\
\theta_{\phi}=\frac{\partial \rho}{\partial \phi} \\
=\frac{-p_{g}\left(M_{a}-M_{w}\right)}{R T} \\
\theta_{T}=\frac{\partial \rho}{\partial T} \quad \frac{-\left(M_{a}\left(p-p_{g} \phi\right)+M_{w} p_{g} \phi\right)}{R T^{2}}
\end{gathered}
$$

Therefore the uncertainty of density of moist air was calculated according to Equation D.14:

$$
u_{\rho}=\sqrt{\left(u_{p} \theta_{p}\right)^{2}+\left(u_{\phi} \theta_{\phi}\right)^{2}+\left(u_{T} \theta_{T}\right)^{2}}
$$

\section{Uncertainty on Heat Capacity of Moist Air}

The specific heat at constant pressure for dry air $\left(c_{p, a}\right)$, pure water vapour $\left(c_{p, w}\right)$, and moist air $\left(c_{p}\right)$ were calculated according to a method described by Morvay and Grozdenac [70:

$$
\begin{gathered}
c_{p, a}=1.0029+5.4 \times 10^{-5} \cdot T \\
c_{v, a}=1.856+2.0 \times 10^{-4} \cdot T
\end{gathered}
$$




$$
\begin{aligned}
c_{p} & =c_{p, a}+\omega c_{v, a} \\
& =1.2009+5.4 \times 10^{-5} \cdot T+0.622 \frac{\phi p_{g}}{p-\phi p_{g}}\left(1.856+2.0 \times 10^{-4} \cdot T\right)
\end{aligned}
$$

The sensitivity factors for Equation D.17were calculated per Equations A.18 to A.20:

$$
\begin{gathered}
\theta_{T}=\frac{\partial c_{p, m a}}{\partial T} \\
=5.4 \times 10^{-5}+0.622\left(\frac{\phi p_{g}}{p-\phi p_{g}}\right)\left(2 \times 10^{-4}\right) \\
\theta_{\phi}=\frac{\partial c_{p, m a}}{\partial \phi} \\
=\frac{311 \times p \cdot T}{2.5 \times 10^{6}\left(p_{g}-p \cdot T\right)} \\
\theta_{p}=\frac{\partial c_{p, m a}}{\partial p} \quad 0.622 \times\left[\frac{T\left(1.856+2 \times 10^{-4} \cdot \phi\right)}{\left(p_{g}-p \cdot T\right)}+\frac{p \cdot T^{2}\left(1.856+2 \times 10^{-4} \cdot \phi\right)}{\left(p_{g}-p \cdot T\right)^{2}}\right]
\end{gathered}
$$

Simlar to $u_{\rho}$, the uncertainty on the specific heat capacity of moist air was therefore determined with Equation D.14, but using the sensitivity factors calculated in Equations A.18 to A.20. 